\title{
Constraints to informal entrepreneurs in
}

\section{developing countries: An empirical analysis}

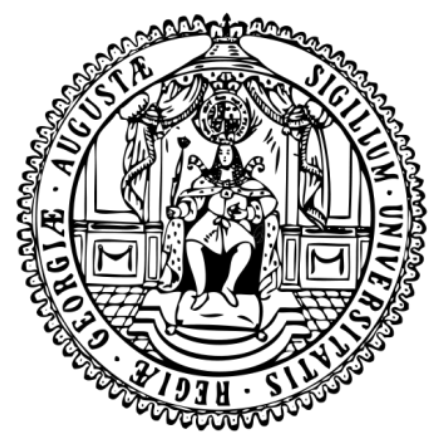

Dissertation

zur Erlangung des wirtschaftswissenschaftlichen Doktorgrades der Wirtschaftswissenschaftlichen Fakultät der

Universität Göttingen

vorgelegt von

Jens Krüger aus Vöhrum

Göttingen, 2013 
Erstgutachter: J.-Prof. Dr. Jann Lay

Zweitgutachter: Prof. Stephan Klasen (Ph.D.)

Tag der mündlichen Prüfung: 06.09.2013 



\section{Acknowledgements}

I would like to thank my supervisors Jann Lay and Stephan Klasen for excellent thesis supervision, Nina Fenton for valuable comments and encouraging advice in difficult times, and my parents Angelika and Manni for their unending support and their faith in me.

Further, I would like to acknowledge the valuable comments provided by former colleagues at the Asian Development Bank (ADB), in particular: Ganeshan Wignaraja, Alisa DiCaprio, Ramesh Subramaniam, Isabela Corpuz, Anna Mae Tuazon, and Hsiao Chink Tang. Thanks also go to Dalisay Maligalig (ADB) for assistance accessing the Thai Labour Force Surveys and to Magnus Andersson and Anders Engvall for advice on interpretation of these data.

I am also grateful to Carola Donner-Reichle for inviting me to present some of the findings of this thesis at ADB's 'Insight Thursday' Forum, and to the participants for their reflections and suggestions.

I greatly benefitted from the opportunity to present a chapter of this thesis at the annual conference of the Center for the Study of African Economies at Oxford University. In particular, I thank Simon Quinn, David McKenzie and Francis Teal for their comments. 



\section{Table of Contents}

Table of Contents $\quad$ i

List of Tables $\quad$ iv

List of Figures vi vi

Abbreviations and Acronyms vii

\section{Introduction and overview 1}

\section{Chapter 1}

1. Barriers to Entry and Returns to Capital in Informal Activities: Evidence from Sub-Saharan Africa 15

1.1. Introduction 16

$\begin{array}{ll}\text { 1.2. Analytical framework and hypotheses } & 18\end{array}$

1.3. Entry costs and capital returns in African MSEs 20

$\begin{array}{lll}\text { 1.3.1. Data } & 20\end{array}$

1.3.2. Basic MSE characteristics 20

1.3.3. Entry barriers $\quad 24$

1.3.4. Returns to capital 29

1.3.5. Returns to capital with a household fixed-effect 35

1.3.6. Some more thoughts on the causes $\quad 39$

1.4. Conclusions 41

Appendix A-1 43

\section{Chapter 2}

2. Gender and the allocation of labour and capital in informal enterprises: Evidence from Sub-Saharan Africa $\quad 47$

2.1. Introduction 48

2.2. Literature Review 49

2.3. Theoretical background 52

2.4. Empirical analysis 56

2.4.1. Data and descriptive statistics $\quad 56$

2.4.2. Econometric analysis $\quad 60$

2.4.3. Quantifying the potential gains from re-allocation 63

2.5. Conclusions 69 


\section{Chapter 3}

3. The role of international trade for employment growth in micro- and small-enterprises: Evidence from developing Asia

73

3.1. Introduction $\quad 74$

3.2. Literature review $\quad 75$

3.3. Empirical Analysis $\quad 79$

3.3.1. General enterprise characteristics $\quad 79$

3.3.2. Enterprise growth and the role of initial firm size 80

3.3.3. What is the role of participating in trade for employment growth? 83

3.3.4. Who are the top performers in terms of employment growth? 90

$\begin{array}{lll}\text { 3.4. Conclusions } & 94\end{array}$

\section{Chapter 4}

4. Firm size dynamics and implications for inequality: Evidence from Thailand 101

4.1. Introduction 102

4.2. Conceptual framework 105

4.2.1. The firm size distribution in developing countries 105

4.2.2. The relationship between firm size and wages 106

4.2.3. Implications for inequality: hypotheses regarding the firm size $\begin{array}{ll}\text { distribution and wage inequality } & 108\end{array}$

4.3. Empirical analysis 109

4.3.1. Data description 110

4.3.2. The context: the changing labour force structure 110

4.3.3. The missing middle in Thailand: the firm size distribution 113

4.3.4. The relationship between wages and firm size 116

4.3.5. Wage inequality in Thailand 119

4.3.6. Linking the firm size distribution and wage inequality 120

4.4. Conclusions 123

Appendix A-4 126

References 128

Eidesstattliche Versicherung $\quad 140$ 


\section{List of Tables}

\section{Chapter 1}

Table 1-1: Employment by sector in seven urban centres in Sub-Saharan Africa (percent)

Table 1-2: Basic descriptive statistics of informal MSEs, by quintiles of capital stock (Int. USD)

Table 1-3: Industry composition of informal MSEs by country (number of observations and percent of firms)

Table 1-4: Perceived problems faced by MSEs in the clothing and apparel sector by enterprise age (share) 25 Table 1-5: Replacement value of assets accumulated in the first year of operation (Int. USD and share of firms)

Table 1-6: Initial investment and other start-up costs relative to income levels (Int. USD)

Table 1-7: Returns to capital - results from OLS including capital-country interactions

Table 1-8: Returns to capital - results from OLS including capital-industry interactions

Table 1-9: Fixed effects specification $\quad 38$

Table 1-10: Risk proxies at different levels of capital stock 39

Table 1-11: Capital constraint proxies at different levels of capital stock (share)40

Table 1-12: Detailed results: Returns to capital

\section{Chapter 2}

Table 2-1: Employment by sector in seven urban centers in Sub-Saharan Africa (percent) 57

Table 2-2: Basic enterprise characteristics by gender and sector

Table 2-3: OLS fixed effects estimates, dependent variable value-added on $\begin{array}{ll}\text { enterprise level. } & 61\end{array}$

Table 2-4: Baseline OLS Fixed effects estimates of CES production function 66 Table 2-5: Value added under actual and optimal allocations of labour and capital (Int. USD) 


\section{Chapter 3}

Table 3-1: General enterprise characteristics $\quad 80$

Table 3-2: Employment growth in developing Asia 81

Table 3-3: Employment growth by initial size quintiles $\quad 82$

Table 3-4: The Role of Trade for Employment Growth, OLS estimates $\quad 88$

Table 3-5: Characteristics of top performers 91

Table 3-6: Probit estimates: dependent variable, being a top performer 92

Table 3-7: Top performers by sector and country group (percent) 94

Table 3-8: First stage estimation results 98

Table 3-9: Firm growth and trade - panel estimations 99

\section{Chapter 4}

Table 4-1: Overview of labour force structure by status, industry, and region (percent)

Table 4-2: The firm size distribution in Thailand, percent of employment by firm size over time, estimates from LFS and from the literature 113

Table 4-3: Firm size distribution by region, 1995 and 2005, percent 115

Table 4-4: Education level by firm size, 1995 and 2005, percent 116

Table 4-5 Wages per enterprise group for employees in private enterprises (Int. USD)

Table 4-6: Inequality measures for overall wage distributions 120

Table 4-7: Inequality decomposition by sector, firm size, and region 121

Table 4-8: Contribution of each variable to wage inequality, percent, estimated using regression based decomposition 122 Table 4-10: OLS regression, dependent variable monthly wage in int. USD, used for regression based inequality decomposition $\quad 126$ 


\section{List of Figures}

\section{Chapter 1}

Figure 1-1: Borrowing constraints and marginal returns to capital 19

Figure 1-2: Histograms of initial investment (current Int. USD) 27

\section{Chapter 4}

Figure 4-1: Wage distributions for private employees in Thailand in 1995 and 2005

Figure 4-2: Wage kernel density estimates by enterprise size 


\section{Abbreviations and Acronyms}

\begin{tabular}{|c|c|}
\hline CES & Constant Elasticity of Substitution \\
\hline CPI & Consumer Price Index \\
\hline DIAL & Development Institutions \& Mondalisation \\
\hline LDC & Least developed country \\
\hline GDP & Gross Domestic Product \\
\hline GE & Generalized Entropy \\
\hline HIES & Household Income and Expenditure Survey \\
\hline ICRISAT & $\begin{array}{l}\text { International Crops Research Institute for the Semi-Arid } \\
\text { Tropics }\end{array}$ \\
\hline ILO & International Labour Organization \\
\hline INS & National Statistical Institutes \\
\hline Int. USD & International US Dollar \\
\hline IV & Instrumental Variable \\
\hline Lao PDR & Lao People's Democratic Republic \\
\hline LFS & Labour Force Survey \\
\hline MLD & Mean Logarithmic Deviation \\
\hline MRK & Marginal Return to Capital \\
\hline MSE & Micro or Small Enterprise \\
\hline OLS & Ordinary least squares \\
\hline PARSTAT & $\begin{array}{l}\text { Regional Program of Statistical Support for Multilateral } \\
\text { Surveillance }\end{array}$ \\
\hline PPP & Purchasing Power Parity \\
\hline PRC & People's Republic of China \\
\hline $\mathrm{RCT}$ & Randomized Control Trial \\
\hline SME & Small or Medium-size Enterprise \\
\hline$S$ & Sub-Saharan Africa \\
\hline
\end{tabular}


TFP

UNCTAD

WAEMU

WBES

WDI
Total Factor Productivity

United Nations Conference on Trade and Development

West African Economic and Monetary Union

World Bank Enterprise Surveys

World Development Indicators 


\section{Introduction and overview}

Informal enterprises account for 72 percent of non-agricultural employment in Sub-Saharan Africa, 51 percent in Latin America, and 65 percent in Asia, using the definition of the International Labour Organization (ILO, 2002). Other studies confirm the finding that informal entrepreneurs and workers in informal enterprises make up a significant proportion of the world's workforce and gross domestic product (GDP) (Schneider et. al, 2010; Chen et al., 2006; OECD, 2002) and have significant potential for job creation (McMillan and Woodruff, 2002; Mead and Liedholm, 1998).

This means that government policies that affect informal enterprises have farreaching implications for economic growth, employment, and for factors influenced by these variables, such as inequality. However, there is little consensus as which approach to informal enterprises is most likely to promote specific policy objectives, such as economic growth, or the reduction or mitigation of inequality, or on how policy will affect the trade-offs between different objectives. The potential policy approaches range from focus on improving enforcement of rules and regulations with the aim of limiting the share of informal enterprises in the economy, to 'turning a blind eye' to informal activity, and to actively extending government support to informal enterprises and workers. Even among those who accept the need to support informal entrepreneurs, there is little consensus on the most appropriate tools. While microfinance is perhaps the most commonly applied, informal entrepreneurs could also benefit from other interventions, such as education and training, access to markets and inputs, or insurance.

The lack of consensus on the appropriate approach is caused, at least in part, by the lack of rigorous empirical evidence on informal enterprises and the economic factors that determine their performance. Two fundamental questions, which are largely empirical in nature, underlie the debate: how much potential do informal firms have to contribute to economic growth, and employment creation? And, if that potential exists; what constrains prevent informal entrepreneurs from reaching their full potential?

The contribution of the thesis is to investigate, using survey data, a number of questions about the constraints facing informal entrepreneurs. Although distinct questions are asked, and different contexts studied, the results, taken together, are all highly relevant to the fundamental questions outlined above. This thesis will therefore help strengthen the basis for informed policy among governments and international organizations, as well as contributing to the academic debate. 


\section{The informal economy: the academic debate}

All modern societies have formalized arrangements to regulate economic activity, ${ }^{1}$ and it is almost inevitable that some activities will be conducted fully or partly outside of these structures. Conceptually, any such activities can be considered 'informal', and the entities carrying out these activities can be called informal enterprises. The International Labour Organization (ILO) (1993) notes that the informal economy consists of units (known as informal enterprises in this thesis) engaged in the production of goods or services. Their primary objective is to generate employment and incomes for the persons concerned, rather than for shareholders, and they typically operate at a low level of organization, on a small scale, with labour relations being based on informal or casual arrangements, often with family members, rather than formal contracts. Some informal activities, such as drug trafficking, are illegal - explicitly prohibited by legal frameworks. But the informal economy also includes activities that are, in theory, within the reach of the law. Nevertheless, enterprises carrying out these activities may remain part of the informal economy because access to formal arrangements is limited by barriers such as physical distance, ignorance, or lack of capital, poor implementation of rules and regulations, or because economic actors seek to avoid burdens such as tax or paperwork.

Hart (1973) was one of the first researchers to discuss the informal economy in the academic economics literature, in the context of Ghana. The author argued that the existence of an urban informal sector is often a permanent feature of developing economies and identified a key question: "Does the 'reserve army of urban unemployed and underemployed' really constitute a passive, exploited majority"..."or do their informal economic activities possess some autonomous capacity for generating growth in the incomes of the"..."poor?" (Hart, 1973) In other words, is the existence of informal enterprises a side effect of market imperfections, or do they comprise a dynamic, creative sub-sector? This question underlies the policy questions highlighted above, and has been taken up in an ensuing lively academic debate, with seminal contributions including Moser (1978), de Soto (1989), Tokman (1989) and Maloney (2004). A related strand of the literature, summarized by Nichter and Goldberg (2009), has addressed the second policy question, investigating the specific constraints that prevent informal enterprises from growing and realizing their potential.

This thesis follows in the footsteps of, and adds to, both strands of literature. The first chapter examines marginal returns to capital, because high marginal returns are an indication that informal enterprises do indeed have substantial potential to contribute to the economy. In addition, the evidence of the third chapter directly examines the contribution of informal enterprises to employment growth. The thesis also examines the constraints to informal entrepreneurship in a variety of

\footnotetext{
${ }^{1}$ Norms governing economic activity are observed in all human societies, even in 'primitive' or 'tribal' settings (Sahlins,1972).
} 
contexts and from a variety of perspectives. In the final chapter the thesis also traces some of the implications of informal entrepreneurship and the growth of small firms for the economy as a whole - specifically, wage inequality.

\section{An operational definition of informal enterprises}

In order to analyse informal enterprises, an operational definition is required. The operational definition of informal enterprises and the informal economy developed by the ILO (1993) is widely accepted. Under this definition, informal enterprises are defined as private enterprises that are unregistered or have a small number of employees, do not maintain a complete set of accounts and are not legal entities separate of their owners. The ILO definition also excludes enterprises that produce goods or services exclusively for use of the household, and enterprises in agriculture, hunting, forestry and fishing.

This thesis follows the operational definition of the ILO as far as possible, but in some contexts a narrower definition is required in order to operationalize the concept. For example, the data used in Chapter 4 of this thesis do not allow us to distinguish strictly between formal and informal enterprises. In this chapter, therefore, we focus on micro- and small enterprises (MSEs). Although not all MSEs are informal, and not all informal enterprises are MSEs, the ILO guidelines explicitly refer to small size as a factor that can be used to identify informal enterprises, and there is, in practice a substantial overlap between the two categories. Hence, the findings of the analysis can be considered relevant to the overall theme of this thesis.

It is important to note the distinction between informal enterprises, which are the focus of this thesis, and informal employment. Informal employment, following the ILO (1993) definition, includes own account workers employed in their own informal enterprises, employees of informal enterprises and workers in informal workers cooperatives. This thesis will contain findings relevant to these workers and therefore to the understanding of informal employment. However, there are a number of reasons why formal sector firms, including large ones, may choose to employ workers informally. These workers are also considered to be informally employed, following the ILO definition. ${ }^{2}$ The issues facing these workers, and the academic and policy questions related to informal employment, differ significantly from the issues facing informal enterprises. The issues of informal employment are therefore largely beyond the scope of this thesis, which is concerned purely with informal enterprises.

\footnotetext{
2 Following the definition of ILO (1993), employees are considered to have informal jobs if their employment relationship is, in law or in practice, not subject to national labour legislation, income taxation, social protection or entitlement to certain employment benefits.
} 


\section{Informal entrepreneurs: constrained gazelles or deadweights?}

The academic debate on informal enterprises and entrepreneurs falls, roughly, into two schools of thought. On the one hand, researchers have argued that most informal enterprises are inefficient, with little potential for growth (Banerjee and Newman, 1993; Aghion and Bolton, 1997; Lloyd-Ellis and Bernhardt, 2000). Informal enterprises can provide subsistence opportunities to workers with no other options. They may serve as a social safety net, and help households diversify their income sources to reduce risk. But the activities carried out by informal enterprises are unlikely to be productive enough to help workers or their households exit poverty (Maloney, 2004).

In the extreme, one could argue that informal enterprises act like deadweights, holding back developing economies, and preventing workers exiting poverty. Several arguments underlie this position. Firstly, some informal economic activities, such as drug trafficking, are illegal because they have negative consequences in themselves. But even where activities are legal and have limited or no negative implications, the prevalence of informal enterprises reduces the size of the tax base, ceteris paribus, reducing government revenue. This can prevent governments improving and expanding service and infrastructure provision, and increase the tax burden for those enterprises which are formally registered. This makes it difficult for formal enterprises to compete, even if they are equally or more efficient, which stunts growth. There is empirical evidence that entrepreneurs in developing countries do see competition by informal firms as an important obstacle to doing business (Dinh et al., 2010). There are also feedback mechanisms at play: several empirical studies have found that lowering taxes would decrease the size of the informal sector (Ihrig and Moe, 2004; Saracoğlu, 2008).

In addition, informal sector workers usually lack employment rights and access to benefits such as social security, sick leave and maternity leave. Wages are usually low, and child labour often common. These characteristics of informal enterprises can be seen, in themselves, as negative. They can also have negative effects on workers and the economy in the longer term if they prevent workers from building up their human capital and becoming more productive.

Another school of thought has looked at informal enterprises from a more positive perspective. Some have seen informal enterprises as dynamic and flexible economic entities, driving innovation and economic development, along the lines of the numerous small firms and start-ups in Silicon Valley. While acknowledging the small size and low turnover of most informal enterprises in developing countries, this school of thought has nonetheless argued that, with the appropriate support, these firms may have the potential to be productive and to drive growth - that at least some informal firms are 'constrained gazelles' with 
potentially high returns to capital (Grimm et al., 2012; McKenzie and Woodruff, 2006; Kremer et al., 2010).

At the extreme, this school has argued that informal enterprises, with their creativity, dynamism and flexibility, are more efficient than formal-sector enterprises, particularly those which are fully or partially controlled by government. This line of argument has been particularly prevalent in the literature on command and transitional economies. In numerous cases small firms, often informal, played an important role in driving economic growth during the early years of transition and in preventing complete economic collapse as inefficient state-owned enterprises were wound down. The fact that most informal enterprises have failed to grow is seen by this school not as evidence of shortcomings within the enterprises, but as evidence of inadequacies in the supporting environment, including excessive interference by government (McMillan and Woodruff, 2002).

Constraints to informal entrepreneurs: access to capital isn't everything.

If at least some informal enterprises can be seen as 'constrained gazelles', the question arises what major constraints prevent them from expanding, employing more people, and contributing to economic growth. This question is closely related to the productivity and growth potential of the enterprises. If the main constraint could be addressed through relatively straightforward measures such as improving access to finance, then relaxing that constraint would reveal untapped potential for economic growth. But if the major constraints are intrinsic to the firms, or very difficult or expensive to tackle, such as lack of skills, or limits on the time the entrepreneur can devote to business, it could be argued that their growth potential is minimal.

An overview study by Nichter and Goldmark (2009) of the most influential studies on firm growth in developing countries of the past 50 years identifies four key factors that are associated with low firm growth in developing countries. These are: firm characteristics (e.g. firm age, formality, firm size or access to finance), individual characteristics of the enterprise owner, head or workers (e.g. education, gender, or work experience), relational factors (e.g. value chains or social networks) and contextual factors (e.g. business environment). It should be noted that these constraints often interact with or influence each other. For example, individual entrepreneurs of a particular gender or ethnicity may have better access to social networks, which in turn gives them better access to finance. Or, conversely, firms that lack access to financial capital may find it difficult to build up social capital by providing gifts or entertaining guests.

\section{Firm Characteristics and Credit constraints}

Probably the most frequently studied and well confirmed firm-level constraint to informal entrepreneurs is lack of access to finance, due to credit market 
imperfections. Numerous studies have examined the role of credit constraints in hindering firms from expanding (Tybout, 1983; Dinh et al., 2010; Dollar et al., 2005). The finding of high returns to capital in MSEs in Latin America, Africa, and Asia confirms the presence of credit constraints in developing countries (Udry and Anagol, 2006; de Mel et al., 2008; McKenzie and Woodruff, 2006).

A recent stream of literature uses randomized experiments to analyse factors determining the success of MSEs, controlling for unobserved heterogeneity between firms. Most of these experiments suggest the presence of significant credit constraints. The experiments randomly allocate cash or in-kind transfers to informal or small enterprises and analyse the effects on the firms. Such experiments have been carried out in Ghana (Fafchamps et al., 2011), Sri Lanka (De Mel et al., 2009) and the Philippines (Karlan and Zinman, 2010). Most of the studies show a positive effect on profits of these transfers, suggesting that credit constraints are a significant issue.

Poor access to credit is often connected with other firm characteristics. In particular, informal firms often find it harder to access formal credit markets than do formal firms. Also, the small size of most informal enterprises has been shown to hinder access. Bigsten et al. (2003) show empirically that small firms can be particularly badly affected by credit constraints. The authors use firm data from Burundi, Côte d'Ivoire, Ghana, Kenya, and Zimbabwe and find that even though demand for credit in Africa seems low, success rates in loan applications for bigger firms are substantially higher than success rates for small firms. The findings show that 33 percent of all firms in the sample are credit constrained. However, only 10 percent of large firms are assessed as being credit constrained, compared to 64 percent of micro-sized firms. Further evidence confirms that young and small firms are particularly affected by capital constraints (Beck et al. 2005; Evans and Jovanovic, 1989).

Based on this literature, it is also reasonable to assume that there are substantial feedback effects between firm size and capital constraints: capital constraints influence the firm size distribution, by making firm expansion difficult. Theoretical and empirical work shows that credit constraints indeed skew the firm size distribution towards smaller firms and that the skewedness decreases with firm age (Cabral and Mata, 2003; Cooley and Quadrini, 2001; Dinh et al., 2010; Angelini and Generale, 2008).

\section{Individual characteristics}

Besides credit constraints and risk, individual characteristics of the individual entrepreneur or firm owner have been found to constrain informal entrepreneurs. One such characteristic is gender. Women actively participate in informal entrepreneurship, and women have been estimated to make up over half of informal entrepreneurs in developing countries (Mead and Liedholm, 1998). 
However, there is evidence that these female entrepreneurs find it difficult to grow their enterprises past the micro- level. Mead and Liedholm (1998), for example, found a significantly slower average rate of employment growth in female-headed than male-headed firms.

Furthermore, evidence from randomized control trials (RCTs) shows that the impacts of grants or loans to entrepreneurs can vary depending on the gender of the entrepreneur receiving them (e.g. Fafchamps et al., 2011; De Mel et al., 2009; Karlan and Zinman, 2010; Mel et al., 2012). These results may be specific to the contexts where the RCTs were implemented, and they provide few insights into the mechanisms underlying the differing impacts. However, taken together, they suggest that either the constraints facing male and female entrepreneurs or the underlying productivity of their firms, or both, differ. Given the importance of informal entrepreneurship to the livelihoods of women and their households, the factors constraining female entrepreneurs are clearly worthy of further investigation.

There is also substantial empirical evidence on the role of education for MSE growth. A number of studies have found that MSE owners and workers tend to have relatively low levels of education. The evidence regarding the impact of education on MSE growth is mixed (Teal and Söderbom, 2001; Mead and Liedholm, 1998). It seems to be the case that a country specific threshold needs to be reached before one can observe positive correlations between educational attainments and firm performance (Nichter and Goldmark, 2009; McKenzie and Woodruff, 2006). Also, education may interact with other individual characteristics such as gender (de Mel et al., 2009).

\section{Relational Factors}

Access to social networks has been found to have beneficial impacts on MSEs, but certain relational factors can also act as constraints to MSE growth. On the one hand, in the presence of market failures, social networks can help to overcome constraints related to transaction costs, contract enforcement, and regulations. For instance, Fafchamps (2000) shows that entrepreneurs in Kenya prefer to do business with clients they have already interacted with. Barr (1998) quantitatively analyses the effects of social networks using data from manufacturing firms in Ghana. The study divides social networks into innovation networks (mostly used by bigger firms) and solidarity networks, which are common for smaller firms. The author defines innovation networks as groups of entrepreneurs that exchange information, for example on market developments and new technologies, in order to enhance firm performance. This is contrasted with solidarity networks, within which the main purpose of information exchange, for example about client behaviour, circumstances and intentions, is not to increase productivity but to reduce uncertainty. The findings show that innovation networks have a significant positive impact on firm productivity 
whereas the impact of solidarity networks on productivity is marginal. On the other hand there is evidence that social networks can have negative effects on firm performance due to abusive demands of network members or forced solidarity (Luke and Munshi, 2006). Forced solidarity may hinder even potentially successful firms from accumulating and investing capital. Findings from informal firms in West Africa show that social networks within the city have positive impacts on factor use and consequently value added of informal firms (Grimm et al., 2010). This is in line with the findings of Fafchamps (2000). By contrast, social ties to the village of origin are found to have robust negative effects on value added (Grimm et al., 2010).

\section{Contextual Factors}

Business risk can be a major constraint to informal entrepreneurs, and can be considered a contextual factor, using the categorization of Nichter and Goldmark (2009). ${ }^{3}$ Cash flows, especially for young and small enterprises in developing countries are volatile. Risk-averse entrepreneurs may be reluctant to take the risks necessary to start capital accumulation. This may in turn prevent them from investing in new technologies that could boost efficiency (Binswanger and Rosenzweig, 1986). Also, when investments are partially irreversible, firms might require a 'liquidity premium' - a level of precautionary savings deemed comfortable enough for the investment (Fafchamps and Pender, 1997).

Business risk is often related to institutional and governance constraints. This can make risk particularly high in developing countries, many of which have inadequate or poorly enforced legal arrangements relating to small-scale enterprises. As Fafchamps (1999) points out, 'true business risk' might be accompanied by 'opportunistic' or contractual risk if no proper contract enforcement mechanisms are in place (which is likely to be the case in developing countries). In particular, in a risky environment where contract enforcement is difficult, it is easy to claim inability to stick to the obligations agreed towards a business counterpart. The effect of intuitional weaknesses and corruption on firms has been quantified by Fisman and Svensson (2007) in the context of Uganda. The study finds that a one percent increase in the prevalence of bribery reduces firm growth by three percent. The empirical evidence on the effects of risk on marginal returns to capital is mixed, however. Overall, the expected positive effects cannot be confirmed (McKenzie and Woodruff, 2006; de Mel et al. 2008; Grimm et al., 2011).

MSEs can also be constrained by characteristics of the domestic market, both on the demand side (small market size), and on the supply side (difficulties in accessing inputs and technology). Evidence shows that a small domestic market

\footnotetext{
${ }^{3}$ Some risks are firm or industry-specific. However many are a factor of the economic and institutional context. The lack of access to insurance or other measures to mitigate business risk can also be considered a contextual factor.
} 
and hence limited domestic demand, potentially combined with a low elasticity of demand for the particular products commonly produced by MSEs, can impede firms from growing (Lachaud, 1990). Recent empirical evidence confirms the importance of this constraint (Böhme and Thiele, 2012).

Exporting evidently helps enterprises to overcome the small size of local markets (Bigsten et al., 2004; Diao et al., 2006). Empirical evidence from Asia and Africa shows that after entering the export market productivity increases occur, which can be largely attributed to the exploitation of scale economies (van Biesebroeck, 2005). Firms may also be constrained on input markets as certain inputs are not produced locally and most equipment used is imported from abroad (Dinh et al., 2010).

Government policy for the informal sector: the need for an evidence base.

While the questions discussed above regarding informal enterprises have been a lively subject of academic debate, they also have important implications for policy. For example, there is little consensus on the appropriate pace of formalization. If the informal economy is largely unproductive, it would be appropriate for the government to proceed with formalization as quickly as it can, concentrating on improving enforcement and implementation of formal arrangements, particularly those that provide worker rights. Government support for informal workers would be largely limited to providing a social safety net for those displaced from subsistence informal activities, or helping them to find formal sector jobs.

On the other hand, if informal entrepreneurs really are 'constrained gazelles', there is a chance that rapidly imposing a heavy tax or regulatory burden on them could stifle their potential for growth. Instead, it would be appropriate to offer support to informal entrepreneurs, allowing them to expand, provide more employment and, eventually, contribute to the formal economy (Tokman, 1989). Overall, it is unclear what policy options should be used.

Because the questions on which these choices are based are empirical in nature, the appropriate policy can be chosen only with the help of rigorous empirical analysis. Impact evaluation has provided some insights into which policies are effective, but an understanding of the fundamental questions underlying the debate is also essential to understand the channels of impact. This thesis investigates a number of questions about informal entrepreneurs and MSEs, all of which contribute to that evidence base from different, but complementary, perspectives. 


\section{Contributions of this thesis}

This thesis aims to narrow the research gap on informal enterprises, helping to answer the key questions identified above. The results on marginal returns to capital in Chapter 1 and on employment growth in Chapter 3 indicate that the potential of informal enterprises may be substantial, if constraints to growth can be overcome. Chapters 1, 2 and 3 provide new evidence on the specific constraints facing informal entrepreneurs. The chapters focus respectively on: monetary entry barriers, inefficient allocation of inputs by gender and lack of access to international markets. The final chapter examines the impact of changes in the firm distribution - influenced heavily by the success or failure of small, largely informal firms - on wage inequality, a variable of significant policy interest. This illustrates some of the implications of the existence and expansion of informal enterprises for the overall economy.

Chapter 1 investigates the patterns of capital entry barriers and returns to capital in informal MSEs using a unique micro data set covering seven countries in SubSaharan-Africa. By understanding the importance of monetary entry barriers and the patterns of returns to capital among informal enterprises we gain insights into their hidden potential, and into the role of capital constraints.

Our results reveal that although informal enterprises are heterogeneous, they are not predominantly engaged in subsistence activities. While an assessment of initial investment identifies some informal activities with negligible entry barriers, a notable cost of entry is associated with most activities. We find very heterogeneous patterns of capital returns. At very low levels of capital marginal returns are extremely high - often exceeding 70 percent per month. Above a capital stock of 150 international dollars (Int. USD), ${ }^{4}$ marginal returns are found to be relatively low, at around four to seven percent monthly. We provide evidence that the high returns at low capital stocks may reflect high risks. At the same time, most informal enterprises appear to be severely capital constrained.

The finding of high returns at low levels of capital stock suggests that policies to alleviate capital constraints for MSEs in SSA could help informal entrepreneurs to utilize the full potential of their enterprises. However, in order to design effective policy interventions, the reasons for these high returns need to be better understood. The role of risk for marginal returns in particular needs to be investigated in more depth. Some of the results described in the chapter suggest that it may play an important role, but the data are insufficient to rigorously test this hypothesis. If risk is a reason for high returns at low levels of capital, alleviation of capital constraints may have limited benefits without measures to help entrepreneurs mitigate and cope with risk. Furthermore, policy interventions

\footnotetext{
${ }^{4}$ In this thesis Int. USD refers to local currency converted into International Dollars using the Purchasing Power Parity (PPP) conversion factors for GDP from the World Development Indicators (World Bank, 2013).
} 
need to take into account interactions with other constraints. For example, social network effects could hinder informal entrepreneurs from reinvesting their profits, limiting the impact of improved financial access. Similarly, the gender effects identified in Chapter 2 may also impact on the effectiveness of policy.

In Chapter 2, we explore the efficiency of informal enterprises, as well as the role of social/individual constraints in constraining their productivity. The chapter asks whether households allocate capital and labour between informal enterprises headed by women and those headed by men in a pareto efficient way. To test for pareto efficiency we apply and follow closely the approach used by Udry (1996) in an agricultural setting to the same data set of informal enterprises in urban areas of seven countries in Sub-Saharan Africa. Controlling for household characteristics (observable and unobservable), sectoral differences and enterprise characteristics we find that profits of female headed enterprises are between 25 and 40 percent lower than the profits of male headed enterprises. This result is inconsistent with pareto efficiency. Our results show that total profits from informal enterprises could be about 20 percent higher if resources were allocated optimally within the household. Our simulations and results from an OaxacaBlinder decomposition show that the inefficient allocation of capital explains most of the gender gap.

Taken together, our findings show that gender should be considered carefully when designing policy tools for the informal sector - the returns to interventions such as the provision of microfinance will be affected by who receives the additional resources. Targeting interventions by gender has potential to increase their effectiveness. However, the chapter was unable to conclusively establish the reasons behind the seemingly inefficient allocation of resources, and this topic would need further investigation before definitive policy recommendations could be made. If the allocation arises not merely from social norms but from unobserved differences in enterprises that are correlated with gender (for example, differences in risk preferences), these unobserved factors could determine the success of targeting. Further research on the risk and time preferences of male and female entrepreneurs, and on other unobserved factors that may vary between male and female headed enterprises would help to close the research gap.

Lack of access to markets and inputs has also been suggested as a constraint to the growth of informal entrepreneurs, but has received less attention in the empirical literature than the role of credit constraints. To address this gap in the literature, Chapter 3 examines the role of international trade for employment growth in MSEs using a representative sample of manufacturing firms in six Southeast Asian countries.

In this sample, employment in firms in the bottom quintile of the initial size distribution grew the fastest, and contributed considerably to overall employment 
creation. After controlling for firm and individual characteristics as well as country and sector dummies, participation in international trade is found to play a significant role in explaining this growth, boosting firm-level growth by three percent on average. Participating in international trade also increases the probability of being a top performing firm by 10 percent.

The fact that firms start exporting quickly after the foundation of a firm suggests that reverse causality is not an issue for our estimates. However, biases arising because of unobserved heterogeneity cannot be ruled out because of the crosssectional character of the available data. This means that the relationship between participation in international trade and employment growth should be interpreted as a correlation rather than a causal relationship. However, evidence from an instrumental variable approach (exploiting the fact that firms were exposed to unexpected variation in real exchange rates between 2005 and 2008), although inconclusive, do not suggest that the relationship is driven by unobserved heterogeneity. Furthermore, first difference estimations computed using panel data from Bangladesh confirm the findings from Southeast Asia. The education of the firm's owner, foreign ownership and firm age are also closely related to firmlevel employment growth.

Overall, the evidence of this chapter suggests that measures to improve access of entrepreneurs to import and export markets could help these firms to expand. In the absence of further research, using panel data or an instrumental variable approach to firmly establish the causal relationship, these sorts of interventions could be worthwhile piloting, with rigorous assessment of their benefits.

The final chapter looks at the role of the firm size distribution for wage inequality in order to understand the implications of the expansion of MSEs for the overall economy. The chapter uses data from nationally representative labour force surveys (LFSs) of 1995 and 2005 in Thailand. The evidence shows that relatively slow wage growth among MSEs increased the wage gap between their workers and workers in medium and larger enterprises, contributing to rising wage inequality. In addition, the firm size distribution changed towards an even more pronounced 'missing-middle' pattern. Firms became clustered at the large and micro to small end of the spectrum, with relatively few medium-sized enterprises. Because of the large gap between the wages in micro to small and medium to large enterprises, this contributed significantly to the increase in wage inequality. This finding holds even when controlling for observed factors influencing the wage distribution but correlated with firm size. Specifically, even when we control for the fact that the smallest enterprises are concentrated in the poorest regions, and in agriculture, which is characterized by low wages, we still find that changes in the firm size distribution impacted on wage inequality.

However, it should be noted that the expansion of wage opportunities, many of which have been provided by MSEs, may have mitigated the effect of rising wage 
inequality and contributed to the fact that overall income inequality remained stable over the period studied. This suggests that, despite their limited or negative contribution to wage inequality over the period studied, MSEs nonetheless have an important role to play in reducing or mitigating overall income inequality. In particular, if they were able to expand beyond a small size, leading to reduction in the typical "missing middle" pattern, this would have potential to decrease wage and income inequality. 


\title{
Chapter 1
}

\section{Barriers to Entry and Returns to Capital in Informal Activities: Evidence from Sub-Saharan Africa*}

\begin{abstract}
This paper investigates the patterns of capital entry barriers and capital returns in informal micro and small enterprises (MSEs) using a unique micro data set from seven countries in Sub-Saharan Africa. Our findings support the characterisation of a heterogeneous informal sector that is not primarily host to subsistence activities. While an assessment of initial investment identifies some informal activities with negligible entry barriers, a notable cost of entry is associated with most activities. We find very heterogeneous patterns of capital returns in informal MSEs. At very low levels of capital, marginal returns are extremely high - often exceeding 70 percent per month. Above a capital stock of 150 international dollars, marginal returns are found to be relatively low, at around 4 to 7 percent monthly. Some of our evidence suggests that the high returns at low capital stocks reflect high risks. At the same time, most MSEs appear to be severely capital constrained.
\end{abstract}

* Based on joint work with Michael Grimm and Jann Lay. 


\subsection{Introduction}

Most urban dwellers in the developing world make their living from informal micro and small enterprises (MSEs) and the performance of those enterprises often decides upon livelihood success and failure. Successful entrepreneurs seem to co-exist with the masses of petty traders or other menial workers who can hardly make a living. It is widely assumed that the earnings potential of many of those entrepreneurs is under-exploited, as they face important economic constraints, such as entry barriers and limited access to credit. This provides a rationale for policy interventions such as micro-credit programs. The presence of entry barriers combined with capital market imperfections may indeed explain the heterogeneity amongst informal entrepreneurs in developing countries. In poverty trap models, returns to capital below a certain threshold of investment are often assumed to be very low or even zero, as entry of other poor individuals into this subsistence segment of the informal sector eats up potential returns. Only if entrepreneurs are wealthy enough or can obtain credit to overcome the barrier to entry, can they earn much higher returns. Returns to capital in MSEs can thus be regarded as a key indicator of the unexploited potential of informal entrepreneurship.

Despite an abundant literature on the informal sector in developing countries (Moser, 1978; Peattie, 1987; Rakowsky, 1994; Maloney, 2004; Henley et al., 2006), the empirical literature on entry barriers and returns to capital in MSEs is fairly recent and surprisingly limited. This is all the more remarkable since a very early insight from the literature on the informal sector is that it comprises very heterogeneous activities or, more specifically, heterogeneous forms of production (Hart, 1973). Existing studies on capital returns consistently find very high returns, often in the order of more than 60 percent annually. De Mel et al. (2008), for instance, use data from a randomised experiment to estimate returns to capital of Sri Lankan microenterprises. In this experiment, the authors randomly give cash or in-kind transfers, which represent 55 to 110 percent of the median investment, to microenterprises. They find a significant and positive correlation between transfers and real profits of the enterprises. Using the random treatment as an instrument for changes in the capital stock the authors estimate the returns to capital to be in a range from 55 to 70 percent per year. McKenzie and Woodruff (2006) find very high returns at low levels of capital, yet little evidence for the existence of high entry costs, for the case of informal Mexican enterprises, although start-up costs vary considerably by sector. As we will follow their empirical approach very closely, our findings can be readily compared to theirs.

For Sub-Saharan Africa, there is also evidence of extremely high returns to capital (Udry and Anagol, 2006; Schündeln, 2004; Kremer et al., 2010). Kremer et al. (2010) for instance study retail firms in rural Kenya and find an average 
annual real marginal rate of return of 113 percent, although the results also revealed substantial heterogeneity across firms. The rates of returns are derived from information on foregone earnings due to insufficient inventory or stockouts, and alternatively, by assessing whether firms take advantage of quantity discounts from wholesalers. Both procedures yield very similar estimates.

With respect to the causes of the observed pattern of high returns at relatively low levels of capital, the evidence is inconclusive, although some findings do suggest an important role for capital market constraints (Banerjee and Duflo, 2004; Schündeln, 2006; de Mel et al., 2008). In general, high returns in MSEs point at the huge potential of these firms, as a very large share of urban employment is generated by MSEs. Based on the same dataset used in this paper, Brilleau et al., (2005) find for instance that the share of informal sector employment uniformly exceeds 70 percent in urban Sub-Saharan Africa.

In this paper we estimate capital returns for MSEs in Sub-Saharan Africa and examine entry barriers into small-scale economic activities. We address the following questions: First, do informal activities exhibit high entry barriers (startup costs) relative to the income and wealth levels of entrepreneurs? Second, how do capital returns vary with the size of the capital stock; do we also find high returns at low levels of capital or the inverse as some of the theoretical literature suggests? And third, what can be said about the causes of the observed patterns of capital returns? To answer these questions, we use a unique, albeit crosssectional, micro data set on informal enterprises covering the economic capitals of seven countries in Sub-Saharan Africa. In our empirical approach, we closely follow the study by McKenzie and Woodruff (2006).

The remainder of the paper is organised as follows. Section 1.2 outlines our analytical framework and formulates the hypotheses that are tested in Section 1.3. Section 1.4 concludes. 


\subsection{Analytical framework and hypotheses}

In what follows we develop a simple model in which prospective entrepreneurs face entry barriers and non-convex production technologies and then derive testable assumptions under alternative hypotheses about capital market imperfections. In the literature on entrepreneurial activity in developing countries, incomplete capital markets have long been stressed as a major economic constraint (e.g. Tybout, 1983; Bigsten et al., 2003). If capital markets function poorly because credit contracts cannot be easily enforced, so goes the argument, capital fails to flow to its most productive uses and marginal returns across entrepreneurial activities are not equalised. Faced with different costs of capital because of differences in wealth and their capacity to provide collateral, borrowers may have to choose to invest in different technologies (Banerjee and Duflo, 2005).

In such a setting, the informal sector may be divided into different segments characterised by different entry barriers in terms of skill or capital requirements (e.g. Fields, 1990; Cunningham and Maloney, 2001). This basic idea is reflected and formalised in a number of models of economic development and poverty traps, which emphasise the role of the distribution of wealth (e.g. Banerjee and Newman, 1993; Galor and Zeira, 1993). In these models, the segmentation of economic activities and the co-existence of high and low returns are caused by the interaction of non-convex production technologies and capital market imperfections. If gainful entrepreneurial activities require a certain level of startup capital that cannot be obtained from capital markets, poorly endowed individuals will be prevented from entry. This implies that poor individuals get stuck in low-productivity activities and hence the whole economy may end up in a poverty trap; the higher the share of initially poor people, the higher the share of those in low-productivity industries. ${ }^{5}$

These models typically assume very low levels of returns, or subsistence returns, at very low levels of capital and higher returns once a certain threshold has been passed. In the simplest of worlds, the entrepreneur maximises the difference between output $y$ and the costs of capital ( $r k)$, i.e. profit $\pi$ subject to his borrowing constraint $\bar{B}$. He can only produce a non-zero output using neoclassical technology $f$ if he is able to raise at least $\bar{K}$. Otherwise his production will be absorbed entirely by the costs of capital and his profit will be zero.

\footnotetext{
${ }^{5}$ Risk and risk aversion can also create such poverty traps.
} 
Max. $\quad \pi=y-r K$

s.t. $\quad y=f(K) \quad$ if $\quad K>\bar{K}$

$$
\begin{aligned}
& y=r K \quad \text { if } \quad K \leq \bar{K} \\
& K \leq \bar{B}
\end{aligned}
$$

The entrepreneur will chose his capital stock such that

$$
f^{\prime}(K)=r \quad \text { if } \quad \bar{B}>\bar{K}
$$

If his borrowing constraint is binding, i.e. $\bar{B} \leq \bar{K}$, then the entrepreneur will be indifferent between different sizes of capital stock, as he earns zero profits anywhere between $0 \leq K \leq \bar{K}$. Returns to an additional unit of capital, i.e. $\pi^{\prime}(K)$ , will hence be 0 between $0 \leq K \leq \bar{K}$. Once his borrowing capacity allows the entrepreneur to pass the threshold $\bar{K}$, he earns very high marginal returns that fall to zero when he reaches the optimal level of capital $K^{*}$. The resulting patterns of marginal returns to capital as a function of the borrowing constraint $B$ are presented in the graph below.

Figure 1-1: Borrowing constraints and marginal returns to capital

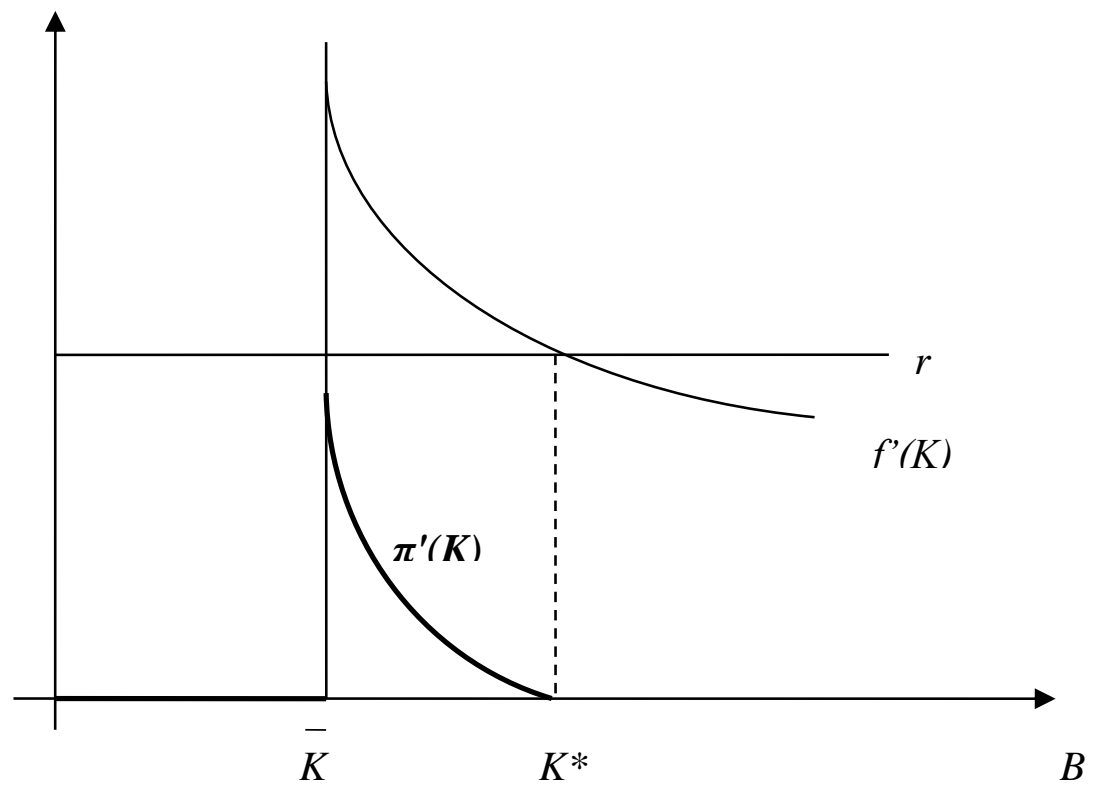

Source: Author's compilation. 
This simple exposition allows us to formulate two basic hypotheses to be tested subsequently: First, the existence of a threshold $\bar{K}$ should be observable in the distribution of initial investment undertaken by MSEs. Second, returns to capital should be low at low levels of capital, and high but decreasing in $K$ at higher levels. Note that this theoretical insight contradicts most of the empirical evidence presented in the introduction. In what follows, we will test whether this framework has also to be rejected for the economies we focus on.

\subsection{Entry costs and capital returns in African MSEs}

\subsubsection{Data}

We test these hypotheses by using data from a set of surveys (1-2-3 surveys or Enquêtes 1-2-3) in seven economic capitals of the West-African Economic and Monetary Union (WAEMU) in the early 2000s. ${ }^{6}$ A 1-2-3 survey is a multi-layer survey organised in three phases and specially designed to study the informal sector. $^{7}$ Phase 1 is a representative labour force survey collecting detailed information on individual socio-demographic characteristics and employment. Phase 2 is a survey which interviews a representative sub-sample of informal production units identified in Phase 1. The focus of the second phase is on the characteristics of the entrepreneurs and their production unit, including the characteristics of employed workers. It also contains detailed information on input use, investment, sales and profits. Phase 3 is a household expenditure survey interviewing (again) a representative sub-sample of Phase 1. The datasets from all three phases are organised in such a way that they can be linked. For this paper we use data from Phase 2, a cross-sectional sub-sample of informal entrepreneurs in seven urban centres in Sub-Saharan Africa (Brilleau et al., 2005a).

\subsubsection{Basic MSE characteristics}

The 1-2-3 surveys define informal enterprises as production units that (a) do not have written formal accounts and/or (b) are not registered with the tax administration. Part (b) of this definition varies slightly between countries, as registration may not always refer to registration with tax authorities. The sodefined informal sector accounts for the vast majority of employment in the WAEMU cities covered by the surveys, as illustrated in Table 1-1. The share of informal sector employment exceeds 70 percent in all cities considered - in Cotonou and Lomé even 80 percent. Employment in informal firms is typically

\footnotetext{
${ }^{6}$ These urban centres are Abidjan, Bamako, Cotonou, Dakar, Niamey, Lomé and Ouagadougou. The surveys were carried out by AFRISTAT and the National Statistical Institutes (INS) with the support of Developpement Institutions \& Mondalisation (DIAL) as part of the Regional Program of Statistical Support for Multilateral Surveillance (PARSTAT) between 2001 and 2003. For a more detailed description of the data see Brilleau et al. (2005a).

${ }^{7}$ See Roubaud (2008) for a detailed assessment of this type of survey instrument.
} 
self-employment, i.e. the employed individual is also the MSE owner. However, employees and/or helping family- and non-family workers account for 30 to 40 percent of employment in this sector.

Table 1-1: Employment by sector in seven urban centres in Sub-Saharan Africa (percent)

\begin{tabular}{|c|c|c|c|c|c|c|c|c|}
\hline $\begin{array}{l}\text { Principal } \\
\text { employment }\end{array}$ & Cotonou & Ouaga. & Abidjan & Bamako & Niamey & Dakar & Lomé & Total \\
\hline $\begin{array}{l}\text { Public } \\
\text { administration }\end{array}$ & 6.3 & 10.4 & 5.5 & 7.5 & 13.5 & 5.7 & 5.2 & 6.6 \\
\hline Public firm & 2.2 & 2.3 & 1.1 & 2.5 & 1.8 & 1.8 & 2.3 & 1.8 \\
\hline Private formal firm & 9.9 & 11.8 & 17.6 & 11.4 & 11.8 & 15.0 & 10.5 & 14.2 \\
\hline $\begin{array}{l}\text { Private informal } \\
\text { firm } \\
\text { of which }\end{array}$ & 80.3 & 73.4 & 74.7 & 77.5 & 71.1 & 76.4 & 81.0 & 76.2 \\
\hline Owners & 63.7 & 67.5 & 60.4 & 73.4 & 72.2 & 65.2 & 68.6 & 65.0 \\
\hline Family workers & 19.2 & 16.3 & 16.1 & 8.6 & 14.5 & 17.6 & 13.6 & 15.5 \\
\hline $\begin{array}{l}\text { Non-family } \\
\text { workers }\end{array}$ & 17.1 & 16.2 & 23.5 & 18.0 & 13.3 & 17.2 & 17.8 & 19.5 \\
\hline Associations & 1.3 & 2.1 & 1.1 & 1.1 & 1.8 & 1.1 & 1.0 & 1.2 \\
\hline
\end{tabular}

Source: Brilleau et al. (2005), and authors' computations based on 1-2-3 surveys (Phase 2, 2001/02, AFRISTAT, DIAL, INS).

The 1-2-3 surveys do not (explicitly) apply a size criterion, but more than 90 percent of the enterprises employ a maximum of three people including the owner and any family members employed. As shown in Table 1-2, around 70 percent of informal enterprises function in 'pure self-employment' mode, i.e. they only consist of the owner. Accordingly, the average enterprise size - including all employed family- and non-family-members - is only 1.6 individuals. The information in Table 1-2 has been computed from a sample of 6,521 informal enterprises from all seven countries that will be used for all the subsequent empirical analyses. This number includes 243 MSEs reporting zero profits and 892 MSEs reporting zero capital stock.

These small enterprises had been in operation for more than seven years on average. The median age, however, is significantly lower, only five years. Owner's experience in the business is typically lower than the enterprise age, mainly reflecting the fact that some MSEs are transferred within the family. MSE owners have only 3.7 years of schooling on average and about half of them are female.

Average monthly profits of informal enterprises are about 380 International US Dollars (Int. USD) ${ }^{8}$ with median profits at 112 Int. USD. Profits are computed as value added (sales minus input costs including expenses for products for re-sale). The questionnaire has very detailed sections on sales of transformed, non-

\footnotetext{
${ }^{8}$ Whenever Int. USD are mentioned this refers to local currency converted to International USD using Purchasing Power Parity (PPP) conversion factors for Gross Domestic Product (GDP) from the World Development Indicators (World Bank, 2013).
} 
transformed or re-sold products as well as offered services. The same holds for the input side, which covers raw materials, intermediates, products for re-sale, taxes, rents and other utility costs. All these items are covered for the last month in the survey. Note that interest payments are not deducted from value added.

Average capital stock is fairly high, at around 1,000 Int. USD, but this result is driven by a few MSEs with very high capital stocks - the median MSE capital endowment stands at only 75 Int. USD. We measure capital stock by the replacement value of all business-related assets, including the business establishment, machines, furniture, vehicles and utilities. More specifically, the entrepreneur is asked to report all the equipment that she has used in the last year to operate her business and the replacement value of each item. ${ }^{9}$ While this implies that the corresponding equipment is used for the operation of the business, it is impossible to determine whether this is its sole use or whether it is also used for other purposes in the household. We will come back to this point in the discussion of our results. Another complication of computing capital stocks stems from the fact that capital is also bound by inventories (or stocks of raw materials). This is ignored in the above calculation, but we will take this into account when we analyse entry barriers and returns to capital below.

Table 1-2: Basic descriptive statistics of informal MSEs, by quintiles of capital stock (Int. USD)

\begin{tabular}{|c|c|c|c|c|c|c|c|}
\hline & Mean & Median & $\begin{array}{c}1 \\
(0-10) \\
\end{array}$ & $\begin{array}{c}2 \\
(10-42) \\
\end{array}$ & $\begin{array}{c}3 \\
(42-155) \\
\end{array}$ & $\begin{array}{c}4 \\
(155-731) \\
\end{array}$ & $\begin{array}{c}5 \\
(733- \\
106166) \\
\end{array}$ \\
\hline Age of the enterprise & 7.4 & 5 & 6.7 & 7.1 & 8.2 & 7.7 & 7.4 \\
\hline Owner's age & 36.3 & 35 & 35.2 & 35.8 & 36.8 & 36.1 & 37.8 \\
\hline $\begin{array}{l}\text { Owner's years of } \\
\text { schooling }\end{array}$ & 3.7 & 3 & 3.3 & 2.5 & 3.2 & 3.9 & 5.5 \\
\hline Owner's experience & 6.9 & 4 & 6.1 & 6.6 & 7.6 & 7.1 & 6.9 \\
\hline Owner female & 0.51 & & 0.6 & 0.7 & 0.5 & 0.4 & 0.3 \\
\hline Firm size & 1.6 & 1 & 1.1 & 1.2 & 1.5 & 1.9 & 2.5 \\
\hline $\begin{array}{l}\text { Share of pure self- } \\
\text { employment }\end{array}$ & 0.69 & & 0.9 & 0.9 & 0.7 & 0.6 & 0.4 \\
\hline $\begin{array}{l}\text { Monthly profit (in } \\
2001 \text { Int. USD) } \\
\text { Capital stock (in }\end{array}$ & 380.3 & 112 & 206.7 & 179.9 & 323 & 412 & 783.3 \\
\hline 2001 Int. USD) & 997.2 & 76.8 & 2.1 & 23.4 & 83.6 & 351.8 & 4554.4 \\
\hline $\begin{array}{l}\text { Number of } \\
\text { observations }\end{array}$ & 6521 & 6521 & 1324 & 1293 & 1306 & 1302 & 1296 \\
\hline
\end{tabular}

Notes: Quintiles of capital (minimum and maximum capital in Int. USD in parentheses). 2001 international dollars are on the basis of the Purchasing Power Parity (PPP) converters for GDP from the World Development Indicators (World Bank, 2013).

Source: Authors' computation based on 1-2-3 surveys (Phase 2, 2001/02, AFRISTAT, DIAL, INS).

\footnotetext{
${ }^{9}$ Unfortunately, we do not have any information about sales of or damage to capital goods.
} 
For a first assessment of MSE heterogeneity, we also report the above characteristics by capital quintiles. The first quintile basically works without capital. These MSEs mainly comprise trading activities and other services (industry composition not reported). The profits of these enterprises are around 200 Int. USD, almost two times median profits. Typically, these MSEs are made up of self-employed individuals. This also holds for entrepreneurs in the second capital quintile. They resemble those without capital, but are significantly less educated and earn about 30 Int. USD less per month. In the third quintile, profits are more than 70 percent higher than in the second quintile while the average capital stock approximately quadruples. Yet, it remains low at only about 80 Int. USD on average. The owners of these firms have fewer years of schooling that the average, but 0.7 years more than those with very little capital. Fewer owners are female and their firms are slightly bigger than in the lower quintiles. From the third to the fourth quintile, changes are similar to moving from the second to the third. Capital stock again quadruples, owner's average education increases, as does firm size and the share of male owners. However, monthly profits only increase by 90 Int. USD on average, to 412 Int. USD. Much more pronounced are the differences in capital and profits between the fourth and the fifth quintile. Average capital stock of MSEs in the fifth quintile is almost 5,000 Int. USD and monthly profits are much higher than in other enterprises. These entrepreneurs also tend to be much better educated than the average and more than half of them employ at least a second person.

These descriptive statistics indeed hint at a considerable degree of heterogeneity within the informal sector, although MSEs of the bottom 40 percent of the capital distribution share a number of common characteristics. This heterogeneity - also in profits - seems to be linked to capital stock, which, in turn, may be associated with the respective sector of activity. Therefore, Table 1-3 shows the industry distribution of the MSEs for each country and for the sample as a whole. Overall the most important sector is 'petty trading' ( 27.1 percent), followed by 'other manufacturing and food' (16.0 percent) and 'other services' (11.8 percent), i.e. services that are not covered by the other listed industries. The smallest sector in terms of its share is the transport sector, which is likely to require substantial start-up costs, including investment in physical capital and cost for licences (4.6 percent). The relative importance of the various industries is in line of what one would expect when looking at demand patterns. Whereas small services, small traded goods and food have a high share in the households' budgets, transport or repair services have a rather small share. It is also interesting to see that the industry distribution is relatively homogenous across the seven countries, with two exceptions: 'Other manufacturing and food' are particularly frequently reported in Ouagadougou and Niamey. These cities have in turn relatively low shares for the sector 'hotels and restaurants', so it might be that the border between 'producing or processing food' and 'selling food in a restaurant' was not drawn in exactly the same way in the seven cities under study. The industry composition seems to be relatively unrelated to the level of GDP per capita; the 
richer centres in the sample such as Abidjan and Dakar do not have a substantially different distribution than Niamey and Lomé.

Table 1-3: Industry composition of informal MSEs by country (number of observations and percent of firms)

\begin{tabular}{lrrrrrrrr} 
Industry/City & Cotonou & Ouaga. & Abidjan & Bamako & Niamey & Dakar & Lomé & Total \\
\hline Clothing and & 98 & 78 & 122 & 137 & 56 & 98 & 117 & 706 \\
apparel & 10.5 & 8.2 & 12.3 & 14.0 & 7.9 & 9.8 & 12.3 & 10.8 \\
\hline Other & 102 & 223 & 103 & 134 & 225 & 151 & 106 & 1,044 \\
manufacturing & & & & & & & & \\
\& food & 11.0 & 23.3 & 10.4 & 13.7 & 31.6 & 15.2 & 11.1 & 16.0 \\
\hline Construction & 70 & 68 & 68 & 101 & 39 & 91 & 55 & 492 \\
& 7.5 & 7.1 & 6.9 & 10.3 & 5.5 & 9.1 & 5.8 & 7.5 \\
\hline Wholesale/retail & 104 & 103 & 102 & 92 & 46 & 109 & 100 & 656 \\
shops & 11.2 & 10.8 & 10.3 & 9.4 & 6.5 & 10.9 & 10.5 & 10.1 \\
\hline \multirow{2}{*}{ Petty trading } & 235 & 251 & 262 & 265 & 194 & 283 & 279 & 1,769 \\
& 25.3 & 26.2 & 26.5 & 27.1 & 27.2 & 28.4 & 29.2 & 27.1 \\
\hline Hotels & 89 & 78 & 80 & 40 & 8 & 50 & 66 & 411 \\
restaurants & 9.6 & 8.2 & 8.1 & 4.1 & 1.1 & 5.0 & 6.9 & 6.3 \\
\hline & 67 & 51 & 63 & 49 & 41 & 36 & 68 & 375 \\
Repair services & 7.2 & 5.3 & 6.4 & 5.0 & 5.8 & 3.6 & 7.1 & 5.8 \\
& 80 & 22 & 43 & 37 & 26 & 54 & 39 & 301 \\
\hline \multirow{2}{*}{ Transport } & 8.6 & 2.3 & 4.3 & 3.8 & 3.7 & 5.4 & 4.1 & 4.6 \\
& 85 & 83 & 147 & 124 & 78 & 125 & 125 & 767 \\
\hline \multirow{2}{*}{ Other services } & 9.1 & 8.7 & 14.9 & 12.7 & 10.9 & 12.5 & 13.1 & 11.8 \\
\hline Total & 930 & 957 & 990 & 979 & 713 & 997 & 955 & 6,521 \\
& 100 & 100 & 100 & 100 & 100 & 100 & 100 & 100 \\
\hline
\end{tabular}

Notes: Shares (in percent) in italics.

Source: Authors' computation based on 1-2-3 survey (Phase 2, 2001/02, AFRISTAT, DIAL, INS).

\subsubsection{Entry barriers}

We now turn to the empirical analysis of the existence of entry barriers into informal activities. We expect that MSEs engage in petty (or subsistence) activities that require little capital as well as more capital intensive activities that involve considerable initial investment. In some industries we expect more of these activities, for example in trade, than in others, for example in transport. We therefore first analyse distributions of initial investment in equipment that should reflect these patterns. In a second step, we also consider other start-up costs including expenses for other inputs and inventories.

Before we quantitatively examine these entry barriers, we briefly report and comment on some evidence from questions that ask entrepreneurs for the problems they face. Table 1-4 reports the share of entrepreneurs who report to have problems in a specific area. We distinguish MSEs (only in the clothing and apparel sector to reduce heterogeneity) by their age in order to determine whether 
those problems are different when an enterprise starts operating. Two groups of problems figure prominently for MSEs in the clothing and apparel sector; on the one hand, those related to the lack of demand (not enough clients, too much competition) and, on the other, those associated to the access to capital in a broad sense (access to credit, lack of locality, machines, and equipment). Access to raw material is a problem only for 25 percent of the MSEs, but much more so for younger ones. Demand-related problems seem to be equally important for MSEs at all ages, and so for a vast majority. Half of the firms report inadequate access to credit. The answer to this question (and the next question on credit too expensive) is likely to be biased by actual experience of demanding/being declined credit, which might explain why more of the older firms report problems in this area. This seems plausible, as problems that result from credit constraints, such as the lack of locality, machines, and equipment, are indeed cited more frequently by younger firms suggesting that these costs may represent important barriers to entry. Other constraints, such as the lack of qualified personnel, technical or management problems, and institutional or governance constraints appear to be much less important. There is also no evidence that these problems are more important when firms start operating. ${ }^{10}$

Table 1-4: Perceived problems faced by MSEs in the clothing and apparel sector by enterprise age (share)

\begin{tabular}{|c|c|c|c|c|c|}
\hline \multirow[b]{3}{*}{ Problem } & \multirow[t]{3}{*}{ All } & \multicolumn{4}{|c|}{ Enterprise age } \\
\hline & & less than & & & more than \\
\hline & & 1 year & $2-3$ years & $4-8$ years & 8 \\
\hline Access to raw materials & 0.25 & 0.35 & 0.22 & 0.25 & 0.23 \\
\hline Not enough clients & 0.67 & 0.68 & 0.72 & 0.67 & 0.64 \\
\hline Too much competition & 0.59 & 0.56 & 0.59 & 0.59 & 0.60 \\
\hline Access to credit & 0.48 & 0.46 & 0.46 & 0.47 & 0.51 \\
\hline Credit too expensive & 0.28 & 0.27 & 0.34 & 0.25 & 0.27 \\
\hline Recruitment of qualified personnel & 0.12 & 0.13 & 0.14 & 0.10 & 0.11 \\
\hline Lack of adequate locality & 0.38 & 0.43 & 0.38 & 0.40 & 0.34 \\
\hline Lack of machines, equipment & 0.44 & 0.46 & 0.46 & 0.45 & 0.40 \\
\hline Technical difficulties of production & 0.16 & 0.16 & 0.19 & 0.17 & 0.15 \\
\hline Management difficulties & 0.13 & 0.07 & 0.14 & 0.14 & 0.13 \\
\hline Too many regulations and taxes & 0.10 & 0.07 & 0.09 & 0.11 & 0.11 \\
\hline Number of observations & 706 & 93 & 164 & 194 & 255 \\
\hline
\end{tabular}

Source: Authors' computation based on 1-2-3 survey (Phase 2, 2001/02, AFRISTAT, DIAL, INS).

Although our dataset is cross-sectional, it allows us to identify investment paths since, for each enterprise asset, we know the date of purchase. Furthermore, we know when an enterprise was established. As a proxy for initial investment in equipment we therefore use the accumulated investment undertaken during the

\footnotetext{
${ }^{10} \mathrm{We}$ are aware that these descriptive statistics are biased by the fact that some constrained firms never set up a shop. This also holds for the subsequent analyses and is a bias that is impossible to address with the data at hand.
} 
first year of operation. As we expect measurement error in the investment history to be severe for investments undertaken a long time ago, the subsequent analysis of this section only considers enterprises that have been established four years before the survey or later. This leaves us with a sub-sample of 3,144 informal enterprises.

We first examine initial investment by industry. Table 1-5 hence shows the replacement value of business assets accumulated in the first year of operation at certain quantiles of the initial-investment distribution. The statistics are again based on the pooled data from all seven countries in the dataset.

Table 1-5: Replacement value of assets accumulated in the first year of operation (Int. USD and share of firms)

\begin{tabular}{lccrrrrrrr}
\hline & $\begin{array}{c}\text { Share } \\
\text { without } \\
\text { initial } \\
\text { invest- }\end{array}$ & & & & & & & & \\
& Obs. & ment & Mean & Mean (>0) & p10 & p25 & p50 & p75 & p99 \\
\hline Clothing and apparel & 319 & 0.18 & 813 & 994 & 0 & 14 & 233 & 615 & 10955 \\
Other manfg \& food & 493 & 0.23 & 708 & 919 & 0 & 5 & 46 & 364 & 20781 \\
Construction & 128 & 0.30 & 262 & 377 & 0 & 0 & 31 & 119 & 3961 \\
Wholesale/retail shops & 329 & 0.39 & 684 & 1119 & 0 & 0 & 24 & 193 & 14974 \\
Petty traders & 943 & 0.38 & 177 & 288 & 0 & 0 & 10 & 35 & 2607 \\
Hotels and restaurants & 229 & 0.14 & 802 & 937 & 0 & 30 & 93 & 396 & 8860 \\
Repair services & 159 & 0.17 & 1150 & 1386 & 0 & 36 & 200 & 708 & 30347 \\
Transport & 171 & 0.29 & 3645 & 5109 & 0 & 0 & 932 & 3397 & 34074 \\
Other services & 373 & 0.42 & 760 & 1318 & 0 & 0 & 15 & 296 & 15401 \\
\hline Total & 3144 & 0.31 & 734 & 1060 & 0 & 0 & 30 & 275 & 12740 \\
\hline
\end{tabular}

Source: Authors' computation based on 1-2-3 survey (Phase 2, 2001/02, AFRISTAT, DIAL, INS).

Overall, levels of initial investment in equipment are fairly low. Quite a number of activities do not seem to require any initial investment. This holds for 31 percent of all enterprises and somewhat less for 'capital intensive' informal industries, such as repair services and hotels and restaurants. In most activities, initial investment however remains low also at higher quantiles. The median petty trader, for example, still does not invest more than 10 Int. USD during the first year after establishing the enterprise. However, although 29 percent of all enterprises in the transport sector do report zero initial investment, the median initial investment (among those MSEs that do invest) is about five times larger than for the repair services sector and the clothing sector, the industries with the second and third largest values. The top 25 percent in the transport sector invest more than 3,300 Int. USD in the first year. Overall, there is substantial 
heterogeneity of initial investment across industries, ${ }^{11}$ as also illustrated by Figure 1-2 showing the distribution of (log) initial investment for all enterprises, the service, the manufacturing and the transport industries. Discontinuities in these distributions could be taken as a sign of entry barriers within a given sector. The service sector seems to have such a barrier at very low levels of capital of around 50 Int. USD. There are only some small spikes in the distribution for the manufacturing sector. The transport sector shows a more pronounced spike above 1000 Int. USD. Overall, this brief descriptive analysis does not lend support to the hypothesis of significant entry barriers.

Figure 1-2: Histograms of initial investment (current Int. USD)
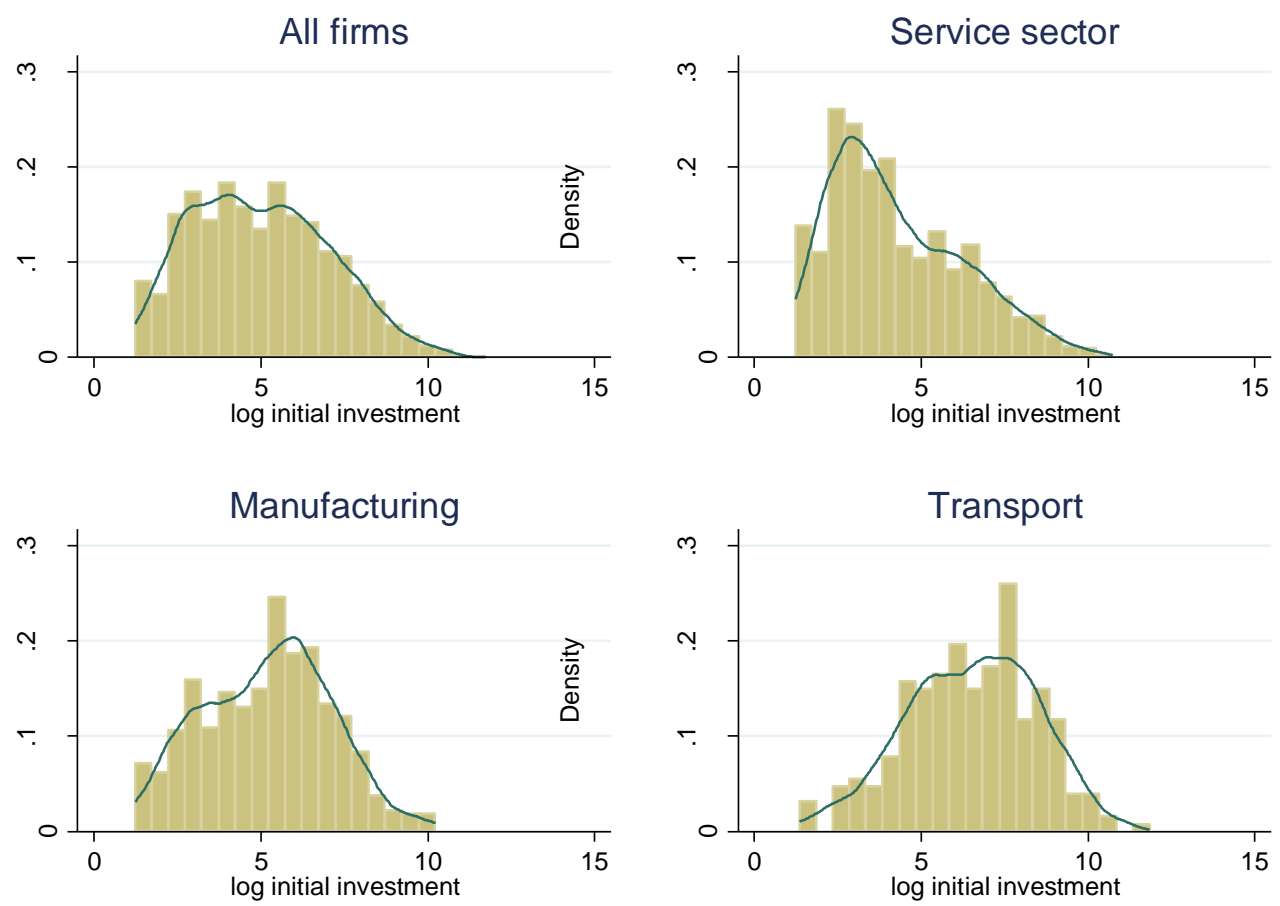

Notes: The histograms exclude zero investment.

Source: Authors' computation based on 1-2-3 surveys (Phase 2, 2001/02, AFRISTAT, DIAL, INS).

However, as indicated above, entrepreneurs incur additional costs when they want to start a business. These costs include recurrent expenses, such as expenses for raw materials and building up inventories. While these costs will in principle be recovered once the final product is sold, they need to be financed when the business starts operating. Unfortunately, our dataset does not allow us to compute those costs at start-up. We only know the monthly recurrent expenses that we report in Table 1-6 (based on the same sample as Table 1-5) along with initial

${ }^{11}$ It turns out that the distributions of start-up costs across industries in the different countries are fairly similar to those reported in Table 1-6. 
investment and median profits as a reference point. Admittedly, these monthly expenses are an imperfect proxy of this component of start-up costs. For some industries, for example the wholesale and retail sector, inventories bought during the last month may be a reasonable proxy for this component of start-up costs. A petty trading activity, however, can possibly be started with a fraction of the reported monthly purchases of inventories. Moreover, in many cases inputs may only be bought once an order has been received and hence these costs may have more the character of variable than fixed costs. The interpretation of these figures will hence be somewhat speculative. To illustrate the relative size of the different components of start-up costs, Table 1-6 also reports median monthly MSE profits.

Table 1-6: Initial investment and other start-up costs relative to income levels (Int. USD)

\begin{tabular}{|c|c|c|c|c|c|c|c|c|c|c|c|}
\hline & \multicolumn{4}{|c|}{$\begin{array}{c}\text { Non- } \\
\text { labour } \\
\text { expenses }\end{array}$} & \multicolumn{2}{|c|}{$\begin{array}{c}\text { Raw } \\
\text { material }\end{array}$} & \multicolumn{2}{|c|}{ Inventory } & \multicolumn{2}{|c|}{$\begin{array}{l}\text { Labour } \\
\text { expenses }\end{array}$} & \multirow{2}{*}{$\begin{array}{c}\text { Monthly } \\
\text { profits } \\
\text { p50 }\end{array}$} \\
\hline & Mean & $\mathrm{p} 50$ & Mean & $\mathrm{p} 50$ & Mean & p50 & Mean & $\mathrm{p} 50$ & Mean & $\mathrm{p} 50$ & \\
\hline Clothing and apparel & 813 & 233 & 164 & 58 & 111 & 27 & 5 & 0 & 5 & 0 & 77 \\
\hline Other manfg \& food & 708 & 46 & 396 & 170 & 308 & 105 & 27 & 0 & 8 & 0 & 98 \\
\hline Construction & 262 & 31 & 624 & 34 & 509 & 0 & 9 & 0 & 32 & 0 & 187 \\
\hline Wholesale/retail shops & 684 & 24 & 1477 & 414 & 48 & 0 & 1318 & 359 & 4 & 0 & 131 \\
\hline Petty traders & 177 & 10 & 511 & 182 & 52 & 0 & 424 & 136 & 3 & 0 & 70 \\
\hline Hotels and restaurants & 802 & 93 & 944 & 545 & 590 & 384 & 263 & 0 & 9 & 0 & 170 \\
\hline Repair services & 1150 & 200 & 306 & 88 & 87 & 0 & 95 & 0 & 11 & 0 & 125 \\
\hline Transport & 3645 & 932 & 683 & 284 & 92 & 0 & 31 & 0 & 17 & 0 & 293 \\
\hline Other services & 760 & 15 & 230 & 35 & 28 & 0 & 66 & 0 & 8 & 0 & 102 \\
\hline Total & 734 & 30 & 560 & 151 & 157 & 0 & 304 & 0 & 8 & 0 & 105 \\
\hline
\end{tabular}

Notes: Non-labour expenses include raw materials, inventories, and all other recurrent expenses (for example fuel).

Source: Authors' computation based on 1-2-3 surveys (Phase 2, 2001/02, AFRISTAT, DIAL, INS).

While labour expenses seem to be negligible, monthly non-labour expenses can be substantial compared to initial investment. The industry patterns correspond to expectations with raw materials being more important for manufacturing and construction, while inventories account for the major part of non-labour expenses for trading activities. It seems that investment in equipment indeed accounts for a large part of start-up costs in manufacturing activities (with the likely exception of food processing). This is less the case at lower levels of capital, as the difference between mean and median is much smaller for non-labour expenses than for initial capital. For trading activities, the costs of building-up inventories may be more important than initial investment in equipment.

A comparison of start-up costs with median monthly profits shows that both equipment costs and non-labour expenses can be substantial - albeit not insurmountable - in some industries while they are negligible in others. In the 
transport and the clothing and apparel sector, for instance, almost three months of earnings are necessary to cover median initial investment. When we combine the information on expenses on equipment capital and recurrent monthly costs, this adds up to less than 30 Int. USD combined start-up costs for only 12 percent of the MSEs. Hence, while there are indeed some informal activities with negligible entry barriers, there is some fixed cost associated to entry into most informal activities. However, it should be noted that the costs shown here must be seen as an estimated upper bound.

\subsubsection{Returns to capital}

We now turn to the estimation of the returns to capital at different levels of capital stock. Unfortunately, the cross-sectional character of our data does not allow us to estimate the returns to initial investment (or to additional investment), but only to total capital stock. In our empirical model, profits $\pi_{i h j}$ of MSE $i$ in household $h$ residing in country $j$ are not only a function of capital $K_{i h j}$, but also of a vector of exogenous variables $X_{i h j}$ and two unobserved factors, one at the household level $\vartheta_{h j}$, for example household wealth, and one at the individual level $\vartheta_{i h j}$, which we primarily think of as entrepreneurial ability. These factors do not only influence profit directly, but simultaneously determine the size of the capital stock.

$\pi_{i h j}=f\left(K_{i h j}\left(\vartheta_{h j}, \vartheta_{i h j}\right), X_{i h j}, \vartheta_{h j}, \vartheta_{i h j}\right)$

In log-linearised form and with $u_{i h j}$, a random error, the equation can be expressed as

$\ln \left(\pi_{i h j}\right)=\alpha+\beta_{K} \ln K_{i h j}+X_{i h j}^{\prime} \delta+\beta_{\vartheta 1} \vartheta_{h j}+\beta_{\vartheta 2} \vartheta_{i h j}+u_{i h j}$.

The observable exogenous characteristics of the entrepreneur in the models estimated below are the MSE owner's years of schooling, experience and gender. We also include total labour input in hours (including both household and hired labour). Further 'exogenous' variables include industry and country dummies as well as industry-country interaction terms. As returns to capital, labour and schooling may differ across countries and industries we also include the corresponding interaction terms.

The cross-sectional estimation of equation (1.7) is confronted with a number of potential biases. First, $\beta_{K}$ may be biased due to the mentioned omitted variables that are correlated with both capital stock and profit. The classical example of such a variable is unobserved ability of an entrepreneur. Certain managers will have abilities that allow them to accumulate more capital and to generate more profits than others. The omission of these abilities will lead to an upward bias of 
$\beta_{K}$. Moreover, the estimation of equation (7) may be complicated by reverse causality. Higher profits allow faster capital accumulation, which would again lead to an upward bias of $\beta_{K}$. Finally, the estimation has to deal with classical measurement error in both profits and capital stocks, which will bias $\beta_{K}$ downward. We explain below how we address these different biases.

A test for heterogeneity in returns, i.e. in $\beta_{K}$ as a function of $K$, can be introduced in various ways. Our approach is to simply split the sample into entrepreneurs with different levels of capital stock. Without the intention to ignore the above caveats, Table 1-7 below reports the results from OLS regressions for all enterprises and for sub-samples of low (lower than 150 Int. USD), medium (higher than 150 Int. USD and lower than 1000 Int. USD) and high capital stock (higher than 1000 Int. USD). These thresholds were chosen on the basis of the above shown distribution of initial investment (specifically the 1000 Int. USD threshold) as well as non-parametric plots of capital profitability (profit/capital) against capital (not reported). The latter suggest very high capital profitability at low levels of capital that falls very quickly with increasing levels of capital. At around 150 Int. USD capital profitability starts to decrease much slower than at lower levels. In addition, the thresholds were chosen such that the sub-samples remain sufficiently large. Applying these thresholds implies a split of the sample into about 50 percent of low-capital, 30 percent of medium-capital and 20 percent of high-capital MSEs.

We estimate equation (1.7) on these different samples as double-logspecification, i.e. we regress $\log$ profits on $\log$ capital and log labour using OLS. ${ }^{12}$ Note that the double-log specification assumes a constant capital elasticity of profits and marginal returns of capital - our main variable of interest eventually depend on capital profitability $(\pi / K)$. More precisely marginal returns will be the product of $\beta_{K}$ and $(\pi / K)$. Since the estimated elasticity is an average effect, we should compute (average) marginal returns at the average of $(\pi / K)$. However, we will also evaluate returns at different levels of capital stock that we know to exhibit different levels of capital profitability. In the first set of results reported in Table 1-7 below, we interact log capital with country dummies - with Dakar (Senegal) as the reference category. The second set of regressions, reported in Table 1-8, includes interactions of capital with industry dummies. Here, manufacturing has been chosen as reference category. ${ }^{13}$

\footnotetext{
${ }^{12}$ We also estimate a specification without taking logs regressing monthly profits on a second-degree polynomial in both capital and labour. The estimates are similar to those from the double-log specification and are available from the authors on request.

${ }^{13}$ The regressions exclude enterprises that report to operate without any capital (and/or zero profits), which leaves us with 5,403 observations (of 6,584). We will address to the possible biases introduced by this procedure later. In all regressions, we drop influential outliers, identified using the DFITS-statistic. As suggested by Belsley et al. (1980), we use a cutoff-value $|D F I T S|_{i h j}>2 \sqrt{k / N}$ with, $k$ the degrees of freedom (plus 1 ) and $N$, the number of observations. This procedure reduces the (sub-) samples quite considerably;
} 
Table 1-7: Returns to capital - results from OLS including capital-country interactions

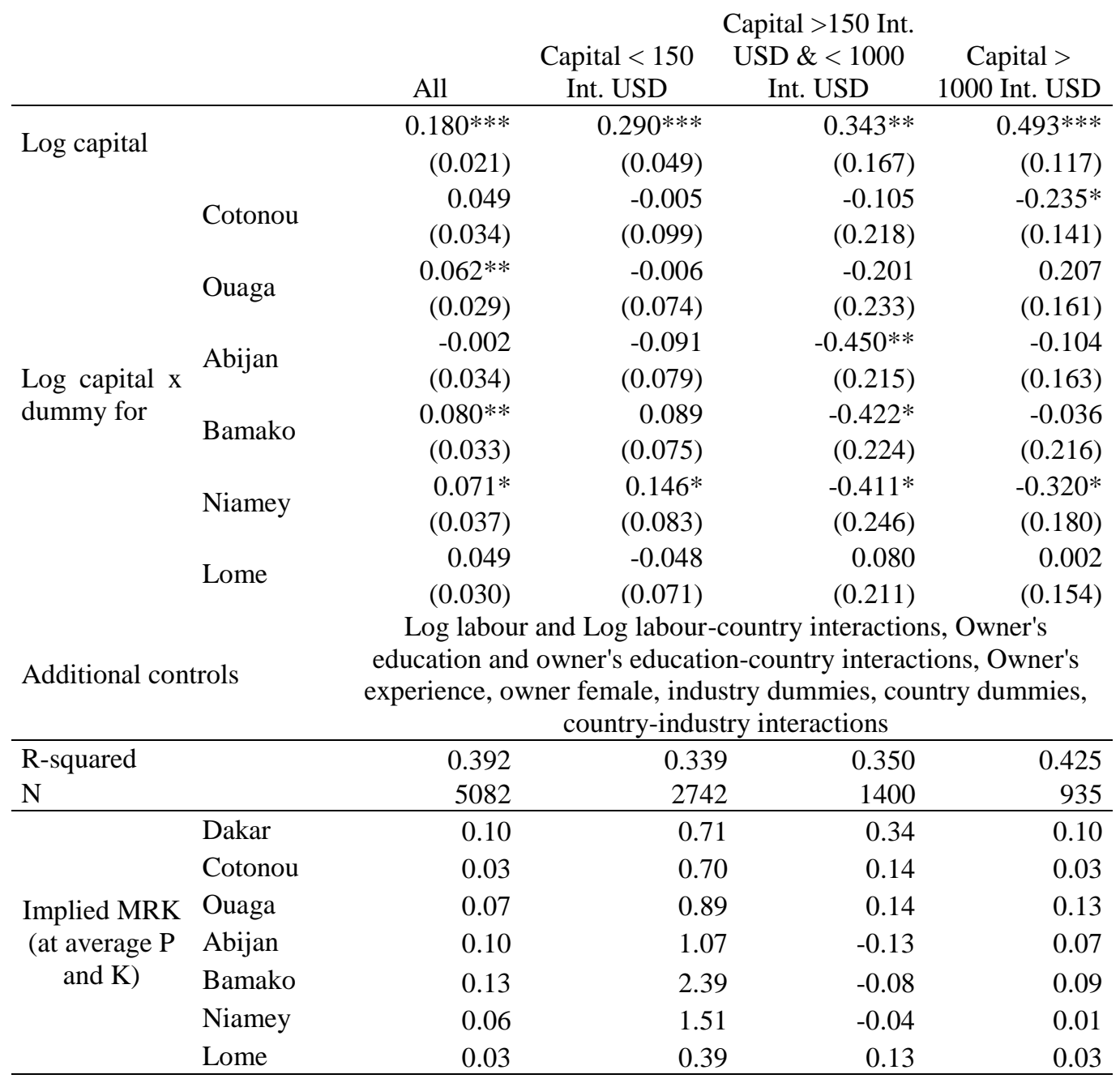

Notes: $* \mathrm{p}<0.05, * * \mathrm{p}<0.01, * * * \mathrm{p}<0.001$. Robust standard errors corrected for clustering at the 'segment'-level (around 10 observations per segment) in parentheses. MRK = marginal monthly return to capital. The full results are available from the authors on request.

Source: Authors' computation based on 1-2-3 surveys (Phase 2, 2001/02, AFRISTAT, DIAL, INS).

The first column of Table 1-7 reports the results from the full sample. Overall, the estimations explain an acceptable portion of the variation in profits with $\mathrm{R}$ squared always between 0.3 and 0.4. The coefficients of the control variables (not reported, but available from the authors on request) ${ }^{14}$ correspond to expectations, but show quite some variation across countries. The profit elasticity of capital fluctuates between 0.18 and 0.25 between countries and formal tests reject parameter equality across countries. Evaluated at country-specific mean capitalprofitabilities these parameters translate into marginal returns to capital (MRK) between 3 and 13 percent per month. We now split the sample according to the

the losses in sample size range from 5 to 10 percent. This may partly be due to measurement and reporting errors, but it may also reflect the high degree of heterogeneity among informal MSEs.

${ }^{14}$ In the remainder of the paper we will discuss a number of findings that could not reported in a table due to space limitations. All these tables are available from the authors on request. 
thresholds defined above. The results for the three sub-samples are reported in columns two to four of Table 1-7. ${ }^{15}$ Column two of Table 1-7 shows one of the key results of this paper: Very high marginal returns at low levels of capital. With the exception of Togo (Lomé), monthly marginal returns to capital exceed 70 percent and are even higher for some countries. This result is driven by very high profit-capital ratios at low levels of capital. Table 1-7 shows that $\beta_{K}$ is significantly different from 0.29 (the base coefficient for Dakar) only for Niamey at the 10 percent level, which is why an F-test for the joint significance of the capital-country interactions does not reject parameter equality across countries for MSEs with low capital stocks.

At higher levels of capital, the marginal returns to capital are much lower. This is despite the fact that the coefficient of log capital increases with higher capital stocks. Profit-capital ratios are, however, much lower at higher levels of capital stock. At medium levels of capital between 150 and 1,000 Int. USD, the log capital coefficients differ significantly and considerably between countries. For Abidjan, Bamako, and Niamey, the interaction terms are strongly negative and hence the correlation between $\log$ profits and log capital is not significantly different from zero for this set of countries in this range of capital stock. The implied MRKs are even negative in those cases. For the other countries, we find MRKs around 13 to 14 percent with the exception of Senegal where monthly returns amount to 38 percent. At levels of capital above 1,000 Int. USD, there seems to be less heterogeneity. Only for Cotonou and Niamey are capital coefficients much lower than in Dakar. This also explains why the MRKs are much lower for these countries. The low returns for Lomé, in contrast, are driven by a low profit-capital ratio. In the other countries, monthly capital returns are between 7 and 13 percent.

These findings may be partly driven by differences in the industry composition of informal MSEs across countries (see Table 1-3 above). As our dataset is not large enough to include to full set of country-industry-capital interaction terms, ${ }^{16}$ Table 1-8 reports the results from regressions that instead of country-capital interactions includes industry-capital interactions. We have aggregated industries into four categories: (1) Manufacturing, (2) construction, hotels, transport, (3) trade, and (4) repair and other services. ${ }^{17}$

\footnotetext{
${ }^{15}$ All the results are robust to slight variations in the thresholds.

${ }^{16}$ Alternatively, one may analyze the variation within one industry and include country-capital interactions. The only industry with a sufficient number of observations for such an exercise is the trade sector. The results (not reported) confirm our main finding. Marginal returns to capital at low levels of capital stock exceed $65 \%$ except in Lomé and Bamako (35 and $33 \%$ respectively).

${ }^{17}$ Within these aggregate sectors, capital coefficients were found to be homogeneous.
} 
Table 1-8: Returns to capital - results from OLS including capital-industry interactions

\begin{tabular}{|c|c|c|c|c|c|}
\hline & & All & $\begin{array}{c}\text { Capital < } 150 \\
\text { Int. USD }\end{array}$ & $\begin{array}{l}\text { Capital >150 } \\
\text { Int. USD \& < } \\
1000 \text { Int. USD }\end{array}$ & $\begin{array}{c}\text { Capital > } \\
1000 \text { Int. USD }\end{array}$ \\
\hline \multirow[t]{2}{*}{ Log capital } & & $\begin{array}{r}0.205 * * * \\
(0.018)\end{array}$ & $\begin{array}{r}0.363 * * * \\
(0.041)\end{array}$ & $\begin{array}{r}0.288 * * * \\
(0.038)\end{array}$ & $\begin{array}{r}0.510 * * * \\
(0.088)\end{array}$ \\
\hline & $\begin{array}{l}\text { Construction, } \\
\text { hotels, } \\
\text { transport }\end{array}$ & $\begin{array}{r}0.096 * * * \\
(0.026)\end{array}$ & $0.155^{*}$ & 0.003 & -0.136 \\
\hline \multirow[t]{2}{*}{$\begin{array}{l}\text { Log capital } \mathrm{x} \\
\text { dummy for }\end{array}$} & Trade & $\begin{array}{r}0.007 \\
(0.024)\end{array}$ & $\begin{array}{r}-0.084 \\
(0.054)\end{array}$ & $\begin{array}{l}-0.034 \\
(0.059)\end{array}$ & $\begin{array}{r}-0.043 \\
(0.139)\end{array}$ \\
\hline & $\begin{array}{l}\text { Repair and } \\
\text { other services }\end{array}$ & $\begin{array}{r}-0.038 \\
(0.025)\end{array}$ & $\begin{array}{r}-0.235 * * * \\
(0.059)\end{array}$ & $\begin{array}{r}-0.034 \\
(0.056)\end{array}$ & $\begin{array}{r}-0.087 \\
(0.130)\end{array}$ \\
\hline
\end{tabular}

Log labour and Log labour-country interactions, Owner's

Additional controls education and owner's education-country interactions, Owner's experience, owner female, industry dummies, country dummies, country-industry interactions

\begin{tabular}{llrrrr}
\hline R-squared & & 0.3807 & 0.3339 & 0.3641 & 0.3961 \\
$\mathrm{~N}$ & 5091 & 2748 & 2338 & 932 \\
\hline & $\begin{array}{l}\text { Manufacturing } \\
\text { Construction, }\end{array}$ & 0.06 & 1.31 & 0.06 & 0.06 \\
$\begin{array}{l}\text { Implied MRK } \\
\text { (at mean P } \\
\text { and K) }\end{array}$ & $\begin{array}{l}\text { hotels, } \\
\text { transport }\end{array}$ & 0.09 & 2.68 & 0.07 & 0.06 \\
& $\begin{array}{l}\text { Trade } \\
\text { Repair and } \\
\text { other services }\end{array}$ & 0.10 & 1.35 & 0.06 & 0.07 \\
& 0.04 & 0.47 & 0.04 & 0.04 \\
\hline
\end{tabular}

Notes: $* \mathrm{p}<0.05, * * \mathrm{p}<0.01, * * * \mathrm{p}<0.001$. Robust standard errors corrected for clustering at the 'segment'-level (around 10 observations) in parentheses. MRK = marginal monthly return to capital. The full results are available from the authors on request.

Source: Authors' computation based on 1-2-3 surveys (Phase 2, 2001/02, AFRISTAT, DIAL, INS).

The results suggest that the cross-country heterogeneity identified above may indeed be partly explained by differences in industry compositions. Overall, we find much less heterogeneity in the capital coefficient across industries than across countries. In fact, at medium and high levels of capital none of the industry-capital interaction terms turns out to be significant (columns three and four of Table 1-8). Marginal returns at these levels of capital are 4 percent for the repair and other services sector, and 6 or 7 percent for all other sectors. In this specification, there is now more heterogeneity in returns at low levels of capital. However, even though MRKs fluctuate between 47 percent (for repair and other services) and 268 percent (for construction, hotels, and transport), the main finding from above is not altered: We consistently find very high marginal returns to capital at low levels of capital. ${ }^{18}$ In the following, we discuss the robustness of the above results and present a number of additional robustness and specification checks. We first address the possible implications of how we measure our key

\footnotetext{
${ }^{18}$ Semi-parametric estimates (not reported) confirm the identified patterns of capital returns. This approach also reveals considerable heterogeneity within the sub-samples. The estimates show that marginal returns are (extremely) high - up to several hundred percent - at (very) low levels of capital, but decline very rapidly.
} 
variables and the problem of missing or zero values for capital and profits. Then, we analyse parameter heterogeneity by gender. Finally, we address the possibility of omitted variable biases, in particular ability bias.

Random measurement errors in profits and capital tend to bias the estimated coefficients towards zero, so this source of bias does not give rise to major concerns in light of the significant effects. It is difficult to judge whether and how measurement error changes with higher or lower levels of profits and capital stock. We think there is little reason to assume that measurement error is less pronounced at lower levels of capital stocks, which would then partly explain higher returns at lower levels of capital. For capital, we have briefly discussed the problem that capital might not just be used for business purposes. How this affects our estimates depends on whether non-business use is systematically higher or lower at higher levels of capital. One may argue that more expensive capital goods, like machines, are likely to be of exclusive use to the business. Yet, our estimates of similar capital returns across industries can be taken as evidence against systematic differences in non-business use of reported capital stock. ${ }^{19}$

The inclusion of zero and missing values (as zeros) for the capital stock in the regressions lowers the estimated returns to capital, but the estimated coefficients still indicate very high but decreasing returns at low levels of capital. The coefficients on labour, education, and experience are much higher. The size of the sub-sample, which again is reduced by excluding influential outliers, increases by almost 1000 observations. We have also run Tobit regressions that explicitly model censoring, without major implications for the results.

Heterogeneity in returns may also stem from gender differences, as shown for example by de Mel et al. (2008) for Sri Lankan MSEs. To test this hypothesis we also run regressions (on the entire and the split samples) that include - instead of country-capital or industry-capital interactions - interactions of key inputs with the female-owner dummy. ${ }^{20}$ For all inputs, including capital, the coefficients are only found to be significantly different for women at higher levels of capital stock. This also holds for capital profitability that is much higher for men than for women at higher levels of capital stock. This implies that marginal returns to capital are very high for both men and women at low levels of capital stock (albeit a bit lower for women). In both the medium and the high capital stock range, marginal returns in enterprises headed by women are much lower with about 2 percent compared to 8 and 7 percent for those headed by men.

As explained above, our results may be biased because of other omitted variables. These biases, in particular, ability bias, cannot be easily removed. A first

\footnotetext{
${ }^{19}$ We also distinguish between different types of capital goods (machines, transport means, or furniture) with no major implication with regard to our results. Similarly, including inventories in capital stocks does not affect the results.

${ }^{20}$ Note that female entrepreneurs account for 62 percent of low capital, 40 percent of medium capital, and only 26 percent of high capital entrepreneurs.
} 
straightforward attempt to solve this problem is to include ability proxies into the estimated equation. We have constructed two such proxies from the information available in the 1-2-3 surveys using principal component techniques. The first is an 'intellectual ability index', which includes information on literacy, language spoken at home, type of school (private or public), and father's schooling. The second index proxies 'financial literacy' and is constructed using questions regarding the knowledge of credit and other financial products. A third index measures whether the household has a tradition of being engaged in a particular business. Including these proxies into our regression (not reported) does not affect the results.

\subsubsection{Returns to capital with a household fixed-effect}

An alternative to the inclusion of admittedly imperfect proxies to control for ability is to include a household fixed-effect into the above regressions. Quite a number of households own more than one enterprise, allowing us to explore the co-variation of profits and capital across firms within the same household, thus removing the omitted household-level variables from the estimated equation. This procedure may mitigate the ability bias if entrepreneurs in the same household are more similar to each other in terms of their ability than they are compared to entrepreneurs outside the household, which is quite plausible.

An analysis of intra-household differences also allows us to test the assumption that factor returns are equated across different activities within the household. A rational household should equate returns, as otherwise pareto-improving factor reallocations would be possible. In other words, given fixed characteristics of the household certain constraints, for example credit or labour market constraints, faced by the individual entrepreneur should not be visible - within the household..$^{21}$ If instead, we detect differences in marginal returns to capital, we can take this as suggestive evidence for inefficient capital allocations. Theoretically, such inefficiencies could arise, for example, due to noncooperative behaviour within the household. Optimal capital allocations, however, can also be consistent with differing marginal returns across activities in the presence of (a) some non-linearity in capital stocks that prevents the household from equalizing returns, or (b) risk and risk aversion. The above fairly smooth distributions of entry costs seem to suggest that non-linearities are unlikely to be of great importance in most of MSE activities, at least at lower levels of capital stock. Yet, if activities are associated with different risks and households choose to hold portfolios with different risks, they should equate riskadjusted returns. In this case, the fixed-effects estimates should reflect the differences in returns that can be attributed to risk differences. Finally, while risk

\footnotetext{
${ }^{21}$ In this case, the no-log specification should render zero coefficients for capital, while the log-specification should allow us to test the equation of marginal returns using capital profitabilities.
} 
may be the main reason for $(\mathrm{d} \pi / d K)$ to be different from zero within-households, it cannot be ruled out that single activities, in some cases operated by different individuals, are faced with different constraints, for example different access to capital. In sum, the below fixed-effects results should not only be seen as a robustness check and an attempt to address ability bias, but also as a first attempt to reveal the possible causes of the observed pattern of returns to capital.

Before we discuss the results, it should be noted that the fixed-effects estimation is prone to selection bias because of the implied reduction of the sample to only those MSEs in households with more than one enterprise.

The results of the fixed effects estimates are reported in Table 1-9. To start with, we have 946 households owning 2,079 enterprises (i.e. with at least two MSEs). Again, we exclude MSEs that report zero profits and/or zero capital and remove influential outliers from the respective (sub-) samples. In the case of the whole (sub) sample, this leads to a considerable reduction of the sample. The first set of estimates is based on only 600 households with 1,301 firms. In addition to the double-log specification from above, we now also estimate a model without taking logs. The coefficients in the 'no log' specification can directly be interpreted as the marginal return to capital. ${ }^{22}$

Overall, the fixed-effects estimates yield similar results to the estimates without fixed-effects. ${ }^{23}$ Capital returns are of a similar magnitude at low levels of capital. In the no-log specification, marginal returns are about 90 percent. As nonlinearities in capital stocks are unlikely to explain these intra-household differences at low levels of capital stock, the identified returns may reflect the high risks associated with activities in this capital range. For the medium range, capital is not significant in either specification, but the magnitude is close to the above estimates. With monthly marginal returns of about 9 percent (last column of Table 1-9) the marginal returns at higher levels of capital are slightly higher than those obtained without fixed effects. At higher levels of capital, intrahousehold differences may be due to activity-specific capital constraints, but nonlinearities, for example for machinery investment, are also likely to come into play. That returns are slightly higher in the fixed-effects model may, on the one hand, reflect the selection of more talented and entrepreneurial households into the sub-sample of those with at least two MSEs. It seems plausible that this selection effect is stronger at higher levels of capital. On the other hand, higher

\footnotetext{
${ }^{22}$ Note that the sub-samples by capital size include only households, in which all enterprises have a capital stock that meets the sub-samples' conditions, for example capital stock smaller than 150 Int. USD.

${ }^{23}$ This also holds when we estimate the earlier specification without fixed effects on the much smaller samples. In the interpretation of the fixed effects estimates it should be noted that the two key variables under consideration, profits and capital stock, are likely to be measured with error. This problem is reinforced when only within-household variation is being used. Such measurement error would bias the returns to capital towards zero; an effect that would be the opposite to the possible ability bias.
} 
returns may also stem from the ability of diversified households to take (some more) risks and earn higher returns. ${ }^{24}$

The fixed-effects estimates hence support our finding of very high returns at low levels of capital. Of course, the reductions in sample size are considerable and one has to be careful not to draw too far-reaching conclusions from these estimates. Nonetheless, we do think that these results may also be taken as an indication that risk plays a major role in explaining the high returns at low levels of capital.

\footnotetext{
${ }^{24}$ While capital stocks and profits between different MSEs within the same household (co-) vary enough to allow us to estimate the fixed-effects model, other characteristics, like education and experience (and to some extent experience) vary little within the household. In addition, some MSEs are operated by the same individual.
} 


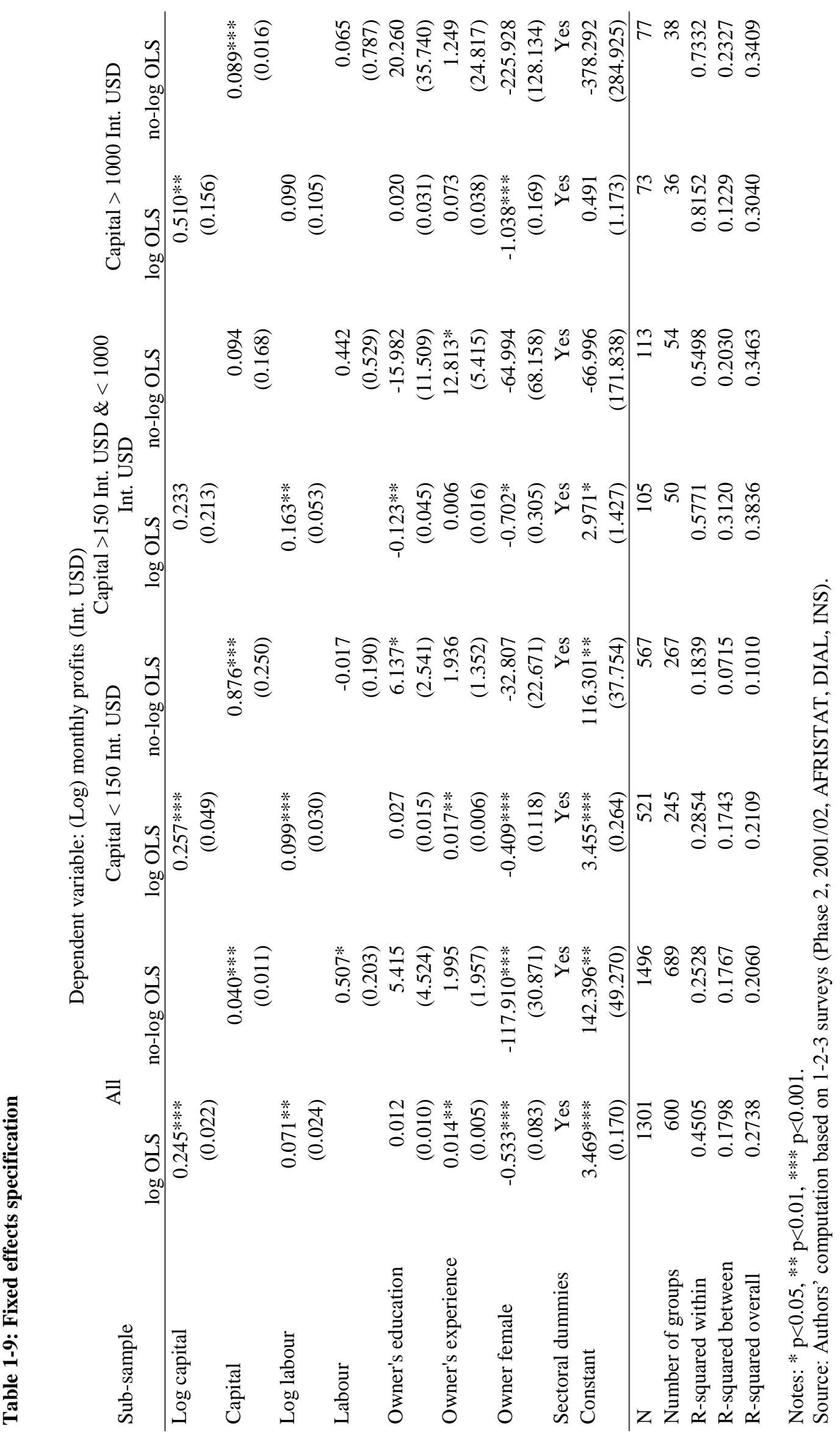




\subsubsection{Some more thoughts on the causes}

A thorough investigation of the causes of the observed pattern of capital returns goes beyond the scope of this paper and is left to future work. This section hence briefly presents only some suggestive evidence on the channels that might explain these patterns. More specifically, we assess the risks associated with activities at different levels of capital. Risks should be higher at low levels of capital if risk really explains the observed high returns, as suggested by the fixed-effects estimates. We then make an attempt to proxy capital constraints and again look at these proxies at different levels of capital. We would expect MSEs with low levels of capital to be more constrained than those with more capital.

Although it is generally difficult to proxy risks - and more so in a cross-sectional dataset - our survey offers a number of possibilities to construct risk proxies. First, we construct 'classical' proxies for risk, the variation of profits or sales. We chose to measure this variation at the country-sector level, where industries are disaggregated as finely as possible while keeping the number of observations in each country-sector cell at least at 30 . Such a procedure yields 123 country-sector cells, for which we compute the coefficients of variation in profits and sales. Second, we use business risk perceptions of the entrepreneur. Specifically, we set a 'risk-of-closure dummy' to 1 if an entrepreneur sees the lack of clients or too much competition as a major business risk - which about 60 percent of all MSEs do. ${ }^{25}$ The sample means of these - admittedly imperfect - risk proxies are reported in Table 1-10 for different levels of capital stock.

Table 1-10: Risk proxies at different levels of capital stock

\begin{tabular}{lccc}
\hline & $\begin{array}{c}\text { Capital < 150 Int. } \\
\text { USD }\end{array}$ & $\begin{array}{c}\text { Capital > 150 Int. } \\
\text { USD \& < 1000 } \\
\text { Int. USD }\end{array}$ & $\begin{array}{c}\text { Capital > 1000 } \\
\text { Int. USD }\end{array}$ \\
\hline $\begin{array}{l}\text { Coefficient of variation in } \\
\text { sales }\end{array}$ & 1.98 & 2.01 & 1.97 \\
$\begin{array}{l}\text { Coefficient of variation in } \\
\text { profits }\end{array}$ & 2.04 & 1.93 & 1.91 \\
$\begin{array}{l}\text { Perceived risk of closure } \\
\text { due to lack of clients or too } \\
\text { much } \\
\text { (percent) competition }\end{array}$ & 0.61 & & \\
\hline
\end{tabular}

Source: Authors' computation based on 1-2-3 surveys (Phase 2, 2001/02, AFRISTAT, DIAL, INS).

The descriptive statistics in Table 1-10 support the view that risk may partly explain the observed pattern of returns. Both the coefficient of variation in profit and sales are lowest for higher levels of capital. The coefficient of variation of

${ }^{25}$ The corresponding question in the survey reads 'which are major threats to the existence of the MSE'. 
profits, likely the better indicator for risk, is higher for low levels of capital compared to the other two groups. High capital MSEs (with lower returns) are hence more frequently found in sectors with lower variation in profits. However, the differences in these indicators are far from being significant (the standard errors of the above means of the coefficients of variation are in a range of 0.5 to 0.9 ). According to the third indicator, risk is not highest for activities at low levels of capital. The threats to business survival appear to be slightly stronger at medium levels of capital, a finding that does not fit with the idea of marginal returns reflecting high risks.

More detailed analysis of the above risk indicators, for example by country or by capital profitability (not reported), does not render consistent results. This is also why we think that the presented evidence provides at best some weak support for risk as major factor behind the above pattern of capital returns. Yet, in our view, these non-findings can be attributed to some extent to the lack of adequate risk (and risk aversion) proxies as well as the rather simple empirical approach. Furthermore, the effects of risk on returns (and capital stocks) may interact with capital market constraints. This interaction is not measured in our analysis.

Finally, we briefly examine the possible role of capital constraints in explaining the observed pattern. To this end, Table 1-11 reports three proxies of capital constraints, again by capital stock range. At least for low levels of capital, for which we find extremely high marginal returns, we would expect MSEs to be severely capital constrained.

Table 1-11: Capital constraint proxies at different levels of capital stock (share)

\begin{tabular}{|c|c|c|c|}
\hline & $\begin{array}{c}\text { Capital }<150 \text { Int. } \\
\text { USD } \\
\end{array}$ & $\begin{array}{c}\text { Capital > } 150 \text { Int. } \\
\text { USD \& < } 1000 \\
\text { Int. USD }\end{array}$ & $\begin{array}{c}\text { Capital > } 1000 \\
\text { Int. USD } \\
\end{array}$ \\
\hline $\begin{array}{l}\text { No access to external } \\
\text { capital }\end{array}$ & 0.88 & 0.81 & 0.77 \\
\hline Liquidity constraints & 0.14 & 0.10 & 0.10 \\
\hline Access to formal credit & 0.03 & 0.03 & 0.07 \\
\hline $\begin{array}{l}\text { Share in lowest wealth } \\
\text { quintile }\end{array}$ & 0.26 & 0.16 & 0.09 \\
\hline $\begin{array}{l}\text { Share in highest wealth } \\
\text { quintile }\end{array}$ & 0.15 & 0.22 & 0.32 \\
\hline
\end{tabular}

Source: Authors' computation based on 1-2-3 surveys (Phase 2, 2001/02, AFRISTAT, DIAL, INS).

Table 1-11 shows that MSEs with low levels of capital stock are indeed more capital constrained than others. 88 percent of these firms have financed their capital stock only out of own savings without recourse to any source of external funds, including formal and informal credit, family funds or support from 
friends. ${ }^{26}$ This holds for 81 and 77 percent of firms at medium and high levels of capital stock, respectively. Similarly, 14 percent of the entrepreneurs report being liquidity constrained, ${ }^{27}$ compared to 10 percent in the other two groups. When we split up MSEs by the wealth of the households, in which they are operated, the empirical picture is also in line with expectations. Of the high capital MSEs, 32 percent can be found in households in the highest wealth quintile. Yet, there are both rich households with low capital MSEs and poor households with high capital MSEs.

While these findings are all in line with expectations, they hardly provide sufficient evidence of the importance of capital constraints. In fact, the descriptive statistics are somewhat fuzzy. The relatively high share of low-capital MSEs in high wealth households for example, may rather be taken as an indication that there are further factors explaining capital accumulation. For instance, as seen above, many households seem to practice extensive growth, i.e. they invest in several small or very small firms instead of setting up one large firm. This would mean that households are not capital constrained, but rather risk averse. Moreover and more generally, as McKenzie and Woodruff (2006) also pointed out, MSEs should, in principle, be able to re-invest their very high returns to accumulate capital. Capital constraints would then only partly be reflected in high returns. Intangible assets such as location, reputation and access to a network of reliable business partners are other unobserved factors which could play a role in explaining the high observed marginal returns. No suitable proxies for these factors are available in our dataset.

\subsection{Conclusions}

We have analysed the patterns of capital entry barriers into informal activities as well as returns to invested capital using a unique micro data set on informality covering seven urban centres in Sub-Saharan Africa. Our assessment of initial investment of MSEs suggests that most informal activities exhibit important entry barriers, at least when operating costs are taken into account. We can also identify a sub-sector for which fixed costs of entry are negligible. A relatively small fraction of informal entrepreneurs undertakes very substantial initial capital investments, in particular in the transport sector. These findings in conjunction with our descriptive analysis of MSE characteristics point at substantial heterogeneity among informal activities.

We also find heterogeneous returns to capital. Marginal returns are extremely high at low levels of capital stock. In this capital range, we consistently find

\footnotetext{
${ }^{26}$ For each item of capital stock, the entrepreneur is asked for the source of funding. From this information, we construct the dummy for 'No access to external capital'.

${ }^{27}$ The 'liquidity constraints' dummy is set to 1 if entrepreneurs perceive the lack of liquidity as a major threat to survival of their enterprise.
} 
marginal monthly returns of at least 70 percent. However, we also show that marginal returns decline very rapidly with increasing levels of invested capital. At capital stocks above 150 Int. USD, we find monthly marginal returns of four to seven percent using a simple OLS approach and around nine percent using a household fixed-effects estimator. The annualised return at higher levels of capital would thus be around 50 to 70 percent, which is much higher than the effective rates charged by typical micro-credit providers (between 15 and 25 percent) and within the range of informal money lenders' rates (60 percent and more).

Our findings on returns are in line with earlier studies on small-scale activities from different contexts. We hence provide yet another piece of evidence that the informal sector does not primarily host small-scale activities with low capital stocks and close to zero returns, as suggested by our simple theoretical exposition and often articulated in the discourse on the informal sector. Rather, MSEs with very low capital stocks - or at least an important share of them - earn high returns and hence seem to have the potential to grow out of poverty. While our static analysis remains silent on this important dynamic dimension, we provide some evidence on the factors that hold back these entrepreneurs.

We analyse in particular capital constraints and risk as possible causes of high returns at low levels of capital. While MSEs with low levels of capital stock are likely to be severely capital constrained, their access to capital is not different enough from other MSEs to explain the extreme differences in returns across the capital stock distribution. Our approach to assessing the role of risk is somewhat innovative, as we interpret our finding of high marginal returns at low levels of capital stock in a household fixed-effects profit function estimation to mainly result from differences in risks between the informal activities operated by the household. We provide some evidence in favour of a prominent role for risk in explaining high returns to capital in small-scale economic activities. Yet, this piece of evidence should be interpreted with care, as our results cannot be fully corroborated by other indicators of risks we consider. Finally, we understand this work as a first step towards a better understanding of the constraints and opportunities faced by informal entrepreneurs in Sub-Saharan Africa. A more detailed investigation into the causes of the heterogeneity in returns is needed in particular since informal activities are likely to remain the main income source of the poor in that region in the decades to come. 


\section{Appendix A-1}

Table 1-12: Detailed results: Returns to capital

In capital

In capital x Cotonou

In capital x Ouagdougou

In capital x Adbidjan

In capital x Bamako

ln capital x Niamé

ln capital x Lomé

ln labor

In labor x Cotonou

ln labor x Ouagdougou

In labor x Adbidjan

ln labor x Bamako

ln labor x Niamé

ln labor x Lomé

Onwer's eduction

In Owner's education x Cotonou ln Owner's education $x$

Ouagdougou

In Owner's education x Adbidjan

ln Owner's education x Bamako

ln Owner's education x Niamé

ln Owner's education x Lomé

Owner's experience

Female Owner

Benin

Burkina Faso

Côte d'Ivoir

Mali

Niger

Togo

Clothing and apparel

Other manufacturing \& food

Construction

Wholesale/retail shops

Hotels and restaurants

Repair services

Transport

Other services
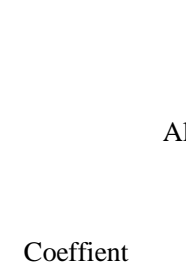

All$$
\begin{aligned}
& 0.180 \\
& 0.04 \\
& 0.0
\end{aligned}
$$$$
0.06
$$$$
0.080
$$$$
0.049
$$$$
0.061
$$$$
0.222
$$$$
0.077
$$

0.090

0.113

0.035

$-0.062$

0.029

0.027

0.040

$-0.019$

$-0.016$

$-0.039$

$-0.001$

0.020

$-0.420$

$-2.091$

$-0.933$

$-0.097$

$-0.649$

$-0.505$

$-0.783$

0.083

0.150

0.986

0.101

0.731

0.511

0.549

0.260
Capi Capital < 150 Int.
USD Capital $>150$ Int.
USD \& $<1000$ Int.
USD
Robust
Standard
Coeffient $\quad$ error Capital > 1000 Int. USD

$$
\text { Co }
$$




\begin{tabular}{|c|c|c|c|c|c|c|c|c|}
\hline Benin $\mathrm{x}$ Clothing and apparel & -0.832 & 0.238 & -1.252 & 0.299 & -0.857 & 0.360 & -0.907 & 0.440 \\
\hline Burkina $x$ Clothing and apparel & -0.900 & 0.218 & -1.526 & 0.269 & -0.418 & 0.428 & -0.917 & 0.529 \\
\hline Côte x Clothing and apparel & -0.423 & 0.229 & -1.068 & 0.303 & 0.199 & 0.349 & -2.372 & 0.603 \\
\hline Mail x Clothing and apparel & -0.355 & 0.212 & -0.436 & 0.247 & -0.553 & 0.400 & -0.939 & 0.533 \\
\hline Niger $x$ Clothing and apparel & -0.795 & 0.263 & -0.507 & 0.297 & -0.794 & 0.414 & & \\
\hline $\begin{array}{l}\text { Togo x Clothing and apparel } \\
\text { Benin x Other manufacturing \& }\end{array}$ & -0.241 & 0.196 & -0.572 & 0.263 & 0.108 & 0.370 & -1.052 & 0.502 \\
\hline food & 0.039 & 0.232 & -0.113 & 0.261 & 0.517 & 0.460 & -0.485 & 0.498 \\
\hline $\begin{array}{l}\text { Burkina x Other manufacturing \& } \\
\text { food } \\
\text { Côte x Other manufacturing \& }\end{array}$ & -0.143 & 0.204 & -0.232 & 0.240 & 0.165 & 0.450 & -1.402 & 0.489 \\
\hline $\begin{array}{l}\text { food } \\
\text { Mail x Other manufacturing \& }\end{array}$ & -0.268 & 0.208 & -0.574 & 0.241 & 0.629 & 0.435 & -2.604 & 0.604 \\
\hline & -0.405 & 0.204 & -0.511 & 0.229 & 0.145 & 0.420 & -1.151 & 0.511 \\
\hline & -0.179 & 0.201 & -0.177 & 0.214 & 0.288 & 0.410 & -2.777 & 0.657 \\
\hline $\begin{array}{l}\text { Togo x Other manufacturing \& } \\
\text { food }\end{array}$ & -0.050 & 0.218 & -0.130 & 0.248 & 0.450 & 0.453 & -0.746 & 0.588 \\
\hline Benin $x$ Construction & -0.025 & 0.213 & 0.135 & 0.281 & -0.354 & 0.369 & -1.174 & 0.527 \\
\hline Burkina $x$ Construction & -0.433 & 0.213 & -0.652 & 0.297 & -0.566 & 0.438 & -1.867 & 0.526 \\
\hline Côte x Construction & -0.712 & 0.213 & -0.666 & 0.251 & -0.805 & 0.364 & -2.441 & 0.659 \\
\hline Mail x Construction & -0.280 & 0.200 & -0.343 & 0.237 & -0.184 & 0.413 & -1.509 & 0.647 \\
\hline Niger x Construction & -1.595 & 0.287 & -2.152 & 0.344 & -0.468 & 0.478 & -3.427 & 0.568 \\
\hline Togo x Construction & -0.606 & 0.214 & -0.519 & 0.261 & -0.603 & 0.418 & & \\
\hline Benin x Wholesale/retail shops & -0.277 & 0.228 & -0.599 & 0.271 & -0.662 & 0.481 & -0.259 & 0.439 \\
\hline Burkina x Wholesale/retail shops & 0.195 & 0.221 & 0.169 & 0.280 & 0.185 & 0.503 & -0.624 & 0.502 \\
\hline Côte x Wholesale/retail shops & 0.105 & 0.219 & -0.040 & 0.261 & 0.387 & 0.427 & -1.858 & 0.622 \\
\hline Mail x Wholesale/retail shops & -0.188 & 0.242 & 0.187 & 0.311 & -0.453 & 0.502 & -0.759 & 0.567 \\
\hline Niger x Wholesale/retail shops & 0.298 & 0.243 & -0.263 & 0.266 & 1.182 & 0.414 & -1.856 & 0.535 \\
\hline Togo x Wholesale/retail shops & -0.098 & 0.192 & -0.076 & 0.236 & 0.015 & 0.421 & -0.627 & 0.516 \\
\hline Benin $x$ Hotels and restaurants & 0.184 & 0.244 & 0.246 & 0.327 & -0.341 & 0.511 & 0.710 & 0.519 \\
\hline Burkina $x$ Hotels and restaurants & -0.327 & 0.236 & -0.249 & 0.325 & -0.567 & 0.488 & -0.618 & 0.536 \\
\hline Côte $\mathrm{x}$ Hotels and restaurants & -0.312 & 0.244 & -0.549 & 0.363 & -0.342 & 0.465 & -1.300 & 0.619 \\
\hline Mail x Hotels and restaurants & -0.410 & 0.259 & -0.237 & 0.348 & -0.864 & 0.482 & & \\
\hline Niger $\mathrm{x}$ Hotels and restaurants & -0.167 & 0.251 & 0.418 & 0.287 & -0.263 & 0.561 & & \\
\hline Togo x Hotels and restaurants & -0.049 & 0.246 & 0.303 & 0.319 & 0.101 & 0.550 & -1.692 & 0.568 \\
\hline Benin x Repair services & -0.683 & 0.223 & -1.017 & 0.320 & -0.608 & 0.455 & -0.274 & 0.431 \\
\hline Burkina $x$ Repair services & -0.611 & 0.214 & -0.953 & 0.255 & -0.728 & 0.454 & -0.452 & 0.512 \\
\hline Côte x Repair services & -0.533 & 0.228 & -0.234 & 0.298 & -0.877 & 0.441 & -1.332 & 0.581 \\
\hline Mail x Repair services & -0.717 & 0.203 & -0.763 & 0.244 & -0.817 & 0.453 & -0.010 & 0.630 \\
\hline Niger x Repair services & -1.026 & 0.242 & -1.383 & 0.316 & -1.575 & 0.468 & -1.241 & 0.771 \\
\hline Togo x Repair services & -0.847 & 0.224 & -0.524 & 0.266 & -1.177 & 0.470 & -1.366 & 0.593 \\
\hline Benin $x$ Transport & -0.414 & 0.252 & & & 0.355 & 0.459 & -0.551 & 0.384 \\
\hline Burkina $x$ Transport & -0.559 & 0.266 & & & & & -1.659 & 0.480 \\
\hline Côte x Transport & 0.110 & 0.281 & 1.275 & 0.366 & 0.834 & 0.422 & -1.845 & 0.522 \\
\hline Mail x Transport & -0.548 & 0.292 & 0.085 & 0.289 & -1.048 & 0.398 & -1.034 & 0.683 \\
\hline Niger $\mathrm{x}$ Transport & -1.413 & 0.276 & -1.910 & 0.332 & & & -3.374 & 0.495 \\
\hline Togo x Transport & -0.079 & 0.261 & & & 0.460 & 0.508 & -0.702 & 0.462 \\
\hline Benin $x$ Other services & -0.244 & 0.205 & 0.049 & 0.272 & -0.194 & 0.467 & -0.535 & 0.450 \\
\hline Burkina x Other services & 0.050 & 0.220 & -0.139 & 0.247 & 0.878 & 0.510 & -0.686 & 0.599 \\
\hline
\end{tabular}


Barriers to Entry and Returns to Capital in Informal Activities: Evidence from Sub-Saharan Africa

\begin{tabular}{|c|c|c|c|c|c|c|c|c|}
\hline Côte x Other services & -0.139 & 0.186 & -0.247 & 0.203 & 0.256 & 0.436 & -1.890 & 0.583 \\
\hline Mail x Other services & -0.280 & 0.194 & -0.424 & 0.209 & 0.741 & 0.431 & -1.750 & 0.599 \\
\hline Niger x Other services & -1.628 & 0.225 & -1.516 & 0.261 & -1.284 & 0.479 & -2.931 & 0.569 \\
\hline Togo x Other services & -0.396 & 0.190 & -0.636 & 0.221 & 0.010 & 0.428 & -0.761 & 0.514 \\
\hline Constant & 3.737 & 0.160 & 3.429 & 0.256 & 2.393 & 1.000 & 0.614 & 0.897 \\
\hline $\mathrm{N}$ & 5082 & & 2742 & & 1400 & & 935 & \\
\hline R-squared & 0.392 & & 0.339 & & 0.350 & & 0.425 & \\
\hline
\end{tabular}

Source: Authors' computation based on 1-2-3 survey (Phase 2, 2001/02, AFRISTAT, DIAL, INS). 
Barriers to Entry and Returns to Capital in Informal Activities: Evidence from Sub-Saharan Africa 


\title{
Chapter 2
}

\section{Gender and the allocation of labour and capital in informal enterprises: Evidence from Sub-Saharan Africa*}

\begin{abstract}
This paper tests whether households allocate capital and labour between informal enterprises headed by women and those headed by men in a pareto efficient way. To test for pareto efficiency we follow closely and apply an approach used by Udry (1996) in an agricultural setting to a data set of informal enterprises in urban areas of seven countries in Sub-Saharan Africa. Controlling for household characteristics (observable and unobservable), sectoral differences and enterprise characteristics we find that profits of female headed enterprises are between 40 and 25 percent lower than the profits of male headed enterprises. This result is inconsistent with pareto efficiency. Our results show that total profits from informal enterprises could be about 20 percent higher if resources were allocated optimally within the household. Our simulations and results from an OaxacaBlinder decomposition show that the inefficient allocation of capital explains most of the gender gap.
\end{abstract}

\footnotetext{
${ }^{*}$ Based on joint work with Nina Fenton.
} 


\subsection{Introduction}

Many city dwellers in developing countries generate income in informal household enterprises. ${ }^{28}$ In the seven economic centres in Sub-Saharan Africa (SSA) analysed in this paper, these enterprises account for around 75 percent of employment. Numerous constraints impede these enterprises from growing and hence prevent people from escaping from poverty. See for instance Grimm et al. (2010) and Grimm et al. (2011) for studies that examine kinship ties, low returns to capital and entry barriers as potential external constraints for these entrepreneurs. This paper focuses on constraints facing female entrepreneurs. These may include prejudicial beliefs and discriminatory behaviour, which can affect the intra-household allocation of inputs (Amine and Straub, 2010). Constraints facing female entrepreneurs are examined not only as an explanation for low incomes of women, but also as a constraint to maximization of household incomes: inefficient resource allocation reduces total household profits.

This study is motivated by findings by Grimm et al. (2011) using the same data set that will be analysed in this chapter. Two findings of this study hint at inefficient resource allocations within households. Firstly, returns to capital are not equalised within households. Secondly, the study shows that informal enterprises have high returns to capital at low levels of capital stock and lower returns at higher levels of capital stock. The percentage of female business owners in the entire sample is 50 percent but only 30 percent of enterprises in the highest capital stock segment are headed by a woman. These findings together suggest that the allocation of capital is inefficient and a re-allocation of capital from the male dominated enterprises with high capitals stocks to the female dominated enterprises with low capital stocks, and therefore high returns to capital, could make a household better off.

Therefore, this paper investigates the role of gender plays in determining the allocation of household resources across different informal enterprises in urban areas of seven countries in SSA. We follow closely the approach of Udry (1996), who found that about 6 percent of output is lost due to inefficient allocation of resources, in a rural area. Applying this to an urban setting and controlling for household characteristics (both observable and unobservable), sectoral differences and enterprise characteristics we find that profits of female headed enterprises are between 25 and 40 percent lower than profits of male headed enterprises. This effect is large in magnitude and inconsistent with pareto efficiency. In a final step we estimate a baseline constant elasticity of substitution (CES) production function and compare predicted profits using the actual and

${ }^{28}$ In Brilleau et al. (2005) and in this paper, informal sector employment is understood to comprise employment in firms that neither have formal written accounts nor are registered with the tax administration. 
optimal resource allocations. Our results show that profits from informal enterprises could be up to 20 percent higher if resources were allocated optimally within households. The potential increase in profits is mostly driven by a reallocation of capital from the male headed to the female headed enterprise. The results from an Oaxaca-Blinder decomposition show that about 60 percent of the differences in profits occur due to differences in endowments (particularly the unequal distribution of capital) of enterprises headed by mean and enterprises headed by women. Hence, the main driver for the inefficiencies we observe is the unequal distribution of capital between male and female entrepreneurs together with decreasing returns to capital. A comparison with the results of Udry (1996), which found that 6 percent of output was lost due to inefficiencies in intrahousehold allocation, supports the view that these inefficiencies based on gender are even greater in urban than in rural areas.

However, our results on the gains from redistribution need to be interpreted with caution. Findings from randomised control trials shows that additional capital does not have an effect on female headed enterprises with an initial capital stock below a certain threshold (Fafchamps et al., 2011; Karlan and Zinman, 2010; De Mel et al., 2009). Our findings rule out differences in sectors, productions functions, endowments, and unobservable household level characteristics as an explanation for the difference in resource allocation between male and female headed enterprises. However, different preferences of male and female entrepreneurs may also play a role in explaining the differences between male and female headed enterprises that we observe. For example, time differences may differ between male and female entrepreneurs. This could lead to a resource allocation that appears inefficient.

The remainder of the paper is organised as follows. Section 2.2 provides a brief review of relevant findings in the literature on how gender differences affect resource allocation within households. In Section 2.3 we adapt the theoretical approach taken by Udry (1996) to our urban context of informal enterprises. Section 2.4 shows the empirical results and section 2.5 concludes.

\subsection{Literature Review}

\section{Testing for efficiency using different theoretical approaches}

To be able to develop testable hypotheses regarding the efficiency of intrahousehold resource allocation a theoretical model with assumptions that are realistic for an urban, developing country context is needed. Much of the economics literature has modelled households as one unit, maximizing a household utility function. This 'unitary' model implies either that preferences 
are identical within households, or that one 'dictator' makes decisions on the allocation of the pooled resources. The assumptions of the unitary model have been broadly rejected by empirical evidence (Schultz, 1990). Consequently, socalled 'collective' models have been developed to allow for the possibility that household members have different preferences. Different levels of bargaining power have been introduced to describe intra household resource allocation mechanisms. It is important to note that even under the assumptions of these models, the allocation of resources within the household is still found to be pareto efficient in theory (Browning and Chiappori, 1998).

The predictions of the collective model have been tested in various regional contexts. Early examples from developed countries include studies by Bourguignon et al. (1993) using French data, Browning and Chiappori (1998) using Canadian data, Lundberg et al. (1997) using data from the United Kingdom and Thomas and Chen (1994) using data from Taiwan. These studies confirm that the predicted outcomes of the collective model hold, including efficient allocation of resources. Outcomes consistent with the collective model have also been found in developing country contexts. Quisumbing and Maluccio (2003), for example, use data from Bangladesh, Ethiopia, Indonesia and South Africa. They proxy household member bargaining power by assets and education brought into the marriage. In the unitary model nothing but total household income should influence the demand of the household. However, analysing the effect of bargaining power on household expenditures shows that assets controlled by women or men affect household expenditures in different ways in three out of four countries. But, despite the evidence that bargaining power matters, they cannot reject the hypothesis that allocations of expenditures are pareto efficient in all four countries, which suggests that a collective model is appropriate.

One prominent study that rejects pareto efficiency is Udry (1996). ${ }^{29}$ Using data collected by the International Crops Research Institute for the Semi-Arid Tropics (ICRISAT) he tests the hypothesis that yields of different land plots are identical within households, controlling for plot characteristics and crop type. This hypothesis is rejected. Yields on plots of the same crop, within the same household, are significantly lower when that plot is controlled by a woman. On average the yield of female-controlled plots is less than 70 percent of the yield on plots controlled by men. This finding is inconsistent with efficiency. The study finds that one of the reasons for lower yields on plots controlled by women is inefficient allocation of inputs. Fertilizer is much more intensively used on plots controlled by mean than on plots controlled by women. As fertilizer shows diminishing returns, output could be higher if more fertilizer were allocated to the

\footnotetext{
${ }^{29}$ Akresh (2005) also finds inefficient resource allocations within households in the regions where the data used by Udry (1996) was collected. However, using the nationally representative sample of Burkina Faso, Akresh (2005) cannot detect pareto-inefficiencies in the rest of the country.
} 
women's plots. Furthermore, the magnitude of the loss due to inefficiencies is computed by estimating a CES production function and comparing actual yields with the yields that are predicted if resources were optimally allocated. Using this methodology Udry (1996) shows that 6 percent of output is lost due to inefficient input allocations.

Similarly a study by Goldstein and Udry (2008) on Ghana shows that women seldom have sufficient political power to ensure that their land is not expropriated. Since plots are likely to be taken away when they are fallow, women tend to leave their plots fallow for shorter periods and invest less than would be optimal. This study confirms that allocations of resources within households are often inefficient and that the gender dimension plays a major role in explaining these inefficiencies.

Another example is Andrews et al. (2010). From their theoretical model the authors show that in the case of pareto-efficiency the marginal rates of substitution of male and female labour should be equated over the crops within the household. The authors use data from the Uganda National Household Survey of 2005 and 2006. The study detects a gender division between cash crops and food crops. This gender division can be pareto efficient if labour is allocated according to comparative advantage and in line with the production technology available. However, the empirical tests reveal that pareto improvements would be possible if labour inputs were reallocated across plots and partners compensated adequately.The finding that gender differences play an important role is supported by a recent stream of literature that uses randomised experiments to analyse gender differences in small and medium sized enterprises (SMEs). These experiments randomly allocate cash or in-kind transfers to enterprises and analyse the effects on the firms. Such experiments have been carried out in Ghana (Fafchamps et al., 2011), Sri Lanka (De Mel et al., 2009) and the Philippines (Karlan and Zinman, 2010). The results from Ghana show that there is no effect of randomly allocated grants in enterprises run by woman with initial profits below the median. For enterprises run by men however, both grants and in-kind transfers have a significant and positive effect in profits. In Sri Lanka, men invest the randomly allocated grants and as a consequence profits rise by up to 14 percent of the grant amount. Women, in contrast, only invest large grants but do not earn any return on this investment. In the Philippines randomly allocated microcredit increases profits only in male led enterprises which in turn use the extra money to send the children to school. The loans have no effect on enterprises led by women.

Evidence on reasons for the gender gaps detected in these experimental studies is scarce. In Ghana it seems that capital alone is not enough boost enterprise growth in subsistence enterprises. In Sri Lanka, the evidence shows that the sectoral division of male and female headed enterprises may play a role as female headed 
enterprises operate in sectors where enterprises invest less and returns to investment are low. Finally, the findings presented in the first chapter of this thesis suggest that gender differences may play a role for resource allocation within households as marginal returns to capital are not equalised within household enterprises and the gender dummy is negative and significant in most specifications. However, the evidence from urban areas is still limited. In this paper we try to narrow this research gap. To test for efficiency we adopt the methodology used by Udry (1996) and apply it to an urban context in seven countries in SSA.

This evidence on gender differences in informal enterprises will contribute to an evidence-based assessment of the gender impacts of micro-finance policies, and the effectiveness of targeting women for these and other interventions.

\subsection{Theoretical background}

To derive testable hypotheses on the efficiency of intra household resource allocation we follow very closely the theoretical model developed by Udry (1996), adapted slightly to the urban context. ${ }^{30}$

In our model the household comprises 2 members, denoted by subscript j. One member is female and the other is male ( $F$ stands for the woman, $M$ stand for the man) with individual utility functions $u_{j} j \in\{F, M\} .{ }^{31}$ These utility functions depend on the consumption of a vector of private goods $C$ bought in the market. Each household member cares about the private consumption of the other household member, to some degree. The labour supply of each household member is denoted by $L_{j}$. Hence, the utility functions of the household members can be written as:

$u_{j}=u_{j}\left(C_{F}, C_{M}, L_{F}, L_{M}\right)$

\section{Household production by informal enterprises}

We assume that the goods these urban households produce are produced by two informal enterprises rather than agricultural plots, as assumed in Udry (1996). One enterprise is led by a woman and the other is headed by a man. We let the superscript $i, i \in\{F, M\}$ denote the two enterprises, and $G^{i}$ denote profit in that enterprise. Hence, the overall household profits $\left(Y^{h}\right)$ can be written as:

\footnotetext{
${ }^{30}$ An overview on different versions of collective household models can be found in Apps and Rees (2009). In addition to Udry (1996), models similar to the one used here are also used by Browning and Gørtz (2010) and also by Andrews et al. (2010).

${ }^{31}$ All subscripts refer to persons, whereas superscripts refer to enterprises.
} 
$Y^{h}=\sum_{i=F, M} G^{i}\left(L_{F}^{i}, L_{M}^{i}, L_{H}^{i}, K^{i}, A^{i}\right)$

$L_{F}^{i}$ and $L_{M}^{i}$ stand for male and female labour, $L_{H}^{i}$ for hired labour, $K^{i}$ for capital and a vector of enterprises characteristics $A^{i}$. We assume male, female and hired labour to be homogenous in terms of productivity ${ }^{32}$. This means that the equation can be simplified to:

$Y^{h}=\sum_{i=F, M} G^{i}\left(L^{i}, K^{i}, A^{i}\right)$

Where $L^{i}=L_{M}^{i}+L_{F}^{i}+L_{H}^{i}$

The assumption that different types of labour are homogenous in productivity could be invalid for a number of reasons. Firstly, workers may have different skills. For example, hired labour could be more productive than the labour of the owner if the additional workers are hired because they have specific skills which make them more productive. Second, principal-agent problems may apply. Hired workers will be less motivated than enterprise owners if their wage is not related to enterprise profits. For similar reasons, women may be less productive when working in male-led enterprises than when working in their own enterprises, and vice versa.

Notwithstanding these considerations it will be appropriate to work on the basis of this assumption for several reasons. Firstly, only around 30 percent of enterprises in our sample hire any employees at all, and the average number of employees hired is low, at around 2. Most (around 75 percent) have only one or two employees. In addition roughly half of the employees are family members. It seems highly likely that benefits family employees receive from their employment are correlated with enterprise profits, either in the short or the longer term, through wages received and through solidarity for family members. Even those employees who are not household members are likely to be well known to the household, and to make up part of the same community. Hence, we argue that moral hazard is likely to be attenuated even among these non-related employees by strong social ties. ${ }^{33}$ Secondly, given the high proportion of family members employed, it seems unlikely that skills are the primary motivation for hiring employees. In addition, the hired employees do not differ greatly from the enterprise owners in terms of their years of education. Finally, our results hold even if we restrict the sample to enterprises without employees. ${ }^{34}$

\footnotetext{
32 Jacoby (1991) uses data on peasant households in Peru and shows that female and male labour cannot be aggregated, because farm inputs affect marginal productivity of male and female farmers differently. In our data set no female entrepreneurs work in the enterprise of the male entrepreneur and vice versa. Male enterprise owners predominantly employ men and the same is true for women. Therefore, we do not aggregate male and female labour.

${ }^{33}$ There exists a recent stream of literature on the importance of kinship ties and their effects on consumption and investment. Recent examples include di Falco and Bulte $(2009,2011)$ and Grimm et al. (2010).

${ }^{34}$ Results available from the author on request.
} 
Principal-agent issues may exist in practice even where household members work in a family enterprise. However, the other assumptions of our model, particularly the assumption that the members maximise a joint production function and care to some extent about the utility of other members and the consumption of the household good imply that this does not occur. If the predictions of the model fail to hold, a principal-agent problem arising from failure of the key assumptions is one possible explanatory factor.

The other key assumption for the model is that, although households do hire labour, the amount of labour hired is fixed in the short to medium term and the enterprise owners do not work outside of the enterprise. We make this assumption because we concentrate on the allocation of labour between the enterprises, rather than examining the question of whether the amount of labour the household uses is efficient. In addition we can see that, in practice, most of the enterprise owners work full-time ( 8 hours on average assuming 6 working days per week) in their own enterprises, so either they are unable to access the outside labour market and hence spend their time in their own enterprise, or working in the enterprise is more attractive, leaving them with no time to work in the labour market. However, the main predictions of the model do not depend on the existence of a labour market, since factors can be re-allocated within the household (Udry, 1996; Andrews et al., 2010).

We assume that the household's capital endowment is fixed in the short term, so $K^{F}+K^{M}=K$. This is justified as access to capital markets among enterprises in the sample has been shown to be weak (see Chapter 1). ${ }^{35}$ In addition, as with labour, we are interested in the efficiency of allocation of capital between the household enterprises, not between different households, so this assumption is unimportant for our predictions. ${ }^{36}$

In contrast to Udry (1996) $A^{i}$ does not represent the plot area but enterprise characteristics. Such characteristics include the experience and education of the enterprise head.

Given our assumption that the entrepreneurs do not participate in the labour market but only work in the informal enterprise, the time constraint for the two household members can be written as:

$$
L_{F}=\sum_{i} L_{F}^{i} \quad \text { (2.4) } \quad \text { and } \quad L_{M}=\sum_{i} L_{M}^{i}
$$

We assume a one period game. Therefore, the household can neither borrow nor save. The household budget constraint is:

$p C \leq Y$

\footnotetext{
${ }^{35}$ Roughly 80 percent of all enterprises in the sample have financed their capital stock from savings or retained profits, without any external funding.

${ }^{36}$ Andrews et al. (2010) make a similar assumption for the input factor, land.
} 
Subject to household production (2.3), time (2.4) and budget constraints (2.5) a pareto-efficient allocation of resources within the household solves ${ }^{37}$ :

$\max _{C_{j}, L_{j}^{i}, L_{j}^{i}, Y^{h}} \mu u_{F}(\cdot)+u_{M}(\cdot)$ for $\mu>0$

Given the described setup, the allocation of labour and capital across the enterprises within the household solves:

$\max _{L_{F}^{i}, L_{M}^{i} K^{i}} \sum_{i=F, M} G^{i}\left(L_{F}^{i}, L_{M}^{i}, K^{i}, A^{i}\right)$
subject to $\quad L_{F}^{i}, L_{M}^{i}, K^{i}>0$

We follow further the approach by Udry (1996) and assume that the production functions of these enterprises are concave and strictly increasing in $A$. If we then assume that both enterprises have the same characteristics, resources would be divided equally between enterprises. Labour and capital allocation and hence profit of the two enterprises within households depend on only enterprise characteristics. We can define the profits of the enterprise $i$ in the solution of (7) as follows:

$Q^{i}\left(A^{i}\right)=G^{i}\left[L_{F}^{i}\left(A^{i}\right), L_{M}^{i}\left(A^{i}\right), K^{i}\left(A^{i}\right), A^{i}\right] \quad \forall i \in[F, M]$

$Q^{i}$ is the profit of the enterprise $i$, given the values of $L_{F}^{i} L_{M}^{i}$ and $K^{i}$ (labour and capital allocations) that solve (2.7). These allocations depend only on enterprise characteristics. Denoting the mean of $A^{i}$ by $\bar{A}$ within the household and allowing enterprise characteristics to vary within the household we can write (2.8) as follows using a first order Taylor approximation:

$Q^{i}\left(A^{i}\right)-Q^{i}(\bar{A}) \approx \frac{\delta Q^{i}(\bar{A})}{\delta A}\left(A^{i}-\bar{A}\right) \quad \forall i \in[F, M]$

Equation (2.9) shows that the equation that should be estimated measures the deviation of enterprise profits from the mean enterprise profit as a function of the deviation of enterprise characteristics from mean enterprise characteristics within the household. This is the fixed effects estimator. For our estimation we can rewrite (2.9) as follows:

$Q_{h, i}=X_{h, i} \beta+\gamma F_{h, i}+\varphi_{h}+\varepsilon_{h, i}$

In (2.10) $Q_{h, i}$ is the profit of enterprise $i$ in household $h . X$ is a vector of enterprise characteristics that we regard as exogenous. ${ }^{38}$ These characteristics include the experience and education of the enterprise head. $F_{h, i}$ is a dummy

${ }^{37} \mu$ can be interpreted as the so called pareto weight and represents the extent to which the respective partner can influence the decision process within the household (Browing and Gørtz, 2010 and Apps and Rees, 2009).

${ }^{38}$ Endogeneity of enterprise characteristics is a potential problem. Unfortunately the available data do not allow us to use an instrumental variable approach to control or this. 
variable that indicates the gender of the enterprise head. $\varphi_{h}$ captures effects of unobservable differences across households (such as household wealth) and $\varepsilon_{h, i}$ is an error term, assumed to be randomly distributed. From our theoretical setup we expect $\gamma=0$. This is the main hypothesis tested in this paper: Controlling for enterprise characteristics, profits in informal enterprises in the same household (controlled by different members of the household) are equal.

\subsection{Empirical analysis}

\subsubsection{Data and descriptive statistics}

The data we use for our empirical analysis stem from a set of surveys (1-2-3 surveys or Enquêtes 1-2-3) in seven economic capitals of the West-African Economic and Monetary Union (WAEMU) in the early 2000s. ${ }^{39}$ A 1-2-3 survey is a multi-layer survey organised in three phases and specially designed to study the informal sector. ${ }^{40}$ Phase 1 is a representative labour force survey collecting detailed information on individual socio-demographic characteristics and employment. Phase 2 is a survey which interviews a representative sub-sample of informal production units identified in Phase 1. The focus of the second phase is on the characteristics of the entrepreneurs and their production units, including the characteristics of employed workers. It also contains detailed information on input use, investment, sales, and profits. Phase 3 is a household expenditure survey interviewing (again) a representative sub-sample of Phase 1. The dataset from all three phases are organised in such a way that they can be linked.

For this paper we use data from Phase 2 which is a sample of informal entrepreneurs in urban centres of seven countries in Sub-Saharan Africa (Brilleau et al., 2005). The 1-2-3 surveys define informal enterprises as production units that (a) do not have written formal accounts and/or (b) are not registered with the tax administration. Part (b) of this definition varies slightly between countries, as registration may not always refer to registration with tax authorities. Table 2-1 is based on our sample of 6,521 firms and shows employment by company type. It shows the importance of informal enterprises for employment in urban centres in the seven countries in Sub-Saharan Africa in our sample in the early 2000s. Averaged over all countries in the sample, private informal firms are responsible for more than 70 percent of employment. In Cotonou and Lomé employment by informal firms exceeds 80 percent of employment. Pure 'self-employment' on average accounts for about 70 percent of these workers. The remaining 30 percent

\footnotetext{
39 These urban economic centres are Abidjan (Cote d'Ivoir), Bamako (Mali), Cotonou (Benin), Dakar (Senegal), Niamey (Niger), Lomé (Togo) and Ouagadougou (Burkina Faso). The surveys were carried out by AFRISTAT and the National Statistical Institutes (INS) with the support of Developpement Institutions \& Mondalisation (DIAL) as part of the Regional Program of Statistical Support for Multilateral Surveillance (PARSTAT) between 2001 and 2003. For a more detailed description of the data see Brilleau, et al. (2005a).

${ }^{40}$ See Roubaud (2008) for a detailed assessment of this type of survey instrument.
} 
are split almost equally between enterprises that employ family workers and nonfamily workers.

Table 2-1: Employment by sector in seven urban centers in Sub-Saharan Africa (percent)

\begin{tabular}{lrrrrrrrr}
\hline $\begin{array}{l}\text { Principal } \\
\text { employment }\end{array}$ & Cotonou & Ouaga. & Abidjan & Bamako & Niamey & Dakar & Lomé & Total \\
\hline $\begin{array}{l}\text { Public } \\
\text { administration }\end{array}$ & 6.3 & 10.4 & 5.5 & 7.5 & 13.5 & 5.7 & 5.2 & 6.6 \\
Public firm & 2.2 & 2.3 & 1.1 & 2.5 & 1.8 & 1.8 & 2.3 & 1.8 \\
Private formal firm & 9.9 & 11.8 & 17.6 & 11.4 & 11.8 & 15.0 & 10.5 & 14.2 \\
$\begin{array}{l}\text { Private informal } \\
\text { firm }\end{array}$ & 80.3 & 73.4 & 74.7 & 77.5 & 71.1 & 76.4 & 81.0 & 76.2 \\
of which & & & & & & & & \\
$\quad$ Owners & 63.7 & 67.5 & 60.4 & 73.4 & 72.2 & 65.2 & 68.6 & 65.0 \\
$\quad$ Family workers & 19.2 & 16.3 & 16.1 & 8.6 & 14.5 & 17.6 & 13.6 & 15.5 \\
$\quad$ Non-family & 17.1 & 16.2 & 23.5 & 18.0 & 13.3 & 17.2 & 17.8 & 19.5 \\
$\quad$ workers & 1.3 & 2.1 & 1.1 & 1.1 & 1.8 & 1.1 & 1.0 & 1.2 \\
\hline Associations & & & & & & & & \\
\hline
\end{tabular}

Source: Brilleau et al. (2005), and authors' computations based on 1-2-3 surveys (Phase 2, 2001/02, AFRISTAT, DIAL, INS).

Following the model described in Section 2.2 we restrict the sample to households that have exactly two enterprises, one managed by a woman and one by a man. The results will be prone to selection bias as we reduce the representative sample of about 6,521 firms to 922 firms in 461 households. It could be that these households are more entrepreneurial than households with only one enterprise. In such a case we would expect estimates of input factors to be upwardly biased. An upward bias could also be created by the fact that households with more than one enterprise are better able to diversify risks. In addition, the results are prone to downward bias caused by measurement error. This bias is increased by reducing the sample size. To check for possible selection biases we estimated all specifications for the entire sample and also for subsamples containing; households with more than 2 enterprises, and; households with enterprises headed by a female or male entrepreneur. ${ }^{41}$ All results are robust to this sample variation. Certainly our results should be interpreted with caution due to the relatively small sample size. Nonetheless, the fact that the results are robust across various samples is encouraging.

Profit is defined as value added and is computed as sales minus input costs including expenses for products for re-sale. ${ }^{42}$ Note that labour costs and interest

\footnotetext{
${ }^{41}$ This sub-sample contains about 1,300 firms in about 600 households.

${ }^{42}$ Input costs are measured in detail and include the following items: raw materials, materials for re-sale, rent, water, gas, electricity, telephone, fuel, tools, transport insurance, repair costs, taxes, patents and other charges and fees.
} 
Gender and the allocation of labour and capital in informal enterprises: Evidence from Sub-Saharan Africa

payments are not deducted. ${ }^{43}$ Capital is measured by the replacement value of capital stock. Labour input is measured in hours worked in the enterprise per month by the owner and all employees. The reference period for all of the variables is one month. All monetary values are in international US Dollars (Int. USD). ${ }^{44}$ Table 2-2 shows that the average monthly value added of a male entrepreneur in the wholesale or retail sector is 576 Int. USD monthly compared to 329 Int. USD for the average female entrepreneur. The distribution between firms with pure 'self-employment' and firms that employ either family or nonfamily workers remains similar after restricting the sample. The main enterprise characteristics of this sub-sample are shown in Table 2-2.

\footnotetext{
${ }^{43}$ To check for the robustness of our results we also deducted labour costs. When controlling for labour inputs we excluded paid labour hours. The results are robust to this variation. Results are available from the author on request.

${ }^{44}$ PPP conversion rates from the World Development Indicators by the World Bank (World Bank, 2013) have been used.
} 
Gender and the allocation of labour and capital in informal enterprises: Evidence from Sub-Saharan Africa

Table 2-2: Basic enterprise characteristics by gender and sector

\begin{tabular}{|c|c|c|c|c|c|c|c|c|c|}
\hline & $\begin{array}{l}\text { Value } \\
\text { added } \\
\text { male }\end{array}$ & $\begin{array}{l}\text { Value } \\
\text { added } \\
\text { female }\end{array}$ & $\begin{array}{l}\text { Capital } \\
\text { Male }\end{array}$ & $\begin{array}{l}\text { Capital } \\
\text { Female }\end{array}$ & $\begin{array}{l}\text { Labour } \\
\text { (owner) } \\
\text { male }\end{array}$ & $\begin{array}{l}\text { Labour } \\
\text { (owner) } \\
\text { female }\end{array}$ & $\begin{array}{l}\text { Firm } \\
\text { size } \\
\text { male }\end{array}$ & $\begin{array}{l}\text { Firm } \\
\text { size } \\
\text { female }\end{array}$ & $\begin{array}{l}\% \\
\text { female } \\
\text { owners }\end{array}$ \\
\hline \multicolumn{10}{|c|}{ Clothing and apparel } \\
\hline mean & 450.8 & 166.5 & 1035.6 & 556.9 & 224.7 & 146.7 & 2.1 & 1.6 & 0.51 \\
\hline median & 104.3 & 59.9 & 370.8 & 87.6 & 240.0 & 147.0 & 1.0 & 1.0 & 1.00 \\
\hline $\mathrm{N}$ & 49 & 50 & 49 & 50 & 49 & 50 & 49 & 50 & 99 \\
\hline \multicolumn{10}{|l|}{ Other } \\
\hline \multicolumn{10}{|c|}{ Manufacturing } \\
\hline mean & 536.4 & 147.9 & 2170.5 & 198.0 & 198.7 & 177.0 & 2.3 & 1.3 & 0.47 \\
\hline median & 148.6 & 57.7 & 211.3 & 39.9 & 208.0 & 150.0 & 2.0 & 1.0 & 0.00 \\
\hline $\mathrm{N}$ & 79 & 71 & 79 & 71 & 79 & 71 & 79 & 71 & 150 \\
\hline \multicolumn{10}{|c|}{ Construction } \\
\hline mean & 1174.6 & 0.0 & 446.7 & 0.0 & 176.5 & 0.0 & 2.6 & 0.0 & 0.00 \\
\hline median & 372.8 & 0.0 & 96.6 & 0.0 & 192.0 & 0.0 & 1.0 & 0.0 & 0.00 \\
\hline $\mathrm{N}$ & 69 & 0 & 69 & 0 & 69 & 0 & 69 & 0 & 69 \\
\hline \multicolumn{10}{|c|}{ Wholesale/ retail } \\
\hline mean & 576.8 & 329.4 & 924.3 & 1380.1 & 241.4 & 189.5 & 1.7 & 1.3 & 0.48 \\
\hline median & 214.7 & 93.7 & 199.7 & 36.6 & 258.0 & 189.0 & 1.0 & 1.0 & 0.00 \\
\hline $\mathrm{N}$ & 41 & 38 & 41 & 38 & 41 & 38 & 41 & 38 & 79 \\
\hline \multicolumn{10}{|c|}{ Petty trading } \\
\hline mean & 370.4 & 135.8 & 325.6 & 109.4 & 212.4 & 190.5 & 1.3 & 1.1 & 0.83 \\
\hline median & 79.9 & 44.9 & 23.1 & 19.2 & 233.0 & 180.0 & 1.0 & 1.0 & 1.00 \\
\hline $\mathrm{N}$ & 45 & 217 & 45 & 217 & 45 & 217 & 45 & 217 & 262 \\
\hline \multicolumn{10}{|c|}{ Hotels and restaurants } \\
\hline mean & 624.6 & 345.2 & 1961.6 & 296.2 & 277.2 & 194.5 & 1.9 & 1.7 & 0.82 \\
\hline median & 664.4 & 136.9 & 1197.9 & 123.1 & 270.0 & 192.0 & 2.0 & 1.0 & 1.00 \\
\hline $\mathrm{N}$ & 9 & 40 & 9 & 40 & 9 & 40 & 9 & 40 & 49 \\
\hline \multicolumn{10}{|l|}{$\begin{array}{l}\text { Repair } \\
\text { services }\end{array}$} \\
\hline mean & 231.8 & 507.7 & 1901.3 & 68.1 & 231.4 & 200.0 & 2.4 & 2.0 & 0.0 \\
\hline median & 123.1 & 507.7 & 231.8 & 68.1 & 240.0 & 200.0 & 2.0 & 2.0 & 0.0 \\
\hline $\mathrm{N}$ & 53 & 1 & 53 & 1 & 53 & 1 & 53 & 1 & 54 \\
\hline \multicolumn{10}{|c|}{ Transport } \\
\hline mean & 1096.3 & 14950.0 & 6689.5 & 21385.4 & 227.7 & 84.0 & 1.7 & 1.0 & 0.02 \\
\hline median & 452.8 & 14950.0 & 2993.9 & 21385.4 & 240.0 & 84.0 & 1.0 & 1.0 & 0.00 \\
\hline $\mathrm{N}$ & 60 & 1 & 60 & 1 & 60 & 1 & 60 & 1 & 61 \\
\hline \multicolumn{10}{|l|}{$\begin{array}{l}\text { Other } \\
\text { services }\end{array}$} \\
\hline mean & 291.7 & 123.9 & 1399.3 & 332.8 & 175.0 & 143.4 & 1.6 & 1.3 & 0.43 \\
\hline median & 161.4 & 84.9 & 84.5 & 15.4 & 192.0 & 155.0 & 1.0 & 1.0 & 0.00 \\
\hline $\mathrm{N}$ & 56 & 43 & 56 & 43 & 56 & 43 & 56 & 43 & 99 \\
\hline \multicolumn{10}{|l|}{ Total } \\
\hline median & 177.2 & 61.5 & 239.4 & 30.7 & 216.0 & 180.0 & 1.0 & 1.0 & 0.5 \\
\hline $\mathrm{N}$ & 461 & 461 & 461 & 461 & 461 & 461 & 461 & 461 & 922 \\
\hline
\end{tabular}

Source: Authors' computation based on 1-2-3 surveys (Phase 2, 2001/02, AFRISTAT, DIAL, INS).

On average the value added of an enterprise headed by a man is about three times as high as the value added in the average female headed enterprise. This ratio is similar when using the median value of value added. Even larger differences can be found when examining the differences in capital stocks. The average capital stock of a male headed enterprise is about 5.5 times bigger than the average 
capital stock of a female headed enterprise. Both distributions of capital stock and value added are heavily skewed. Median values are much smaller than the respective means.

When comparing the labour inputs by the gender of the enterprises owners we cannot detect big differences. Assuming six working days per week, both male and female entrepreneurs work about 8 hours daily. Firm size (which includes the owner) is slightly bigger in male headed enterprises. On average male headed enterprise have 1 employee compared to 0.3 in female headed enterprises. Again, the average is driven by a few firms that have a large number of employees. The majority of the firms do not have employees. One of the most important findings for our analysis, shown in Table 2, is the unequal distribution of female and male headed enterprises by sector. In construction, repair services and transport there are virtually no female enterprise heads whereas the sectors of 'hotels and restaurants' and 'petty trading' are dominated by female entrepreneurs.

These descriptive statistics show two relevant findings. First, in some capital intensive sectors (e.g. transport) there are virtually no female enterprise owners. Second, male headed enterprises in all sectors have larger capital stocks and value added, whereas labour inputs by male and female enterprise owners do not differ substantially. This fact, combined with the findings of decreasing marginal returns to capital in all sectors, suggests inefficient resource allocations within households.

\subsubsection{Econometric analysis}

We now test formally for efficiency. We estimate the following equation, derived from the theoretical model: ${ }^{45}$

$Q_{h, i}=X_{h, i} \beta+\gamma F_{h, i}+\varphi_{h}+\varepsilon_{h, i}$

In (2.12) $Q_{h, i}$ is the value added of enterprise $i$ in household $h . X$ is a vector of enterprise characteristics (experience and education of the enterprise head). $F_{h, i}$ is a dummy variable that indicates the gender of the enterprise head. $\varphi_{h}$ captures effects of unobservable differences across households (such as household wealth) and $\varepsilon_{h, i}$ is an error term, assumed to be random. ${ }^{46}$ The hypothesis is that the value added in an enterprise led by a woman does not differ from the value added of a

\footnotetext{
${ }^{45}$ Zero and missing values for value added, labour and capital have been excluded in order to avoid a downward bias. However, running the regression with missing values as zeros did not affect the overall findings.

${ }^{46}$ In all regressions, we drop influential outliers from our sample (and sub-samples). These outliers are identified by the DFITS-statistic. As suggested by Belsley et al. (1980), we use a cutoff-value $|D F I T S|_{i h j}>$ $2 \sqrt{k / N}$ with, $k$ the degrees of freedom (plus 1 ) and $N$, the number of observations. By applying this approach to correct for influential outliers our sample is reduced by about three to five percent.
} 
male headed enterprise in the same household, after controlling for enterprise characteristics $(\gamma=0)$.

The results of estimating (2.12) are reported in the first column of in Table 2-3. For every specification we also report the mean and standard deviation of the dependent variable. The results reported in column 1 show that value added in female headed enterprises are significantly lower (by about 230 Int. USD) than value added in male headed enterprises, even when controlling for all household characteristics using a fixed effects specification. The difference is equivalent to 70 percent of mean value added.

Table 2-3: OLS fixed effects estimates, dependent variable value-added on enterprise level.
(1)
(2)
(3)
(4)

Base Sector FE $\quad \begin{array}{cc}\text { Incl. } \\ \text { Controls }\end{array}$

\begin{tabular}{|c|c|c|c|c|}
\hline $\begin{array}{l}\text { Mean Profit } \\
\text { Std. } \\
\text { deviation of } \\
\text { mean profit } \\
\end{array}$ & $\begin{array}{l}307.98 \\
561.19\end{array}$ & $\begin{array}{l}287.98 \\
445.63\end{array}$ & $\begin{array}{l}316.98 \\
600.64\end{array}$ & $\begin{array}{l}148.89 \\
223.34\end{array}$ \\
\hline $\begin{array}{l}\text { Owner } \\
\text { Female }\end{array}$ & $\begin{array}{c}-233.903 * * * * \\
(38.922)\end{array}$ & $\begin{array}{c}-196.996 * * * \\
(49.316)\end{array}$ & $\begin{array}{l}-79.801 * \\
(41.440)\end{array}$ & $\begin{array}{c}-61.069 * * * \\
(21.319)\end{array}$ \\
\hline $\begin{array}{l}\text { Owner's } \\
\text { education }\end{array}$ & $\begin{array}{c}5.188 \\
(7.780)\end{array}$ & $\begin{array}{r}3.232 \\
(6.209)\end{array}$ & $\begin{array}{c}9.107 \\
(7.009)\end{array}$ & $\begin{array}{c}5.996 \\
(4.660)\end{array}$ \\
\hline $\begin{array}{l}\text { Owner's } \\
\text { experience }\end{array}$ & $\begin{array}{c}1.675 \\
(3.518)\end{array}$ & $\begin{array}{r}6.245 \\
(3.459)\end{array}$ & $\begin{array}{c}1.185 \\
(2.994)\end{array}$ & $\begin{array}{l}-1.207 \\
(1.884)\end{array}$ \\
\hline Capital & & & $\begin{array}{c}0.044 * * * \\
(0.015)\end{array}$ & $\begin{array}{c}0.001 \\
(0.004)\end{array}$ \\
\hline Labour & & & $\begin{array}{c}0.524 * * * \\
(0.149) \\
\end{array}$ & $\begin{array}{c}0.542^{* * *} \\
(0.119) \\
\end{array}$ \\
\hline $\begin{array}{l}\text { Household } \\
\text { fixed effects } \\
\text { Sector fixed } \\
\text { effects }\end{array}$ & $\begin{array}{l}\text { Yes } \\
\text { No }\end{array}$ & $\begin{array}{l}\text { No } \\
\text { Yes }\end{array}$ & $\begin{array}{l}\text { Yes } \\
\text { No }\end{array}$ & $\begin{array}{l}\text { Yes } \\
\text { No }\end{array}$ \\
\hline $\begin{array}{l}\mathrm{N} \\
\mathrm{R} \text {-squared } \\
\text { within } \\
\text { R-squared }\end{array}$ & $\begin{array}{c}650 \\
0.153\end{array}$ & $\begin{array}{c}657 \\
0.052\end{array}$ & $\begin{array}{r}648 \\
0.364\end{array}$ & $\begin{array}{c}278 \\
0.223\end{array}$ \\
\hline $\begin{array}{l}\text { between } \\
\text { R-squared } \\
\text { overall }\end{array}$ & $\begin{array}{l}0.005 \\
0.052\end{array}$ & 0.32 & 0.162 & $\begin{array}{l}0.009 \\
0.062 \\
\end{array}$ \\
\hline
\end{tabular}

Notes: $* \mathrm{p}<0.05, * * \mathrm{p}<0.01, * * * \mathrm{p}<0.001$. Robust standard errors corrected for clustering at the 'segment'-level (around 10 observations) in parentheses.

Source: Authors' computation based on 1-2-3 surveys (Phase 2, 2001/02, AFRISTAT, DIAL, INS). 
However, it could be the case that unobserved characteristics that are correlated with value added are also correlated with sector, and that these differences explain the significance of the gender dummy. If this is the case, and we assume that the households cannot change the sector of their enterprises in the short term, the allocation of resources may not be inefficient, even if the gender dummy is significant, as seen above. Udry (1996) deals with a similar concern regarding differences in productivity between crops, by restricting the sample to households where both men and women farm the same crop, on separate plots. To control for such sectoral effects we estimate a sector fixed effects model. The results are reported in column 2 and show that the gender effect prevails and is of similar magnitude to the results in column $1 .^{47}$ The findings of the first two columns are inconsistent with efficiency and the main hypothesis that arose from our empirical model $(\gamma=0)$ is rejected. ${ }^{48}$

In column 3 of Table 2-3 we relax the assumption that capital and labour allocations are purely driven by enterprise characteristics. This is done to test the hypothesis that lower value added in female-led enterprises can be explained by lower allocations of capital and labour.

In column 3 the gender dummy remains significant on a ten percent level but is much smaller in magnitude than in our first two specifications. This shows that some of the variation in value added is explained by lower allocations of labour and capital to female headed enterprises. ${ }^{49}$ However, these variations in input factor allocations do not fully explain the gender bias. Average value added in female headed enterprises is still lower by 80 Int. USD, or 25 percent of mean value added, in the sub-sample used in column 3, which controls for capital and labour allocations.

There are several possible explanations for the persistence of gender bias, even after controlling for capital and labour. It is probable that women look after the children at the same time as working in the informal enterprise (Udry, 1996). The outputs in terms of this 'household public good' are not measured. This would mean that time spent by a female entrepreneur creates skills for the future entrepreneurs in addition to the enterprise value added. This could change our conclusion on efficiency. Child labour is reportedly used more frequently in male headed enterprises, but younger children may be looked after by women, reducing the productivity of their labour.

\footnotetext{
${ }^{47}$ The results also hold when we limit our sample to households where both firms operate in the same sector. The gender dummy remains significant at the ten percent level and explains more than 40 percent of mean profits.

${ }^{48}$ Because of the cross-sectional nature of our data set we are unable to control for endogeneity of the input choices.

${ }^{49}$ One possibility is that capital allocations are driven by the sector the enterprise operates in. Nonetheless, one can argue that choice of sector in itself reflects a gender effect, as social norms restrict men and women to working only in certain sectors. The descriptive statistics in Table 2-2 lend support to this hypothesis.
} 
To test the robustness of our results to our assumption that labour of the owner is indistinguishable from labour of the employees we also estimate (12) including capital and labour endowment for a sub-sample of enterprises which do not use external labour. The results are reported in column 4. The gender dummy is significant at the 1 percent level and remains very large in this robustness test. It shows that value added in female headed enterprises is about 60 Int. USD lower than for male headed enterprises. If there were differences in productivity of the labour of the owner and employees one would expect the coefficient on labour to vary between columns 3 and 4 . However, the coefficient on labour in our fourth specification changes very little compared to column 3. Also, the other coefficients are relatively stable. The only exception is the coefficient on capital, which is almost zero. This might be caused by measurement error combined with the small sample size. Overall, there is no evidence that our assumption that hired and owner's labour are indistinguishable is inappropriate.

The gender dummy is significant and negative in all our specifications. ${ }^{50}$ This is inconsistent with efficient allocation of resources. Under efficient allocation of resources, the gender dummy should be equal to zero, as described in our theoretical model. In contrast to this prediction we find that value added in female headed enterprises, after controlling for enterprise and household characteristics including unobservables, is between 25 and 40 percent lower, depending on the specification. This effect is partly caused by the inefficient allocation of capital and labour. It is remarkable that our findings are very much in line with the finding of Udry (1996) who also finds the gender differential to be over thirty percent in a rural setting.

\subsubsection{Quantifying the potential gains from re-allocation}

Having established that an important part of the difference in value added between male and female headed enterprises is due to inefficient allocations we now turn to quantifying the increase in value added that would, in theory, be available to these informal enterprises, if the resources were allocated in the optimal way. Our first step is to estimate a baseline production function. Finally we predict value added using the estimated parameters, for the actual allocation of resources and under the optimised allocation, and compare these two estimates.

\footnotetext{
${ }^{50}$ The results are also robust to changing the definition of value added to sales minus all inputs minus labour costs. Under this definition the gender dummy remained significant at the 1 percent level.
} 
We assume decreasing returns to capital. Therefore, we use a constant elasticity of substitution (CES) functional form for our production function (Griffiths et al., $1993,723):{ }^{51}$

$y=A\left(\delta K^{-\rho}+(1-\delta) L^{-\rho}\right)^{-v / \rho}$

Taking logs and adjusting the notation of the economic model so that it can be estimated yields a production function with the following form (see Greene, 1999, 331f. or Kmenta, 1967, 180)

$\ln y_{i, h}=$ const $-\frac{v}{\rho} \ln \left[\delta K_{i, h}^{-\rho}+(1-\delta) L_{i, h}^{-\rho}\right]+u_{i, h}$

In (2.14) y stands for value added, measured by sales minus total expenses, including goods for re-sale and excluding wages and interest payments. $K$ is the replacement value of the capital stock of the respective firm and $L$ stands for labour input in hours. $v$ is a returns to scale parameter, $\delta$ measures the relative importance of the input factors and $\rho$ stands for the substitutability of capital and labour. $u_{i, h}=\varepsilon_{i} \cdot \tau_{h}$ represents the influence of unobserved enterprise-level $\left(\varepsilon_{i}\right.$ which can be interpreted as total factor productivity (TFP)) and household level ( $\tau_{h}$ which includes factors such as household wealth) variables on value added. We eliminate $\varepsilon_{h}$ by estimating (2.14) using household fixed effects. ${ }^{52}$ Following Greene (1999) and Kmenta (1967) a Taylor series approximation of (2.14) can be written as: ${ }^{53}$ :

$$
\begin{aligned}
\ln y \approx \text { const } & +v \delta \ln K+v(1-\delta) \ln L+\rho \vartheta \delta(1-\delta)\left[-\frac{1}{2}(\ln K-\ln L)^{2}\right] \\
& +\ldots \\
=\text { const } & +\beta^{A} K+\beta^{B} L+\beta^{A B} g(K, L)+\ldots
\end{aligned}
$$

In this logarithmic form all terms are linear which enables us to estimate the production function using OLS:

$g(K, L) \equiv\left[-\frac{1}{2}(\ln K-\ln L)^{2}\right]$

All the unknown parameters of (2.15) and (2.16) can now be inferred in a linear fashion:

\footnotetext{
${ }^{51} \mathrm{We}$ also tested whether it is appropriate to use a Cobb-Douglas production function. The hypothesis that the sum of the capital and labour coeffcient is equal to one was strongly rejected.

52 If experienced entrepreneurs can observe TFP early enough that they are able to base their input choices on this information, as seems likely, $\varepsilon_{i}$ will be correlated with inputs. Unfortunately the cross-sectional nature of the data does not allow us to control for this problem by including lagged variables as instruments. No other suitable instruments are available.

${ }^{53}$ To simplify, we drop the $i, h$ subscripts. We follow closely the notation for linearization of a constant elasticity of substitution (CES) production function Greene (1999, 331f) and Kmenta, 1967, 180f).
} 
$v=\beta^{A}+\beta^{B}$

$\rho=\beta^{A B}\left(\beta^{A}+\beta^{B}\right) /\left(\beta^{A} \beta^{B}\right)$

$\delta=\beta^{A} /\left(\beta^{A}+\beta^{B}\right)$

Once we know $\rho$ we can calculate the elasticity of substitution $(\sigma)$ :

$\sigma=(1+\rho)^{-1}$

We estimate a baseline production function using (2.15). The baseline results are reported in column 1 of Table 2-4. $v$ is highly significant and smaller than one, indicating decreasing returns to scale. The coefficients on $\ln$ capital and $\ln$ labour are similar, resulting in a distribution parameter $\delta$ of about 0.5 . Substitutability between capital and labour is relatively high (the substitution parameter implies an elasticity of substitution of 1.44).

Before we can compute the potential gains from resource re-allocation we need to test our assumption that the production functions of the male and female headed enterprises are identical. We do so by including gender interactions in our baseline estimates and testing for joint significance of the interaction terms. The F-Test statistic has a value of 36.43 , rejecting the hypothesis that the production functions for female and male entrepreneurs are identical. The results in column 2 of Table 2-4 show that capital is equally productive in male and female headed enterprises. Labour, by contrast, is significantly less productive in female headed enterprises. ${ }^{54}$ The reason for relatively low productivity is unclear. As discussed above, it is likely that women care for children at the same time as working in the informal enterprise. This could explain lower productivity of labour. Differences in time or risk preferences could also play a role. Therefore, when quantifying the potential gains we assume that the production functions for male and female entrepreneurs differ.

\footnotetext{
${ }^{54}$ Another possible reason for the inefficiencies we detect is that TFP varies by gender. However, our analysis does not provide any support to this hypothesis.
} 
Gender and the allocation of labour and capital in informal enterprises: Evidence from Sub-Saharan Africa

Table 2-4: Baseline OLS Fixed effects estimates of CES production function

(1)

Base Gender interactions

\begin{tabular}{|c|c|c|}
\hline ln Capital & $\begin{array}{c}0.274 * * * \\
(0.022)\end{array}$ & $\begin{array}{l}0.148 * * * \\
(0.027)\end{array}$ \\
\hline In Capital X Female owner & & $\begin{array}{l}-0.011 \\
(0.044)\end{array}$ \\
\hline In Labour & $\begin{array}{c}0.350 * * * \\
(0.048)\end{array}$ & $\begin{array}{l}0.306^{* * *} \\
(0.049)\end{array}$ \\
\hline In Labour X Female owner & & $\begin{array}{c}-0.135 * * * \\
(0.040)\end{array}$ \\
\hline $\mathrm{g}(\mathrm{K}, \mathrm{L})$ & $\begin{array}{c}-0.047 * * * \\
(0.005)\end{array}$ & $\begin{array}{c}-0.031 * * * \\
(0.006)\end{array}$ \\
\hline $\mathrm{g}(\mathrm{K}, \mathrm{L}) \mathrm{X}$ Female owner & & $\begin{array}{r}0.010 \\
(0.009) \\
\end{array}$ \\
\hline Returns to scale $(v)$ Male / all enterprises & $\begin{array}{c}0.624 * * * \\
(0.052)\end{array}$ & $\begin{array}{l}0.454 * * * \\
(0.053)\end{array}$ \\
\hline Returns to scale $(v)$ Female enterprises & & $\begin{array}{l}0.307 * * * \\
(0.061)\end{array}$ \\
\hline Distribution $(\delta)$ Male / all enterprises & $\begin{array}{c}0.560 * * * \\
(0.041)\end{array}$ & $\begin{array}{c}0.674 * * * \\
(0.056)\end{array}$ \\
\hline Distribution $(\delta)$ Female enterprises & & $\begin{array}{c}0.557 * * * \\
(0.136)\end{array}$ \\
\hline Substitution $(\rho)$ Male / all enterprises & $\begin{array}{l}-0.307 * * * \\
(0.028)\end{array}$ & $\begin{array}{c}-0.314 * * * \\
(0.043)\end{array}$ \\
\hline Substitution $(\rho)$ Female enterprises & & $\begin{array}{c}-0.281 * * \\
(0.095)\end{array}$ \\
\hline $\mathrm{N}$ & 740 & 740 \\
\hline $\begin{array}{l}\text { F-Statistics of test for joint significance of } \\
\text { interactions }\end{array}$ & & 36.43 \\
\hline R-squared within & 0.382 & 0.497 \\
\hline R-squared between & 0.163 & 0.154 \\
\hline R-squared overall & 0.245 & 0.296 \\
\hline
\end{tabular}

Notes: $* \mathrm{p}<0.05, * * \mathrm{p}<0.01, * * * \mathrm{p}<0.001$. Robust standard errors corrected for clustering at the 'segment'-level (around 10 observations) in parentheses.

Source: Authors' computation based on 1-2-3 surveys (Phase 2, 2001/02, AFRISTAT, DIAL, INS).

To quantify the inefficiencies we first predict value added using the actual distribution of capital and labour and the parameters $\left(\delta, \rho, v, \varepsilon_{i}\right)$ from Table 2-4. In a next step we maximise the following equation and compare the predicted value added under optimal and actual distributions of labour: 
$\max Y^{h}=\sum_{i=F, M} G^{i}\left(L^{i} K^{i}\right)$

s.t. $L^{M}+L^{F} \leq L, K^{M}+K^{F} \leq K, K^{i}>0, L^{i}>0$

in (2.21) $Y$ stands for sum of value added of the two household enterprises, $L^{i}$ and $K^{i}$ represent labour and capital allocated to the respective enterprise, and $L$ and $K$ represent the endowment of the household with labour and capital.

The results from this maximization exercise are reported in Table 2-5. Using the actual distribution of input factors value added is about 108 Int. USD on average, compared to about 130 Int. USD when resources are allocated optimally within households. Hence, value added could be increased by about 20 percent, on average, by re-allocating capital and labour. Table 2-5 also reports the magnitude of the re-distributions needed to maximise value added of the enterprise within households. On average almost 200 Int. USD or about 19 percent of the average capital stock would need to be transferred from the male to the female headed enterprise, in order to reach the optimal allocation. Given that capital is equally productive in male and female headed enterprises, decreasing returns to capital and the initial unbalanced distribution of capital, this seems a plausible result. For labour the results show that about 20 hours per month or 7 percent of the average labour inputs are re-allocated from male to female headed enterprises, on average. Several factors play a role in this outcome. First, labour in female headed enterprises is less productive than in male headed enterprises. This effect is offset by the fact that initially male headed enterprises are allocated more labour, and by decreasing returns to labour. Also, labour and capital are imperfect substitutes. Since a considerable amount of capital is reallocated to female headed enterprises in order to reach the optimum, complementarities increase the required redistribution of labour.

However, the average effect observed is a combination of two effects. In around 60 percent of households, capital would be reallocated from the male to the female headed enterprise, in order to achieve the maximum value-added. In about 50 percent of cases, labour would be reallocated towards the female headed enterprise. However, in the remaining cases, capital and/or labour would be reallocated from the female enterprise to the male headed enterprise. Because of decreasing returns to capital and labour the increase in value added in the male headed enterprises that receive more inputs outweighs the decrease in enterprise that lose inputs. As a consequence, the average value-added of male headed enterprises increases when inputs are reallocated, even though the average labour and capital allocations of male headed enterprises fall. This complexity illustrates the heterogeneity of household enterprises, and makes it difficult to make policy prescriptions about reallocation of inputs without a close understanding of household circumstances. 
Gender and the allocation of labour and capital in informal enterprises: Evidence from Sub-Saharan Africa

Table 2-5: Value added under actual and optimal allocations of labour and capital (Int. USD)

\begin{tabular}{lcccccc} 
& $\begin{array}{c}\text { Labour } \\
\text { initial }\end{array}$ & $\begin{array}{c}\text { Labour } \\
\text { optimal }\end{array}$ & $\begin{array}{c}\text { Capital } \\
\text { Initial }\end{array}$ & $\begin{array}{c}\text { Capital } \\
\text { Optimal }\end{array}$ & $\begin{array}{c}\text { Profit } \\
\text { Initial }\end{array}$ & $\begin{array}{c}\text { Profit } \\
\text { Optimal }\end{array}$ \\
\hline $\begin{array}{l}\text { Male headed } \\
\text { enterprises }\end{array}$ & 425.01 & 403.45 & 1715.49 & 1517.87 & 81.75 & 91.24 \\
$\begin{array}{l}\text { No. of observations } \\
\text { Female headed }\end{array}$ & 366 & 366 & 366 & 366 & 366 & 366 \\
enterprises & 224.74 & 246.30 & 392.87 & 590.49 & 25.27 & 39.86 \\
No. of observations & 366 & 366 & 366 & 366 & 366 & 366 \\
\hline Total & 324.88 & 324.88 & 1054.18 & 1054.18 & 107.02 & 130.69 \\
& 732 & 732 & 732 & 732 & 732 & 732
\end{tabular}

Source: Authors' computation based on 1-2-3 surveys (Phase 2, 2001/02, AFRISTAT, DIAL, INS).

To disentangle the contributions of capital and labour to the increase in value added we repeated the exercise and kept either labour or capital constant. When only allowing labour to be re-distributed the increase in value added is around 3 percent. Holding the distribution of labour constant and maximizing value added by varying capital within households has a much bigger effect - value added rises by about 16 percent. These results are in line with expectations, since capital was much more unequally distributed than labour.

Another relevant question is what part of the differences in value added can be attributed to different endowments of the enterprises on the one hand, and the fact that production functions vary between men and women on the other. ${ }^{55}$ One way of answering this question is to use the so called Oaxaca - Blinder decomposition. This methodology was made popular by Blinder (1973) and Oaxaca $(1973)^{56}$ and was used to explain differences in average wages between men and women.

For our purposes we follow the approach described by Daymont and Andrisani (1984) and decompose mean differentials in value added between male and female headed enterprises into three groups:

$\bar{Y}_{F}-\bar{Y}_{M}=\left(\bar{X}_{F}-\bar{X}_{M}\right) \hat{\beta}_{M}+\bar{X}_{M}\left(\hat{\beta}_{F}-\hat{\beta}_{M}\right)+\left(\bar{X}_{F}-\bar{X}_{M}\right)\left(\hat{\beta}_{F}-\hat{\beta}_{M}\right)$

To obtain the parameters described in (2.22) we estimated a CES production function as described in (2.15) separately for male and female headed

\footnotetext{
55 The results in Table 2-3 suggest that differences between male and female enterprises can largely be explained by differences in endowments of labour and capital.

56 The approach divided differences in mean wages into an 'price effect' caused by different returns to education for men and women and an 'endowment effect' caused by differences in educational achievements. This approach has been widely used and augmented (see Bourguignon et al., 2008 or Jones and Kelley, 1984 ).
} 
enterprises. ${ }^{57}$ In (2.22) $\bar{Y}_{F, M}$ are group means of predicted value added, $\bar{X}_{F, M}$ represent mean endowments ${ }^{58}$ for male and female headed enterprises, and $\hat{\beta}_{F, M}$ is a vector of coefficients obtained from the production CES function estimation that was done for both sub-groups.

The first part of (2.22) is the endowment effect, the second part the effect caused by different coefficients in male and female headed enterprises and the third part measures interaction effects of endowments and coefficients.

The results show, as could be expected, that predicted value added in male headed enterprises is about 3 times higher than value added in female headed enterprises. The analysis shows that differences in capital, labour and education of the owner account for more than 60 percent of these differences. Applying the coefficients derived from the regression including only male headed enterprises to the characteristics of female headed enterprises shows that differences in the coefficients account for about 40 percent of the differences. The importance of the interaction term is negligible. Since differences in capital account for the majority of the endowment effect we find that the inefficiencies in resource allocations between households are mainly driven by unequal distributions of capital between male and female headed enterprises.

Overall, these results indicate slightly larger potential gains to re-allocation than the results of Udry (1996), who detects a potential increase of 6 percent. The difference between the findings for rural farms and for informal enterprises in an urban setting may arise from a number of factors. The significantly larger capital stocks in the urban enterprises may be one important explanation: this leaves the households with greater potential for redistribution, compared to the households in Udry's rural setting.

\subsection{Conclusions}

In this paper we test whether households allocate capital and labour between informal enterprises headed by women and those headed by men in a pareto efficient way. We use a data set on informal enterprises from seven countries in Sub-Saharan Africa. The input factors are distributed unequally between female and male headed enterprises. The differences are particularly pronounced for capital. Capital stocks in male headed enterprises are on average 5 times higher than in female headed enterprises. Together with decreasing marginal returns to capital this suggests inefficiencies in resource allocation.

\footnotetext{
${ }^{57}$ The constant terms that represent the efficiency parameter do not vary substantially between male and female headed enterprises.

${ }^{58}$ This refers to capital, labour and the experience and education of the enterprise head.
} 
To examine this question more carefully we apply and follow closely an approach used by Udry (1996) in an agricultural setting. Controlling for household characteristics (including unobservables), sectoral differences and observable enterprise characteristics we find that the value added of a female headed enterprise is between 25 to 40 percent lower than the average value added of a male headed enterprise. This result is inconsistent with pareto efficiency.

In a second step we calculate the optimal capital and labour allocation, based on a CES production function. We compare predicted value added using the actual resource allocation with predicted value added in the case where capital and labour are allocated optimally. Our results show that under the optimal resource allocation average value added increases by 20 percent. Comparing optimal and actual resource allocations shows that on average almost 200 Int. USD or 19 percent of the average capital stock would need to be re-distributed from the male to the female headed enterprise to reach the optimal allocation. Similarly, 20 hours per month or 6 percent of the average labour input would need to be reallocated from the male to the female headed enterprise. Decreasing returns and large initial imbalances of capital explain the direction of capital re-distribution in our simulation. The labour effect is a mixed effect of lower labour productivity in female headed enterprises, decreasing returns to labour and complementarities between labour and capital.

These results need to be interpreted with caution as evidence from a number of randomised control trials shows no effect of additional capital on female headed enterprises with an initial capital stock below a certain threshold (Fafchamps et al., 2011; Karlan and Zinman, 2010; De Mel et al., 2009). These studies provide limited insights into the underlying mechanisms and why no rise in profits for female enterprises can be observed. Although we can rule out differences in sectors, enterprise characteristics and unobservable household level variables as the drivers of differences in capital stock between male and female headed enterprises, other unobserved factors may be behind the differences. For example, it could be the case that time (or other) preferences differ between men and women. This could explain the lower capital stocks in female headed enterprises.

In addition to this optimization exercise we carry out an 'Oaxaca - Blinder' decomposition to examine the magnitude of differences in value added associated with endowments versus differences in production functions. We find that about 60 percent of the differences in predicted value added for men and women can be explained by differences in endowments. Differences in the coefficients of the production function account for about 40 percent. Hence, unequal distributions of capital between male and female headed enterprises combined with decreasing returns to capital, are the main driver of the inefficiencies we observe. 
Our findings show that households in urban Sub-Saharan Africa do not allocate resources optimally, so the distribution of labour and capital between men and women matters for final outcomes. These findings are in line with Udry (1996), who found potential gains from reallocating fertilizer and labour from plots controlled by men to plots controlled by women. It seems that the same pattern is observed in urban areas, with female enterprises using a sub-optimal amount of capital, just as they were allocated a sub-optimal amount of fertilizer in the rural context. The misallocation of capital and labour and hence the potential increase in value added in the urban enterprises appear to be larger than in the rural setting explored by Udry. 
Gender and the allocation of labour and capital in informal enterprises: Evidence from Sub-Saharan Africa 


\title{
Chapter 3
}

\section{The role of international trade for employment growth in micro- and small-enterprises: Evidence from developing Asia}

\begin{abstract}
We examine the role of international trade for employment growth in micro- and small enterprises (MSEs) using a representative sample of manufacturing firms in 6 Southeast Asian countries. In this sample, employment in firms in the bottom quintile of the initial size distribution grew the fastest and contributed considerably to overall employment creation. After controlling for firm and individual characteristics as well as country and sector dummies, participation in international trade plays a significant role in explaining this growth, boosting firm-level growth by 3 percent on average. Participating in international trade also increases the probability of being a top performing firm by 10 percent. The fact that firms start exporting soon after their foundation suggests that reverse causality is not an issue for our estimates. However, biases arising from unobserved heterogeneity cannot be ruled out. Therefore, we exploit the fact that firms were exposed to unexpected variation in real exchange rates between 2005 and 2008 to investigate the causal relationship between trade and employment growth. The results are inconclusive, because of the small sample size and, possibly, relatively weak instruments, but they do not suggest that the relationship is driven by unobserved heterogeneity. The education of the firm's owner, foreign ownership and firm age are also closely related to firm-level employment growth. Based on our findings we formulate recommendations for policy measures to boost employment growth in developing Asia.
\end{abstract}


The role of international trade for employment growth in micro- and smallenterprises: Evidence from developing Asia

\subsection{Introduction}

The motivation for this paper stems, firstly, from the importance of micro- and small enterprises (MSEs) as sources of employment in developing countries. Informal enterprises (which are MSEs in the majority of cases) account for 72 percent of non-agricultural employment in Sub-Saharan Africa, 51 percent in Latin America, and 65 percent in Asia, using the definition of the International Labour Organization (ILO, 2002). It has also been found that firms with 6 workers or fewer account for roughly 50 percent of employment in Latin America and substantially more in Africa and Southeast Asia (Fajnzylber et. al, 2006). Fox and Sohensen (2012) find that small scale household enterprises generated most new jobs outside agriculture, and that earnings from household enterprises have the same marginal effect on consumption as wage and salary employment.

Secondly, it has been observed empirically that, despite the severe constraints faced by MSEs in developing countries, a significant number of them have managed to grow, indicating that they do have potential to drive economic growth. However, based on the characteristics of these successful firms there appears to be a significant number of firms which have, so far, failed to realise their growth potential (Grimm et al., 2012). Helping small enterprises to grow is desirable not only to provide employment, but also to provide better employment. Wages in small enterprises tend to be low and it is usually difficult for the owner to provide workers with social security unless the firm can graduate into a larger and more efficient firm. In this context, it is important to understand what constraints prevent firms from realizing their growth potential. Lack of access to credit has been acknowledged by numerous authors as a fundamental constraint to business expansion, especially for MSEs (Dinh et al. 2010; Bigsten et al., 2003). However, other major constraints faced by MSEs such as business risk, or lack of access to markets, inputs and, technology have received less attention.

This paper focuses on the role of international trade for employment growth, with a special focus on MSEs. There are several ways in which participating in international markets can, in theory, help firms to overcome growth constraints. Exporting is one important channel to overcome the small size of local markets and low elasticity of demand. Empirical evidence also shows that exporting helps firms to grow and boost productivity through learning effects and the exploitation of economies of scale (van Biesebroeck, 2005). Similarly, firms in developing countries may be constrained in input markets: many inputs are not produced locally and most equipment is imported from abroad.

Using a representative sample of manufacturing firms in Indonesia, Malaysia, Lao People's Democratic Republic (PDR), Thailand, the Philippines and Vietnam we find that firms that started in the lowest quintile of the initial size distribution grew by about 20 percent annually, compared to about 10 percent for the average 
The role of international trade for employment growth in micro- and smallenterprises: Evidence from developing Asia

firm. ${ }^{59}$ Although small initial size reduces their contribution to overall employment creation even if growth rates are high, they nonetheless account for a substantial 15 percent of total employment creation. We also find that after controlling for firm and individual characteristics as well as country and sector dummies, participating in international trade boosts employment growth by 3 percent on average. In order to control for potential unobserved heterogeneity, we employ an instrumental variable approach, exploiting the 'natural experiment' created by unexpected variation in exchange rates caused by the economic and financial crisis that started in 2008. Although the results are inconclusive, they provide no evidence to suggest that the relationship between firm growth and participation in international trade is driven by endogeneity bias.

Using panel data from Bangladesh between 2007 and 2011 confirms our result from Southeast Asia. Using first differences estimation the results show that the correlation between participation in international trade and employment growth is significant and positive even after controlling for firm level unobservables.

To provide information for policy makers we define top performers as firms in the top quintile of the employment growth distribution. We find that about every third top performing firm started as an MSE and that participating in international trade or having an owner with a college degree increase the probability of being a top performer by about 10 and 5 percent respectively.

The remainder of the paper is organised as follows: section 3.2 provides an overview of the recent economic literature on constraints faced by enterprises in developing countries and the role of MSEs. Section 3.3 describes the empirical findings and section 3.4 concludes and derives policy implications.

\subsection{Literature review}

\section{The importance and potential of the MSE sector}

Evidence from around the world shows the importance of MSEs for employment especially in developing countries. ${ }^{60}$ Given the magnitude of the MSE sector, as described above, it is important to understand whether these enterprises are merely low-productivity, subsistence activities (Banerjee and Newman, 1993; Lloyd-Ellis and Bernhardt, 2000) or have the potential to grow and contribute to employment creation and economic growth (Grimm at al., 2012).

\footnotetext{
${ }^{59}$ Throughout this paper we measure enterprise growth by the annual growth in the number of full time employees since enterprise foundation.

${ }^{60}$ MSEs are frequently defined as firms with up to 5 permanent workers (Nichter and Goldmark, 2009; Liedholm, 2002).
} 
The role of international trade for employment growth in micro- and smallenterprises: Evidence from developing Asia

\section{Empirical evidence on heterogeneous MSE growth patterns}

McMillan and Woodruff (2002) provide evidence of the potential of newly founded firms, mostly small firms, in transitional and developing economies such as the Russian Federation, People's Republic of China (PRC), Poland and Vietnam. The example of Vietnam shows the potential of MSEs. Between 1992 and 1995 private sector employment grew by almost 2.5 million. These new jobs can almost all be attributed to the expansion of household enterprises in the retail and repair sectors and to small manufacturing firms. In the PRC newly founded, mostly small, enterprises contributed substantially to the fact that the share of industrial production by rural firms rose from 9 percent in 1978 to 30 percent in 1991. These examples in developing countries demonstrate the potential for small firm growth in developing and transitional economies.

Mead and Liedholm (1998) find that MSEs create almost twice as many jobs as formally registered large-scale enterprises in Botswana, Kenya, Malawi, Swaziland, and Zimbabwe, although overall employment growth in those countries was slow. The study also finds MSE growth to be heterogeneous. The authors show that most of the MSE growth can be attributed to a minority of enterprises- although even those added only a few workers. They find average annual growth rates of MSEs to be between 8 (Botswana) and 30 percent (Kenya). On average only 27 percent of all enterprises grew, creating 0.14 jobs per year on average. The study also analyses the income generated by MSEs and finds that returns to labour rise substantially once the enterprises consist of more than one person. This increase in efficiency is associated with higher levels of income for the employees and the enterprise owner.

Another study that examines firm growth over the past three years is Dinh et al. (2010). Using the World Bank enterprise surveys (WBESs) between 2006 and 2010 the study examines determinants of average annual firm growth in the past three years using cross-sectional data set, with almost 40,000 observations. The findings show that firm growth is highest for enterprises with fewer than 10 employees. Firms that had been established in the previous 5 years grew faster than older firms and average enterprise growth was lowest in East Asia and the Pacific and highest in South Asia. ${ }^{61}$ Following the growth diagnostic approach by Hausman et al. (2005) the study identifies financial constraints and informal sector competition as the most binding constraints to firm growth in developing countries. Though the study mentions firm heterogeneity between and within countries, the analysis does not include empirical results on country level.

Sleuwaegen and Goedhuys (2002) analyse the firm growth process in Côte d'Ivoire using a representative sample of manufacturing firms. The empirical results show a negative relationship between firm growth and firm age and size in

61 The other sub-regional groups are Sub-Saharan Africa, Europe \& Central Asia, Latin America \& Caribbean, and Middle East \& North Africa. 
The role of international trade for employment growth in micro- and smallenterprises: Evidence from developing Asia

Côte d'Ivoire. However, comparing firm growth by enterprise size between Côte d'Ivoire and Germany shows differences in firm growth patterns between developed and developing countries. This is an extreme example, as Germany is well known for its broad base of small and medium enterprises, but similar results are shown for other developed countries. ${ }^{62}$ Small enterprises grew relatively fast in Germany, resulting in the fact that 28 percent of today's large or medium firms (100 or more employees) started as micro enterprises (1-4 employees). In Côte d'Ivoire only a few large firms started small but larger enterprises (with more than 50 employees) grew faster than in Germany. The findings are consistent with a 'missing middle' in the firm size distribution in developing countries.

To sum up, the reviewed empirical literature on firm growth in developing countries shows that firm growth, in particular for MSEs which account for the majority of firms in most developing countries, is heterogeneous. In most countries only few MSEs show rapid growth. The next section sums up studies on different groups of constraints and identifies the research gap for the role of trade for employment growth in MSEs in Southeast Asia.

\section{What constraints impede MSE growth?}

We assume that the relatively high concentration of MSEs in developing countries and the heterogeneous growth patterns of these firms must be explained by certain constraints these enterprises face. An overview study by Nichter and Goldmark (2009) lends support to this hypothesis. The authors review the most influential studies on firm growth in developing countries of the past 50 years and identify four key factors that are associated with low firm growth in developing countries. These are: individual characteristics (e.g. education, gender, or work experience), firm characteristics (e.g. firm age, formality, firm size or access to finance), relational factors (e.g. value chains or social networks) and contextual factors (e.g. business environment). Since this study focuses on constraints related to access to markets, inputs and technology, the group of relational constraints is particularly relevant.

The set of constraints to MSE growth most relevant for this study originates from demand side issues, input unavailability and lack of technology. A small domestic market and hence limited domestic demand, potentially combined with a low elasticity of demand for the particular products commonly produced by MSEs, may impede firms from growing (Lachaud, 1990). Recent empirical evidence confirms the importance of this constraint (Böhme and Thiele, 2012).

Exporting is evidently a way to overcome the small size of local markets in developing countries (Bigsten et al., 2004; Diao et al. 2006). Empirical evidence from Asia and Africa shows that after entering the export market productivity increases occur, which can be largely attributed to the exploitation of scale

${ }^{62}$ See Stenkula (2006) for an overview of firm size distribution of European countries. 
The role of international trade for employment growth in micro- and smallenterprises: Evidence from developing Asia

economies (van Biesebroeck, 2005). ${ }^{63}$ Firms may also be constrained on input markets as certain inputs are not produced locally and most equipment used is imported from abroad.

In addition to the traditional pattern of exporting (i.e. from a developing country that has comparative advantage in relatively low skilled textile manufacturing to a developed country) falling transport costs and reductions of trade barriers, as well as rapid advancements in production technology, have made it possible for large international firms to 'slice up the value chain' (Krugman et al., 1995). This relatively new phenomenon of regional and global production networks means that it can be easier for firms to start exporting, as they can specialise in only one small step of the production process. This new trend is confirmed by the fact that production network trade has generally grown faster than total world trade in manufacturing (Athukorala, 2011).

Benefits from participating in global markets might also stem from the increasing presence of foreign firms. The evidence on whether the presence of foreign firms creates employment and boosts the success of domestic firms is ambiguous. As described by Markusen and Venables (1999) using the example of Taiwan, it can be the case that foreign firms create additional demand for local products and services, boosting firm growth. On the other hand it is argued that foreign firms compete with local firms both for markets and for skilled workers, and hence crowd out local firms (Aitken and Harrison, 1999). In addition to employment effects caused by the presence of foreign firms there might also be positive skill or technology spillover effects. ${ }^{64}$ However, empirical evidence on these spillover effects is mixed (Görg and Greenaway, 2004).

Given the rapid growth of opportunities for participation in international trade via production networks this paper focuses on the effects of engaging in international trade on employment growth in MSEs using data from 6 Southeast Asian economies. The MSE sector matters as it accounts for over 50 percent of employment in Asia. The constraint of access to markets, inputs, and technology is particularly relevant for the region as many countries either are plugged into, or would like to plug into, regional or global production networks. Therefore, this paper tries to fill the research gap on the effects on trade and investment liberalization on firm growth. In particular we will examine the following questions:

\footnotetext{
${ }^{63}$ See also Wagner (2012) for an overview of empirical studies examining the relationship between exporting and productivity.

${ }^{64}$ An example of such spillovers is the skills acquisition channel. Foreign firms provide training to workers and workers trained by foreign firms might later start working for a local firm.
} 
The role of international trade for employment growth in micro- and smallenterprises: Evidence from developing Asia

- Can we observe employment growth in MSEs and if so, do firms that started small contribute to overall employment growth?

- What role does participating in international trade play for employment growth?

- What are the characteristics of firms that grew particularly fast and what does this mean for policy makers?

\subsection{Empirical Analysis}

For our empirical analysis we use the WBESs from Malaysia and Thailand (2007) and Indonesia, Lao PDR, the Philippines and Vietnam (2009). The surveys are representative samples of registered manufacturing firms with 5 or more employees. The surveys in Indonesia, the Philippines and Vietnam also include firms in the service sector. The questionnaires used in Indonesia, the Philippines and Vietnam are identical. ${ }^{65}$

\subsubsection{General enterprise characteristics}

Our sample comprises almost 5,400 firms in these 6 Southeast Asian countries. ${ }^{66}$ Note that the employment growth rates and determinants of employment growth need to be interpreted with caution. Our data set is cross-sectional and therefore it includes only the firms that survived. Hence, all estimates for employment growth should be interpreted as upper bound figures. ${ }^{67}$

Enterprise growth is measured, for the purposes of this paper, by the growth of employment in firms. Measuring firm growth using other indicators such as profits or capital is not possible as these indicators are not measured consistently across countries.

Table 3-1 summarises the main enterprise characteristics. The results show significant employment growth. Firms in our sample started with 64 full time employees on average and had 114 employees when the surveys were carried out. The median values of the initial firm and current size are considerably lower, with a starting size of 20 employees and a current size of 40 employees. This shows that a small proportion of firms heavily influence the average numbers. The firms in our sample are relatively old, around 16 years on average. The mean and

\footnotetext{
65 For more information on the World Bank Enterprise Surveys see the following website: http://www.enterprisesurveys.org/.

${ }^{66}$ In order to avoid biased estimation results due to influential outliers we excluded the top 2 percent of firms in terms of absolute employment growth. This reduces the sample by about 160 observations.

${ }^{67}$ We examined major enterprise characteristics by firm age. They do not differ substantially across firm age quintiles. This suggests that the bias caused by firms that did not survive might be limited.
} 
The role of international trade for employment growth in micro- and smallenterprises: Evidence from developing Asia

median values of firm age are similar and do not vary substantially across countries.

The orientation towards international markets is somewhat limited - about three quarters of the output is sold domestically. The data allow us to further distinguish between direct and indirect exports. Directly exporting is the preferred mode - on average only 5 percent of the overall output is exported indirectly through an intermediary, while about 20 percent is exported directly. Thailand and Malaysia show the highest share of production being exported with an average of 27 and 34 percent respectively. We define firms that import inputs and also export as participants in international trade. Using this definition, about 21 percent of firms participate in international trade.

Table 3-1: General enterprise characteristics

\begin{tabular}{|c|c|c|c|c|c|c|c|c|c|c|c|}
\hline Country & & $\begin{array}{c}\text { Firm size } \\
\text { (full time } \\
\text { employees) }\end{array}$ & $\begin{array}{l}\text { Initial firm } \\
\text { size (full } \\
\text { time } \\
\text { employees) }\end{array}$ & $\begin{array}{l}\text { Output sold } \\
\text { domestically } \\
(\%)\end{array}$ & $\begin{array}{l}\text { Output } \\
\text { exported } \\
\text { directly } \\
(\%)\end{array}$ & $\begin{array}{c}\text { Output } \\
\text { exported } \\
\text { indirectly } \\
(\%)\end{array}$ & $\begin{array}{l}\text { Firms } \\
\text { that } \\
\text { import } \\
\text { inputs } \\
\text { and also } \\
\text { export } \\
(\%)\end{array}$ & $\begin{array}{l}\text { Female } \\
\text { owner }\end{array}$ & $\begin{array}{c}\text { Onwer } \\
\text { with } \\
\text { college } \\
\text { degree } \\
(\%)\end{array}$ & $\begin{array}{l}\text { Firm } \\
\text { age } \\
\text { (years) }\end{array}$ & $\begin{array}{c}\text { Foreign } \\
\text { ownership } \\
(\%)\end{array}$ \\
\hline \multicolumn{2}{|c|}{ Philippines mean } & 78.72 & 58.16 & 80.94 & 13.67 & 5.40 & 15.75 & 29.20 & 89.20 & 17.57 & 18.52 \\
\hline & $\mathrm{N}$ & 1130 & 1130 & 1130 & 1130 & 1130 & 1130 & 1130 & 1130 & 1130 & 1130 \\
\hline \multirow[t]{2}{*}{ Indonesia } & mean & 88.86 & 51.99 & 91.04 & 6.89 & 2.08 & 7.16 & 25.84 & 32.71 & 16.61 & 5.82 \\
\hline & $\mathrm{N}$ & 1076 & 1076 & 1076 & 1076 & 1076 & 1076 & 1076 & 1076 & 1076 & 1070 \\
\hline \multirow[t]{2}{*}{ Vietnam } & mean & 143.10 & 109.59 & 71.68 & 19.96 & 8.36 & 23.05 & 21.61 & 66.43 & 10.27 & 13.26 \\
\hline & $\mathrm{N}$ & 694 & 694 & 694 & 694 & 694 & 694 & 694 & 694 & 694 & 694 \\
\hline \multirow[t]{2}{*}{ Thailand } & mean & 161.34 & 71.94 & 73.29 & 23.81 & 2.90 & 29.71 & 33.09 & 69.26 & 14.02 & 21.31 \\
\hline & $\mathrm{N}$ & 976 & 976 & 976 & 976 & 976 & 976 & 976 & 976 & 976 & 619 \\
\hline \multirow[t]{2}{*}{ Malaysia } & mean & 129.54 & 48.84 & 66.46 & 28.82 & 4.72 & 36.53 & 8.82 & 43.51 & 18.98 & 21.47 \\
\hline & $\mathrm{N}$ & 1032 & 1032 & 1032 & 1032 & 1032 & 1032 & 1032 & 1032 & 1032 & 1031 \\
\hline \multirow[t]{2}{*}{ Lao PDR } & mean & 64.04 & 44.46 & 80.94 & 9.17 & 9.89 & 9.69 & 37.89 & 42.74 & 10.86 & 14.20 \\
\hline & $\mathrm{N}$ & 351 & 351 & 351 & 351 & 351 & 351 & 351 & 351 & 351 & 350 \\
\hline \multirow[t]{2}{*}{ Total } & mean & 113.62 & 63.50 & 77.52 & 17.67 & 4.81 & 21.22 & 24.81 & 58.87 & 15.58 & 15.66 \\
\hline & $\mathrm{N}$ & 5259 & 5259 & 5259 & 5259 & 5259 & 5259 & 5259 & 5259 & 5259 & 4894 \\
\hline
\end{tabular}

Notes: To correct for outliers we excluded the top 2 percent of firms that showed the highest increase in full time employees.

Source: Author's computations based on WBES.

Only every fourth enterprise owner in our sample is female (Table 3-1). The numbers do not vary substantially across countries. About 60 percent of all enterprise owners have a college degree. Indonesia is the only country where this number is lower than 35 percent. The average percentage of foreign ownership is roughly 15 percent. Taken together, the results of Table 3-1 show that, on average, firms grew, and that a considerable share of firms participates in international trade.

\subsubsection{Enterprise growth and the role of initial firm size}

Table 3-2 describes employment growth in the sample, applying 3 different employment growth measures. The first two columns Table 3-2 show the mean 
The role of international trade for employment growth in micro- and smallenterprises: Evidence from developing Asia

and median values of the simple annual average of employment growth and the compound average - these measures are also used by Mead and Liedholm (1998). The third column shows the average number of jobs that have been created since foundation per year.

Table 3-2: Employment growth in developing Asia

\begin{tabular}{|c|c|c|c|c|}
\hline & & $\begin{array}{l}\text { Average } \\
\text { annual growth } \\
\text { rate (simple } \\
\text { averages) }\end{array}$ & $\begin{array}{c}\text { Average } \\
\text { annual growth } \\
\text { rate } \\
\text { (compound) }\end{array}$ & $\begin{array}{c}\text { Av. No of } \\
\text { workers } \\
\text { added per } \\
\text { enterprise per } \\
\text { year }\end{array}$ \\
\hline \multirow[t]{3}{*}{ Philippines } & mean & $18.80 \%$ & $5.77 \%$ & 0.78 \\
\hline & median & $3.52 \%$ & $2.58 \%$ & 0.36 \\
\hline & $\mathrm{N}$ & 1130 & 1130 & 1130 \\
\hline \multirow[t]{3}{*}{ Indonesia } & mean & $19.17 \%$ & $8.77 \%$ & 2.43 \\
\hline & median & $6.10 \%$ & $4.14 \%$ & 0.33 \\
\hline & $\mathrm{N}$ & 1076 & 1076 & 1076 \\
\hline \multirow[t]{3}{*}{ Vietnam } & mean & $30.42 \%$ & $11.85 \%$ & 6.27 \\
\hline & median & $6.67 \%$ & $5.20 \%$ & 1.97 \\
\hline & $\mathrm{N}$ & 694 & 694 & 694 \\
\hline \multirow[t]{3}{*}{ Thailand } & mean & $51.92 \%$ & $18.13 \%$ & 9.76 \\
\hline & median & $20.00 \%$ & $9.46 \%$ & 4.27 \\
\hline & $\mathrm{N}$ & 976 & 976 & 976 \\
\hline \multirow[t]{3}{*}{ Malaysia } & mean & $28.72 \%$ & $8.24 \%$ & 5.11 \\
\hline & median & $10.61 \%$ & $5.89 \%$ & 1.76 \\
\hline & $\mathrm{N}$ & 1032 & 1032 & 1032 \\
\hline \multirow[t]{3}{*}{ Laos } & mean & $23.80 \%$ & $7.97 \%$ & 1.40 \\
\hline & median & $5.56 \%$ & $4.01 \%$ & 0.37 \\
\hline & $\mathrm{N}$ & 351 & 351 & 351 \\
\hline \multirow[t]{3}{*}{ Total } & mean & $28.84 \%$ & $10.11 \%$ & 4.40 \\
\hline & median & $8.00 \%$ & $5.14 \%$ & 1.10 \\
\hline & $\mathrm{N}$ & 5259 & 5259 & 5259 \\
\hline
\end{tabular}

Notes: Average annual growth rate (simple averages) is defined as:

$[(($ current employment - initial employment $)) /($ initial employment $)] /($ firm age $)$

Average annual growth rate (compound) is defined as:

$\left[((\text { current employment })(\text { initial employment }))^{\wedge}(1 /(\right.$ firm age $\left.))\right]-1$

Source: Author's computations based on WBES.

Our preferred measure of employment growth is the compound measure presented in column 2. Average growth rates ranged from 6 percent (Philippines) to 18 percent (Thailand). Median values of employment growth are about half of the average values, reflecting the heterogeneity between firms. Malaysia is the only country where mean and median employment growth figures are roughly 
The role of international trade for employment growth in micro- and smallenterprises: Evidence from developing Asia

similar, suggesting that the employment growth distribution in Malaysia is close to normal.

Since foundation, the average firm in our sample created about 4 jobs per year. The countries where the firms grew fastest also created the most jobs: in Thailand and Vietnam 10 and 6 jobs were created per firm, per year, on average. The average firm in the Philippines and Lao PDR only created about 1 job per year.

In sum, Table 3-2 shows that enterprises in our sample have grown by about 10 percent since their foundation but that growth patterns are heterogeneous between and within countries. The next section will examine differences in employment growth across the initial firm size distribution to examine how firms that started as MSEs contributed to employment growth.

\section{Do MSEs contribute to overall employment growth?}

Table 3-3 shows employment growth by initial size quintile. ${ }^{68}$ Firms that started in the bottom quintile of the initial size distribution grew by about 21 percent per year. In contrast, firms in the top quintile of the initial size distribution grew by only 1 percent by year. Columns 3 and 4 report the absolute number of jobs created by firms in our sample and the relative importance of the respective quintile for overall job creation.

\section{Table 3-3: Employment growth by initial size quintiles}

\begin{tabular}{ccccc}
$\begin{array}{c}\text { Quintile of } \\
\text { initial size } \\
\text { distribution }\end{array}$ & $\begin{array}{c}\text { Average } \\
\text { annual growth annual growth } \\
\text { rate (simple } \\
\text { averages) }\end{array}$ & $\begin{array}{c}\text { Average } \\
\text { rate } \\
\text { (compound) }\end{array}$ & $\begin{array}{c}\text { Jobs created } \\
\text { (absolute) }\end{array}$ & $\begin{array}{c}\text { Percentage of } \\
\text { jobs created }\end{array}$ \\
\hline 1 & $62.70 \%$ & $20.58 \%$ & 40,773 & $15.47 \%$ \\
2 & $28.85 \%$ & $11.49 \%$ & 36,385 & $13.80 \%$ \\
3 & $21.08 \%$ & $7.61 \%$ & 51,267 & $19.45 \%$ \\
4 & $15.35 \%$ & $6.26 \%$ & 78,299 & $29.71 \%$ \\
5 & $5.53 \%$ & $1.46 \%$ & 56,852 & $21.57 \%$ \\
Total & $28.84 \%$ & $10.11 \%$ & 263,576 & $100.00 \%$ \\
\hline
\end{tabular}

Notes: Average annual growth rate (simple averages) is defined as:

$[(($ current employment - initial employment $)) /($ initial employment $)] /($ firm age $)$

Average annual growth rate (compound) is defined as:

$\left[((\text { current employment })(\text { initial employment }))^{\wedge}(1 /(\right.$ firm age $\left.))\right]-1$

Quintiles computed by country

Source: Author's computations based on WBES.

Overall, the firms in our sample created about 260,000 jobs since their foundation. Firms in the bottom quintile of the initial size distribution created

${ }^{68}$ Note that the initial size quintiles are computed by country. 
The role of international trade for employment growth in micro- and smallenterprises: Evidence from developing Asia

about 41,000 jobs and hence accounted for about 15 percent of all created jobs. Based on the findings in Table 3-3 we conclude that firms in the bottom quintile of the initial size distribution contributed considerably to overall employment growth.

\subsubsection{What is the role of participating in trade for employment growth?}

Having confirmed the hypothesis that firms that started small contribute substantially to overall employment growth, we now test the hypothesis that access to imported inputs and/or foreign markets enables firms to exploit economies of scale and hence boosts employment growth. We use the following model to test this hypothesis:

$E G_{i j}=\beta_{0}+\beta_{1} X_{i j}+\beta_{2} \operatorname{trade}_{i j}+u_{i j}$

The dependent variable is enterprise growth $(E G)$ in firm $i$ located in country $j .{ }^{69}$ This is measured using the compounded measure of employment growth:

$\left[\left(\frac{\text { current employment }}{\text { initial employment }}\right)^{1 / \text { firm age }}\right]-1$

$X_{i j}$ in Equation (3.1) represents a vector of enterprise and individual characteristics. In particular, $X_{i j}$ includes: the number of full-time employees at enterprise foundation, the percentage of the firm that is owned by a foreign entity, a dummy that takes the value 1 if the enterprise owner is female, a dummy that takes the value 1 if the owner has a college degree, the firm's age, and the owner's experience in years.

To measure the effect of participating in international trade on employment growth we include a dummy that takes the value 1 if a firm exports and also imports inputs. ${ }^{70} \mathrm{We}$ also use export intensity (direct and indirect exports over sales) as a proxy for participation in international trade to check the robustness of the results. To make the interpretation of the coefficients straightforward we will use the dummy variable specification when discussing the magnitude of the trade effect, but the other results are available from the author on request. Using different proxies for participation in international trade does not alter the results. Furthermore, we control for heterogeneity across sectors and countries using a set of dummies. ${ }^{71}$ Finally, $u_{i j}$ represents a random error term.

\footnotetext{
${ }^{69}$ Although the data are cross-sectional, respondents were asked how many workers were employed in the firm when it was first established.

${ }^{70}$ The results are robust to variations in this definition (e.g. using an exporter dummy) and to omitting explanatory variable such as the size at enterprise foundation.

${ }^{71}$ The sectors chemicals, auto parts, furniture, office accounting and computing machinery, wood and wood products, non-metallic mineral products, basic metals, fabricated metal products, construction, and transport have been summarized under 'other manufacturing'. The sector dummy 'services' includes the following sub-sectors: hotels and restaurants, IT, wholesale, retail, and services of motor vehicles.
} 
The role of international trade for employment growth in micro- and smallenterprises: Evidence from developing Asia

\section{Potential biases}

It is important to be aware of a number of biases which may affect the estimation results. Measurement error will bias the results downwards, and this tendency is likely to be exacerbated by the fact that the dependent variable used is a change over time. The possibility of reverse causality between participating in international trade and employment growth should also be considered. The model we would like to test is that firms grow because of their participation in international trade, for instance because it allows them to exploit economies of scale. However, it is not implausible that firms are unable to export unless they are already profitable, and therefore growing, so the causality runs from growth to exports, rather than vice versa. If that was the case, our results would be biased upwards. However, despite the cross-sectional character of our data set, we know in which year a firm started exporting. The majority of firms for which these data are provided started exporting in the year the enterprise was set up or one year after. The fact that most firms export shortly after foundation means that the issue of reverse causality between exporting and employment growth is unlikely to be a serious cause of bias.

However, there is a strong possibility of endogeneity bias, which can make causal interpretation of results, and therefore policy implications, misleading. Endogeneity bias arises because it is difficult to isolate the causal effect of exporting on the employment growth of a firm from the effect of unobserved factors that are correlated with exporting. It is plausible that export status is correlated with unobserved factors such as motivation of the manager. Businesses run by highly motivated managers are likely to expand rapidly, even if they do not choose to export or do not succeed in exporting, and the motivated managers will also put more effort into seeking out export opportunities. In this case, an apparently large impact of trade on enterprise growth could, in reality, be largely a reflection of the higher motivation of the business owners.

Similar issues of endogeneity bias have been addressed in empirical studies that examine the effects of participating in international trade on productivity. One remedy is using full information maximum likelihood (Clerides et al, 1998). However, as noted by Bigsten et al. (2004) this approach can be sensitive to the assumptions on the joint error distribution. Another approach is to use matching techniques (de Loecker, 2007; Fernandes and Isgut, 2005; or Girma et al., 2004). The underlying idea behind this technique is to match starting exporters and nonexporters based on propensity score matching to get an idea how a firm would have performed if it had not started exporting. However, matching approaches are able to eliminate biases based only on observables. Given the cross-sectional nature of our data set it is not possible to use fixed-effects techniques to control for endogeneity. 
The role of international trade for employment growth in micro- and smallenterprises: Evidence from developing Asia

\section{An Instrumental Variable approach}

As means of controlling for the potential unobserved heterogeneity discussed above, we apply an instrumental variable (IV) approach, adapting the approach by Park et al. (2010) to our data set. The authors use the unforeseen exchange rate shocks in certain countries during the Asian crisis as a 'natural experiment'. Firms that exported to destination countries such as Thailand experienced heavy demand shocks due to exchange rate variations whereas companies exporting to Europe, for example, did not experience large shocks. The weighted average real depreciation of a firm's pre-crisis trade partners, which captures these exchange rate shocks, is therefore used as an instrument for the change in exports, in order to isolate the causal effect of exporting on productivity.

While Park et al. (2010) focused on the period of the Asian financial crisis, we exploit the variation in exchange rates caused by the financial and economic crisis that started with the collapse of Lehman Brothers in mid-September 2008. In contrast to the Asian crisis exchange rates between the Asian countries and US and Europe fluctuated. The two most common export destinations for our sample firms are Japan and the USA. A significant proportion of firms also export to Europe. $^{72}$ As the main export destinations and the proportions received by each vary by firm, exposure to the shocks varies.

The exchange rate shock variable is a suitable instrument if it is strongly related to export intensity, but unrelated to any unobserved factors. The latter is a reasonable assumption, as the exchange rate shocks experienced between 2005 and 2008 were largely unforeseen by firms (and indeed by economic analysts). The firms in the sample had no significant influence over these economic events, especially as the crisis is widely understood to have been triggered mainly by events in the US (Reinhart and Rogoff, 2009).

The first requirement will be met if trade intensity in 2008 is strongly related to the shock variable. This will be the case if firms who experience an exchange rate shock react by reducing the proportion of goods that they export. This is likely to occur if it is easier for them to re-orient sales towards the domestic market than to find new export partners, in the short term. In this case, the firms who experienced the bigger shocks would have lower export intensities than firms who experienced no shock, or a positive change. ${ }^{73}$

Exporting firms in three countries in our data set (Indonesia, the Philippines, and Vietnam) reported information on their two most important export partners. In

\footnotetext{
${ }^{72}$ About 40 percent of firms indicate either Japan or the USA as their top export destination. Ten percent of all firms report the European Union as their top export destination.

${ }^{73}$ Firms in our data set report exports and the shares of the two most important destination countries in 2008. Due to contracts that have to be fulfilled and have been negotiated before the crisis there could be some delay in the reaction of exporters. Hence, by using data from only 2008 it could be that we are underestimating the impact of the exchange rate shock on export intensities.
} 
The role of international trade for employment growth in micro- and smallenterprises: Evidence from developing Asia

line with Park et al. (2010) we compute the exchange rate shock for each destination country $j$ as follows:

ER_CHANGE $_{\mathrm{j}}=\left\{\left[\ln \left(\mathrm{E}_{\mathrm{j} 2008}\right)-\ln \left(\mathrm{P}_{\mathrm{j} 2008}\right)\right]-\left[\ln \left(\mathrm{E}_{\mathrm{j} 2005}\right)-\ln \left(\mathrm{P}_{\mathrm{j} 2005}\right)\right]\right\}$

In Equation (3.3), $\mathrm{E}_{\mathrm{jt}}$ is the nominal exchange rate (local currency unit per unit of the respective destination country currency) in year $\mathrm{t}$, and $P_{j, t}$ is the price level. ${ }^{74}$ We follow the approach of Park et al. (2010) and create a firm level indicator for exchange rate variations by weighting the exchange rate index by the share of sales destined for the respective destination country in 2008. We obtain a firmlevel exchange rate index:

ER_SHOCK $_{\mathrm{i}}=\mathrm{v}_{i, 1} * \mathrm{ER} \_C H A N G E_{1}+\mathrm{v}_{i, 2} * \mathrm{ER}_{-} \mathrm{CHANGE}_{2}$

The shares of the respective destination countries of firm $i$ are represented by $v_{1,2}$. The numbers 1 and 2 represent the two most important export destinations. ${ }^{75}$ If a firm only reports the share for the most important country, we give that country a weight of 100 percent. The larger the value of the ER_SHOCK variable, the larger the increase in the price of exported goods, on average, in the local currencies of the destination countries. Ceteris paribus, this would reduce exports. Using a firm level variable as an instrument has the advantage that we can still include country and sector dummies in the IV estimation.

Only cross-sectional data are available, so we focus on the relationship between the shock and export intensity in 2008, rather than on the change in exports between 2005 and 2008, as in the approach of Park et al. (2010).

It should be noted that using this approach restricts the sample to firms that export, around $30 \%$ of the sample. As well as reducing the sample size significantly, this means that the equation captures only part of the effect of trade on firm growth. If there is a large benefit to exporting, regardless of quantity (in other words, a non-linear effect), the IV approach will understate the benefits of exporting, as it is restricted only to those firms that export at least part of their production. $^{76}$

\section{Estimation results}

The results are reported in Table 3-4. Columns 1 to 4 report the ordinary least squares (OLS) results. In the first specification we include only the export

\footnotetext{
${ }^{74}$ Exchange rate data stem from the United Nations Conference on Trade and Development (UNCTAD) (2013) database. Data on consumer price indexes stem from the World Bank (2013) World Development Indicators (WDI)

${ }^{75}$ Averaged over all countries in our sample, 74 percent of all exports are destined for the two most important export destinations. Hence, the data constraint of having only data on the two most important export destinations is not critical for our analysis.

${ }^{76}$ Note that the information on export destination shares is very noisy. Only half of all exporters report consistent information on the destination countries and/or the respective shares.
} 
The role of international trade for employment growth in micro- and smallenterprises: Evidence from developing Asia

intensity variable and country and sector dummies, and use data from all 6 countries in the data set. In column 2 we add all control variables as described above. In the third column we use a dummy that takes the value 1 if a firm exports and also imports inputs as a proxy for participation in international trade. In column 4 we show the results using only data from the 3 countries that reported information on their export partners. These countries are the ones used in the IV estimates. In column 5 we report the results of the IV estimation, using the weighted exchange rate shock between 2005 and 2008 as an instrument for export intensity. In column 6 we report OLS estimates using the same sample that was used for the IV estimates. We use Vietnam as the reference country, and machinery and equipment as the reference sector.

The first four specifications show highly significant coefficients on the trade variables, which are stable across all specifications. These results are robust to a number of variations in the key variables. ${ }^{77}$ Another finding that is robust across all specifications is that firms that started small expand faster, controlling for other factors. ${ }^{78}$ The foreign ownership variable is significant and positive in models 2 to 4 . The coefficient is positive and of similar magnitude in all other specifications. The coefficient on the gender of the enterprise owner is negative in most specifications, and is significant for the sample used in the IV specification (only exporting firms). ${ }^{79}$ Education of the owner seems to matter - the dummy education variable is positive and significant in all specifications.

Including control variables leads to a considerable increase in the adjusted Rsquared, but has little effect on the trade variables. The estimates from the 6 country sample are of similar magnitude to the results using the 3 country sample (column 5).

\footnotetext{
${ }^{77}$ The results remain stable when running the regression by size and age groups and using alternative specifications of employment growth (absolute growth of employment or a log specification).

${ }^{78}$ The sign and magnitude of the age variable is in line with other studies such as Dinh et al. (2010) or Wignaraja (2012). One possible explanation for this result is that younger firms find it easier to adapt to new and more efficient production technologies, which enables them to grow faster. We also detected some evidence for a non-linear age effect when including age squared in the specification.

${ }^{79}$ This indicates that export firms headed by female entrepreneurs face particular barriers to employment growth. Further investigation would be needed to identify the reasons for this finding.
} 
The role of international trade for employment growth in micro- and smallenterprises: Evidence from developing Asia

Table 3-4: The Role of Trade for Employment Growth, OLS estimates

\begin{tabular}{|c|c|c|c|c|c|c|c|}
\hline & (1) & (2) & (3) & (4) & (5) & (6) & (7) \\
\hline & \multicolumn{6}{|c|}{ Methodology } & OLS \\
\hline \multirow[t]{2}{*}{$\begin{array}{l}\text { Export } \\
\text { intensity }\end{array}$} & $0.0110 * *$ & $0.0211^{* * *}$ & & $0.0185^{* * *}$ & $0.0313 * * *$ & 0.0638 & 0.0187 \\
\hline & $(0.0053)$ & $(0.0054)$ & & $(0.0041)$ & $(0.0093)$ & (0.1089) & $(0.0177)$ \\
\hline \multirow[t]{2}{*}{ Trade dummy } & & & $0.0302 * * *$ & & & & \\
\hline & & & $(0.0047)$ & & & & \\
\hline \multirow[t]{2}{*}{$\begin{array}{l}\text { Size at } \\
\text { foundation }\end{array}$} & & $-0.0002 * * *$ & $-0.0002 * * *$ & $-0.0001 * * *$ & $-0.0001 * * *$ & $-0.0001 * * *$ & $-0.0001 * * *$ \\
\hline & & $(0.0000)$ & $(0.0000)$ & $(0.0000)$ & $(0.0000)$ & $(0.0000)$ & $(0.0000)$ \\
\hline \multirow[t]{2}{*}{$\begin{array}{l}\text { Foreign } \\
\text { ownership, \% }\end{array}$} & & $0.0002 * * *$ & $0.0002 * *$ & $0.0002 * * *$ & 0.0001 & 0.0002 & 0.0002 \\
\hline & & $(0.0001)$ & $(0.0001)$ & $(0.0000)$ & $(0.0001)$ & $(0.0002)$ & $(0.0002)$ \\
\hline \multirow[t]{2}{*}{ College } & & $0.0149^{* * *}$ & $0.0127 * *$ & $0.0112^{* * *}$ & $0.0117 * *$ & $0.0387 *$ & $0.0371 *$ \\
\hline & & $(0.0039)$ & $(0.0039)$ & $(0.0031)$ & $(0.0059)$ & $(0.0205)$ & $(0.0204)$ \\
\hline \multirow[t]{2}{*}{ Firm age } & & $-0.0025^{* * *}$ & $-0.0025^{* * *}$ & $-0.0019 * * *$ & $-0.0019 * * *$ & $-0.0017 * *$ & $-0.0020 * * *$ \\
\hline & & $(0.0002)$ & $(0.0001)$ & $(0.0001)$ & $(0.0002)$ & $(0.0008)$ & $(0.0006)$ \\
\hline \multirow[t]{2}{*}{ Female GM } & & -0.0036 & -0.0026 & -0.0025 & 0.0041 & $-0.0362 * *$ & $-0.0344 * *$ \\
\hline & & $(0.0042)$ & $(0.0042)$ & $(0.0032)$ & $(0.0055)$ & $(0.0150)$ & $(0.0144)$ \\
\hline \multirow[t]{2}{*}{ Constant } & $0.0752^{* * *}$ & $0.1092 * * *$ & $0.1083 * * *$ & $0.0888^{* * *}$ & $0.0752 * * *$ & 0.0458 & $0.0668^{*}$ \\
\hline & $(0.0082)$ & $(0.0083)$ & $(0.0082)$ & $(0.0060)$ & $(0.0098)$ & $(0.0725)$ & $(0.0370)$ \\
\hline $\begin{array}{l}\text { Country } \\
\text { dummies }\end{array}$ & yes & yes & yes & yes & yes & yes & yes \\
\hline $\begin{array}{l}\text { Sector } \\
\text { dummies }\end{array}$ & yes & yes & yes & yes & yes & yes & yes \\
\hline $\begin{array}{l}\text { Test for } \\
\text { underidentifica } \\
\text { tion (p-value) }\end{array}$ & & & & & & 0.0018 & \\
\hline
\end{tabular}

\begin{tabular}{|c|c|c|c|c|c|c|c|}
\hline $\begin{array}{l}\text { Test for weak } \\
\text { identification } \\
\text { (F statistic) }\end{array}$ & & & & & \multicolumn{3}{|c|}{6.8140} \\
\hline $\mathrm{N}$ & 5327 & 4933 & 4930 & 4843 & 2679 & 308 & 308 \\
\hline $\begin{array}{l}\text { Adjusted R- } \\
\text { squared }\end{array}$ & 0.0506 & 0.1404 & 0.1442 & 0.1634 & 0.0774 & 0.1368 & 0.1505 \\
\hline
\end{tabular}

Notes: Robust standard errors in parentheses, ${ }^{*} \mathrm{p}<0.10, * * \mathrm{p}<0.05, * * * \mathrm{p}<0.01$, In all regressions, we drop influential outliers from our sample, identified using the DFITS-statistic. As suggested by Belsley et al. (1980), we use a cutoff-value $\mid$ DFITS $i j \mid>2 \sqrt{N / k}$ with $\mathrm{k}$, the degrees of freedom (plus 1) and N, the number of observations. Export intensity: Sales/Exports. Instrument used: In of weighted exchange rate shock of the 2 most important export destinations Source: Author's computations based on WBES. 
The role of international trade for employment growth in micro- and smallenterprises: Evidence from developing Asia

As could be expected from the descriptive statistics the Thailand dummy (not reported) is significant and positive. The other country dummies show that after controlling for individual and enterprise characteristics employment growth was significantly lower in Indonesia and the Philippines than in Vietnam. Firms in the electronics sector show the highest growth rates after controlling for country effects and individual and enterprise characteristics.

However, as described above, these results should be interpreted with caution because of the strong possibility that they are affected by endogeneity bias. Therefore, in column 5 we introduce the IV approach described above. We report the second stage IV estimates in column 5. The first stage estimates (see Appendix for the complete results) show the expected negative and highly significant (t-value:-2.61) relationship between export intensity and our exchange rate shock index.

The null hypothesis of underidentifcation is rejected at a 5 percent confidence level. ${ }^{80}$ However, an F Test of whether all excluded instruments are significant suggests that the instrument may be weak. This test in our data set has an F-value of 6.8. According to thresholds defined in Stock et al. (2002) this means that the null hypothesis (the instrument is insignificant) can be rejected only on a 20 percent level. ${ }^{81}$

As explained by Stock et al. (2002), the presence of weak instruments leads to unreliable point estimates, and confidence intervals. This means that the IV estimates should be interpreted with caution, and is likely to explain the fact that the IV specification provides only weak evidence for the impact of trade on employment growth. Neither specification shows a significant coefficient for trade intensity. However, the fact that the coefficient does not change sign, and remains of a similar magnitude is encouraging. Large swings in the coefficient and implausible magnitudes are common characteristics of weak instruments. Also, the first stage results indicate that the exchange rate shocks did affect trade intensity, supporting the appropriateness of this instrument. Another factor behind the lack of a significant result in the IV specification is that the data on export destinations and export shares are very noisy, so many observations need to be dropped, resulting in a small sample size.

As a further robustness check of our results we estimated 3.1 using firm level panel data from the WBESs carried out in Bangladesh in 2007 and 2011. We use total value of exports in int. USD as a proxy for trade. The results are reported in Table 3-9. The first two columns show the results using cross-sectional data from

\footnotetext{
${ }^{80}$ See Baum et al. (2003) for details. In the case of one endogenous regressor and one instrument the null hypothesis of this test is that the correlation matrix between this regressor and the instrument is non-zero.

${ }^{81}$ The results do not change when using Tobit estimation techniques in the first stage regression or using the exchange rate shock between 2006 and 2008. Results are available on request from the author.
} 
The role of international trade for employment growth in micro- and smallenterprises: Evidence from developing Asia

2007 with and without control variables. Column 3 shows results using first differences estimation techniques and panel data from 2007 and 2011. The results show that the correlation between participation in international trade and employment growth is significant and positive even after controlling for firm level unobservables. The example from Bangladesh is encouraging and lends support to the view that firm level unobservables do not substantially bias our results for Southeast Asia.

Taken together, the evidence suggests (subject to the potential biases mentioned above) that participating in international trade raises employment growth. After controlling for sector and country effects as well as differences in firm and individual characteristics employment growth in firms that export and also import inputs was about 3 percent higher than in all other firms. The results are robust to variations in the trade variable and also to variations in the countries included. ${ }^{82}$

\subsubsection{Who are the top performers in terms of employment growth?}

\section{Firm characteristics}

In order to derive suggestions for policy measures, we now examine the characteristics of the firms that have grown the most since their foundation. We define top performers as enterprises in the top quintile of employment of each respective country. ${ }^{83}$ Table $3-5$ shows differences in firm and individual characteristics between top performers and all remaining firms.

Overall, the results show that top performers and the remaining firms differ significantly in all categories except for the education of the owner and the percentage of female owners. ${ }^{84}$ About every fourth top performer is participating in international trade, compared to every fifth firm that is not defined as a top performer. Also top performers started significantly smaller, which is in line with the findings of Tables 3-3 and 3-4. Again the median values for initial size are smaller than mean values, reflecting the skewed initial size distribution. The results also show that every third top performing firm started as an MSE (less than 5 employees). Top performers are on average about 10 years younger. This may reflect the better capability to adopt new technologies that increase productivity. However, this effect may also be caused by firms closing down if they did not grow fast enough.

\footnotetext{
${ }^{82}$ We ran separate regressions including only Malaysia and Thailand and a separate regression including only Indonesia, Lao PDR, the Philippines and Vietnam. The main findings were not altered. Results are available from the author on request.

${ }^{83}$ We also used the approach by Grimm et al. (2012) to define top performers. Our main findings are robust to using this productivity oriented definition of a top performer. Results are available from the author on request.

${ }^{84}$ The results are based in a $\mathrm{T}$ test assuming unequal differences between the groups.
} 
The role of international trade for employment growth in micro- and smallenterprises: Evidence from developing Asia

Table 3-5: Characteristics of top performers

\begin{tabular}{|c|c|c|c|c|c|c|c|c|c|}
\hline & & $\begin{array}{l}\text { Participating } \\
\text { in } \\
\text { international } \\
\text { trade }(\%)\end{array}$ & $\begin{array}{l}\text { Initial } \\
\text { firm } \\
\text { size }\end{array}$ & $\begin{array}{l}\% \text { Firms } \\
\text { started was } \\
\text { MSE (less } \\
\text { than } 5 \\
\text { employees) }\end{array}$ & $\begin{array}{c}\text { Firm } \\
\text { age }\end{array}$ & $\begin{array}{l}\text { General } \\
\text { Manager } \\
\text { expertise }\end{array}$ & $\begin{array}{c}\text { Owner } \\
\text { has } \\
\text { college } \\
\text { degree } \\
(\%)\end{array}$ & $\begin{array}{c}\text { Female } \\
\text { General } \\
\text { Manager } \\
(\%)\end{array}$ & $\begin{array}{c}\text { Foreign } \\
\text { ownership } \\
(\%)\end{array}$ \\
\hline \multirow[t]{3}{*}{ Top performers } & mean & $25.50 \%$ & 22.55 & $27.32 \%$ & 8.47 & 11.04 & $59.98 \%$ & $25.41 \%$ & $20.76 \%$ \\
\hline & median & 0 & 10 & 0 & 7 & 9 & 1 & 0 & 0 \\
\hline & $\mathrm{N}$ & 1047 & 1047 & 1047 & 1047 & 1015 & 1047 & 1047 & 974 \\
\hline \multirow[t]{3}{*}{ Remaining firms } & mean & $20.16 \%$ & 73.68 & $9.45 \%$ & 17.35 & 14.27 & $58.59 \%$ & $24.67 \%$ & $14.40 \%$ \\
\hline & median & 0 & 20 & 0 & 15 & 12 & 1 & 0 & 0 \\
\hline & $\mathrm{N}$ & 4212 & 4212 & 4212 & 4212 & 4101 & 4212 & 4212 & 3920 \\
\hline $\mathrm{T}$ test result & & $* * *$ & $* * *$ & $* * *$ & $* * *$ & $* * *$ & & & $* * *$ \\
\hline \multirow[t]{3}{*}{ Total } & mean & $21.22 \%$ & 63.50 & $13.01 \%$ & 15.58 & 13.63 & $58.87 \%$ & $24.81 \%$ & $15.66 \%$ \\
\hline & median & 0 & 20 & 0 & 13 & 11 & 1 & 0 & 0 \\
\hline & $\mathrm{N}$ & 5259 & 5259 & 5259 & 5259 & 5116 & 5259 & 5259 & 4894 \\
\hline
\end{tabular}

Notes: $* \mathrm{p}<0.10, * * \mathrm{p}<0.05, * * * \mathrm{p}<0.01$ of $\mathrm{T}$ test assuming unequal variances between groups testing hypothesis that the group means are equal.

Source: Author's computations based on WBES.

For top performers the experience of the owner exceeds the firm age, whereas for the other firms the firm age exceeds the years of experience of the owner, on average. So even if one assumes that the owner has worked in the top performing enterprise since its foundation she would have had on average about 3 years of experience when she started working for the company. For the remaining firms it could be that the recent owner who has fewer years of experience than the firm age took over the business from a family member. Such enterprises might find it harder to adopt new production technologies. The percentages of firms whose owner have a college degree or are female do not vary significantly between top performers and other firms. Finally, top performers have a significantly higher percentage of foreign ownership. This is plausible - being part of an international company may facilitate intra-firm knowledge spillovers.

To learn more about the relative importance of the determinants of being a top performer we run a probit model of the following form:

Top performer por $_{i j}=$

$\beta_{0}+\beta_{1} X_{i j}+$ sector dummies + country dummies $+\varepsilon_{i j}$

The dependent variable in Equation (3.5) is a dummy that takes the value 1 if firm $i$ in country $j$ is a top performer. The vector $X$ includes the control variables that were used in Table 3-5. The coefficients and marginal effects from estimating (3.5) are reported in Table 3-6. The Pseudo R squared shows that the chosen indicators are able to explain a substantial part of whether or not firms are top 
The role of international trade for employment growth in micro- and smallenterprises: Evidence from developing Asia

performers. The results show that the gender and expertise of the owner do not significantly influence the likelihood of being a top performer.

Table 3-6: Probit estimates: dependent variable, being a top performer

\begin{tabular}{lcc} 
& Probit & Marginal effects \\
\hline Participation in international trade & $0.4325^{* * *}$ & $0.0941^{* * *}$ \\
Firm size at foundation & $(0.0688)$ & $(0.0147)$ \\
Firms age & $-0.0072 * * *$ & $-0.0016 * * *$ \\
& $(0.0011)$ & $(0.0008)$ \\
GM expertise & $-0.0917 * * *$ & $-0.0200 * * *$ \\
& $(0.0045)$ & $(0.0008)$ \\
Owner has college degree & 0.0028 & 0.0006 \\
Female GM & $(0.0030)$ & $(0.0006)$ \\
& $0.2426 * * *$ & $0.0528 * * *$ \\
\% of foreign ownership & $(0.0600)$ & $(0.0129)$ \\
& -0.0701 & -0.0152 \\
Constant & $(0.0569)$ & $(0.0124)$ \\
& $0.0021 * * *$ & $0.0004 * *$ \\
Country dummies & $(0.0008)$ & $(0.0002)$ \\
Sector dummies & $0.5227 * * *$ & \\
\hline N & $(0.1007)$ & yes \\
\hline
\end{tabular}

Notes: Robust standard errors in parentheses

Source: Author's computations based on WBES.

Initial firm size and the percentage of foreign ownership show significant marginal effects, although the coefficients are very small. Furthermore, the results show that younger firms are more likely to be top performers. Since top performers and other firms do not differ substantially in terms of the owner's education the positive and significant coefficient on the college dummy is unexpected. However, this effect only occurs when we also control for firm age. Hence, the reason for the change of significance in the education variable is that more educated persons tend to be owners of older firms. This means that not considering firm age 'hides' the effect of education. After controlling for firm age, having a college degree increases the probability of being a top performer by roughly 5 percent. The marginal effect of participating in international trade is even bigger. The results show that participating in international trade increases 
The role of international trade for employment growth in micro- and smallenterprises: Evidence from developing Asia

the probability of being in the top quintile of employment growth by about 10 percent.

The country dummies show that, all else equal, the probability of being a top performer is highest in Malaysia, which was chosen as the reference category. This result may be driven by a rapidly expanding rubber sector in Malaysia. The results from the sector dummies show that being in the machinery or services sector significantly lowers the probability of being a top performer. These findings need to be interpreted with caution as the hypothesis that the sector dummies are jointly zero can only be rejected on 5 percent confidence level, according to a joint $F$ test.

The marginal effect estimates should also be interpreted with caution. The potential issues of reverse causality and unobserved heterogeneity discussed in the context of Table 3-4 apply also to the results presented in Table 3-6. Hence, the results are correlations rather than causal links. In addition, our data set only includes firms that survived until the date of the survey. Not accounting for unsuccessful business ventures biases our result upwards. Nonetheless, the findings that education and participating in trade substantially increase the probability of being a top performer are both interesting and relevant for policy makers in Asia.

\section{Sectoral distribution of top performers}

To design targeted policies to foster employment growth it is also important to know which sectors are home to successful entrepreneurs. To examine the sectoral division of top performers Table 3-7 shows the percentage of top performers by country group and sector. Sector definitions are identical in Indonesia, the Philippines and Vietnam and very similar in Thailand and Malaysia. Therefore we present the findings by country group. ${ }^{85}$

\footnotetext{
${ }^{85}$ The data for Lao PDR only distinguish between services and manufacturing. The top performers are approximately evenly distributed between the two groups.
} 
The role of international trade for employment growth in micro- and smallenterprises: Evidence from developing Asia

Table 3-7: Top performers by sector and country group (percent)

\begin{tabular}{|c|c|c|c|c|}
\hline & Indonesia, Philippines and & etnam & Malaysia and $\mathrm{Tl}$ & ailand \\
\hline & sector & $\begin{array}{c}\% \text { of top } \\
\text { performers }\end{array}$ & sector & $\begin{array}{c}\% \text { of top } \\
\text { performers }\end{array}$ \\
\hline 1 & Garments & 14.70 & Rubber & 23.44 \\
\hline & Food Processing & 14.53 & Electronics & 13.40 \\
\hline 3 & Non metallic mineral products & 11.66 & Food Processing & 12.92 \\
\hline 4 & Textiles & 10.64 & Furniture & 11.96 \\
\hline 5 & Other manufacturing & 9.97 & Garments & 9.81 \\
\hline 6 & Rubber & 9.12 & Automobile and parts & 9.57 \\
\hline & Chemicals & 8.45 & Machinery & 7.18 \\
\hline 8 & Electrical Machinery and Apparatus & 6.25 & Textiles & 6.22 \\
\hline & Retail & 4.73 & Chemicals & 3.59 \\
\hline & Fabricated metal products & 4.56 & $\begin{array}{l}\text { Wood and wood } \\
\text { products }\end{array}$ & 1.20 \\
\hline 11 & IT & 1.18 & $\begin{array}{l}\text { Office accounting and } \\
\text { computing machine }\end{array}$ & 0.72 \\
\hline & Machinery & 1.01 & & \\
\hline & Basic metals & 0.84 & & \\
\hline & Transport & 0.84 & & \\
\hline & Construction & 0.68 & & \\
\hline & Wholesale & 0.51 & & \\
\hline & Services of motor vehicles & 0.17 & & \\
\hline & Hotel and restaurants & 0.17 & & \\
\hline To & & 100.00 & & 100.00 \\
\hline
\end{tabular}

Source: Author's computations based on WBES.

In Table 3-7 we sorted the sectors in descending order according to the percentage of top performers. The concentration of top performers is highest in Indonesia, the Philippines and Vietnam where about 20 percent of all sectors include 50 percent of all top performers. In Malaysia and Thailand about 30 percent of all sectors account for 50 percent of the top performers. Note however that every fourth top performing firm is in the rubber sector in Malaysia and Thailand. In both country groups garment and food processing are among the top 5 sectors. However, the share of top performers in high technology industries such as electronics is about 13 percent in Thailand and Malaysia. This is almost twice as high as in Indonesia, the Philippines and Vietnam.

\subsection{Conclusions}

The motivation for this paper stems from the empirical observation that, despite the severe constraints faced by MSEs in developing countries, an important number of them have the potential to grow (Grimm et al., 2012). In particular, we 
The role of international trade for employment growth in micro- and smallenterprises: Evidence from developing Asia

examine the role of participating in international trade for employment growth. We use firm level data from the World Bank Enterprises Surveys in Indonesia, Lao PDR, Malaysia, Thailand, the Philippines and Vietnam. Due to the crosssectional nature of our data set the findings should be interpreted as correlations rather than causal relationships. Although an IV approach was employed to deal with the potential endogeneity issues, the findings are inconclusive. We examine the following questions:

- Can we observe employment growth in MSEs and if so, do firms that started small contribute to overall employment growth?

Using a compounded measure of employment growth we find that firms in the bottom quintile of the initial size distribution grew on average by 20 percent per annum, which is significantly higher than the overall average employment growth rate of about 10 percent. Our results also show that 15 percent of all jobs created by firms in our sample were created by firms in the bottom quintile of the initial size distribution. Based on these results, we conclude that firms that started small contributed considerably to overall employment growth.

- How does participating in international trade contribute to employment growth?

We find that, after controlling for firm and individual characteristics, firms that export and also import inputs grew on average 3 percent faster than all remaining firms, after controlling for country, sector and individual characteristics.

These results need to be interpreted with caution as the sample only includes firms that survived until the date of the survey. Not controlling for unsuccessful firms biases our results upwards. Furthermore, given the variables included in our data set, we cannot rule out the issue of endogeneity between participating in international trade and employment growth. However, the fact that firms start exporting quickly after the foundation lends support to the hypothesis that participating in international trade causes employment growth and not vice versa. The results of the IV estimation do not show a significant effect of trade on employment growth, possibly because the only available instrument is somewhat weak and the sample is small. However, they provide no evidence to suggest that endogeneity is driving the relationship. Also, the first stage estimation results are very similar to Park et al. (2010) who use exchange rate fluctuations during the Asian crisis as an instrument for trading. Further investigation using this IV approach with a larger sample and more precise data could be fruitful. Our findings are in line with other studies such as Dinh et al. (2010) and support the hypothesis that participating in international trade boosts employment growth.

A panel data approach using data from Bangladesh between 2007 and 2011 further confirms our result from Southeast Asia. Using first differences estimation 
The role of international trade for employment growth in micro- and smallenterprises: Evidence from developing Asia

the results show that the correlation between participation in international trade and employment growth is significant and positive even after controlling for firm level unobservables.

\section{What are the characteristics of firms that grew particularly fast?}

We define top performing firms as firms in the top quintile of the employment growth distribution. The results show the high potential of MSEs, as every third top performing enterprises started with fewer than 5 employees. Using probit estimates we show that in addition to participating in international trade, which is associated with a 10 percent boost in the likelihood of being a top performer, the education level of the enterprise owner matters. After controlling for country, sector and other individual and firm characteristics, the results show that the owner having a college degree increases the likelihood of being a top performer by 5 percent. In addition to education of the owner and participating in trade younger firms have a higher probability of being top performers.

What does this mean for policy makers?

The findings that participating in international trade is associated with employment growth and that MSEs play an important role for employment growth suggest that policymakers could boost growth and therefore job creation by making it easier for firms to plug into international trade networks. A number of measures could be considered, such as simplification of customs procedures for MSEs or small volumes of exports, provision of information on customs procedures, or provision of export credit or guarantee products designed to be accessible to MSEs.

Given the finding that education increase employment growth, these sorts of measures are likely to be most effective if they are combined with improved access to and quality of training. Training could cover issues such as the regulations and norms that are necessary to participate in international trade (e.g. quality standards for exports or import regulations to obtain raw materials that cannot be sourced domestically). The findings also suggest that entrepreneurs who are already educated and have some experience are more likely to initiate successful enterprises, and may therefore be more likely to benefit from training. Hence, training and information campaigns could be most effective if they are targeted at persons with a certain minimum of education.

The finding that most firms start exporting soon after establishment also has policy implications. Advice and training on how to plug into international trade networks should be available to potential entrepreneurs even before the establishment of an enterprise.

We observe that only every fourth entrepreneur is female. This may reflect the fact that due to, for example, social norms, potentially talented female 
The role of international trade for employment growth in micro- and smallenterprises: Evidence from developing Asia

entrepreneurs lack the opportunity to establish enterprises in the first place. Overall, the data do not allow us to make specific recommendations for targeting either male or female entrepreneurs, but access to training or other interventions should certainly be open to both genders.

Our results on the question of which sectors are promising are inconclusive. In general, targeting of specific gender groups and sectors needs to be decided case by case depending on a detailed analysis of the national context. 
The role of international trade for employment growth in micro- and smallenterprises: Evidence from developing Asia

\section{Appendix A-3 - First stage results}

\section{Table 3-8: First stage estimation results}

\begin{tabular}{lc}
\multicolumn{2}{c}{ Dependent variable Export intensity } \\
\hline Exchange rate shock & $\mathbf{- 0 . 6 8 4 * *}$ \\
Size at foundation & 0.000 \\
& $(0.000)$ \\
foreign ownership, $\%$ & 0.001 \\
& $(0.000)$ \\
College & -0.049 \\
& $(0.057)$ \\
Firm age & $-0.005^{*}$ \\
& $(0.002)$ \\
Female GM & 0.043 \\
& $(0.041)$ \\
Constant & $0.622^{* * *}$ \\
& $(0.097)$ \\
\hline Country dummies & yes \\
Sector dummies & yes \\
\hline R-squared & 0.196 \\
N & 308 \\
\hline
\end{tabular}

Notes: * $\mathrm{p}<0.05, * * \mathrm{p}<0.01, * * * \mathrm{p}<0.001$.

Source: Author's computations based on WBES. 
The role of international trade for employment growth in micro- and smallenterprises: Evidence from developing Asia

Appendix B-3 - Results using panel data from Bangladesh

Table 3-9: Firm growth and trade - panel estimations

\begin{tabular}{|c|c|c|c|}
\hline \multirow[b]{2}{*}{ Methodology } & (1) & (2) & (3) \\
\hline & $\begin{array}{l}\text { Pooled OLS } \\
\text { (dependent } \\
\text { variable: } \\
\text { compound } \\
\text { enterprise } \\
\text { growth } \\
\text { since } \\
\text { foundation) }\end{array}$ & $\begin{array}{l}\text { Pooled OLS } \\
\text { (dependent } \\
\text { variable: } \\
\text { compound } \\
\text { enterprise } \\
\text { growth since } \\
\text { foundation) }\end{array}$ & $\begin{array}{c}\text { First } \\
\text { differences } \\
\text { (dependent } \\
\text { variable: } \\
\text { employment } \\
\text { growth } \\
\text { between } \\
2007 \text { and } \\
2011 \text { ) }\end{array}$ \\
\hline Data & $\begin{array}{c}\text { cross- } \\
\text { section } \\
2007\end{array}$ & $\begin{array}{c}\text { cross-section } \\
2007\end{array}$ & $\begin{array}{c}\text { panel 2007- } \\
2011\end{array}$ \\
\hline \multirow[t]{2}{*}{ Exports (in 10,000 int. USD) } & $0.000 * * *$ & $0.001 * * *$ & $1.453 * * *$ \\
\hline & $(0.000)$ & $(0.000)$ & $(0.518)$ \\
\hline \multirow[t]{2}{*}{ size at enterprise foundation } & & $-0.000 * * *$ & \\
\hline & & $(0.000)$ & \\
\hline \multirow[t]{2}{*}{ Firm age } & & $-0.002 * * *$ & \\
\hline & & $(0.000)$ & \\
\hline \multirow[t]{2}{*}{ College } & & $0.019 * * *$ & \\
\hline & & $(0.004)$ & \\
\hline \multirow[t]{2}{*}{ Female GM } & & 0.002 & \\
\hline & & $(0.011)$ & \\
\hline \multirow[t]{2}{*}{ Constant } & $68.069 * * *$ & $0.070 * * *$ & -29.009 \\
\hline & $(9.074)$ & $(0.008)$ & $(68.287)$ \\
\hline Country dummies & yes & yes & no \\
\hline Sector dummies & yes & yes & no \\
\hline $\mathrm{N}$ & 1097 & 1089 & 200 \\
\hline Adjusted R-squared & 0.041 & 0.203 & 0.017 \\
\hline
\end{tabular}

Notes: In the first two columns we correct for influential outliers using the methodology of Belsley et al. (1980).

Source: Author's computation based on WBES. 
The role of international trade for employment growth in micro- and smallenterprises: Evidence from developing Asia 


\title{
Chapter 4
}

\section{Firm size dynamics and implications for inequality: Evidence from Thailand*}

\begin{abstract}
We examine the role of firm size dynamics in wage inequality in Thailand between 1995 and 2005 using data from the Thai Labour Force Surveys (LFS). Over this time period wage inequality rose, contrary to the trend for overall income inequality. The data reveal a 'missing middle' pattern in Thailand's firm distribution and a clear correlation between firm size and wages, even controlling for other factors. A regression based decomposition analysis confirms that the firm size distribution plays a significant role in explaining wage inequality, which is significant even controlling for region, sector and education level of workers. The 'missing middle' became more accentuated between 1995 and 2005 . Although wages converged at the bottom of the firm size distribution, the gap between wages paid by the smallest and largest firms increased. The overall effect of the change in relative wages was mildly disequalizing.
\end{abstract}

\footnotetext{
${ }^{*}$ The author would like to thank Nina Fenton for valuable comments.
} 


\subsection{Introduction}

In this paper we examine the implications of firm size dynamics, including the role of micro and small enterprises (MSEs) for inequality, by examining the relationship between the firm size distribution and wage inequality in Thailand between 1995 and 2005. ${ }^{86}$ We use data from the Thai Labour Force Surveys (LFS) of 1995 and 2005.

Much of the academic and policy debate about the firm size distribution in developing countries has related to the phenomenon of 'dualism' or the 'missing middle'. As discussed by Tybout (2000) and by Ayyagari et al. (2003) the firm size distribution in developing countries tends to be characterized by a large number of small and micro enterprises, which coexist with a small number of large enterprises (despite being small in number, these large enterprises may nonetheless be significant providers of employment). Medium-sized enterprises are found to be underrepresented, relative to developed countries. The reasons for this pattern and its implications for the growth of Gross Domestic Product (GDP) and employment have been the subject of lively debate, based on both theoretical and empirical work.

Inequality is also a subject of keen interest. The so-called 'Kuznets hypothesis' suggested that developing countries are likely to experience rising income inequality alongside economic growth, with inequality beginning to fall only after they reach a particular level of per capita income. ${ }^{87}$ However, more recent evidence (see for example Deininger and Squire, 1998 and Fields, 1989) indicates that this relationship is neither universal nor inevitable. This raises the possibility that, with appropriate measures, policymakers may be able to reduce or limit inequality.

Policies aiming to influence the firm size distribution have frequently been suggested as effective measures to reduce inequality or mitigate its rise, particularly in developing countries. ${ }^{88} \mathrm{~A}$ number of governments and development agencies have invested, directly or indirectly, in supporting MSEs with the explicit aim of reducing inequality or promoting 'inclusive growth' ${ }^{89}$ These policies could have substantial implications for inequality, as well as for

\footnotetext{
${ }^{86}$ Although the rest of this thesis focuses on informal enterprises, it is difficult to distinguish informal from formal enterprises using the data analyzed in this chapter, because the surveys focus on labour force participants rather than firms. As explained in the introduction to this thesis, the ILO uses firm size as one criterion in an operational definition of an informal enterprise. In practice there is substantial (although incomplete) overlap between MSEs and informal enterprises. Therefore, this paper focuses on the firm size distribution, regardless of formal registration status. We believe that the findings will nonetheless be relevant to the academic and policy debate on the informal sector.

${ }^{87}$ This hypothesis stems from the frequently-quoted work of Simon Kuznets (Kuznets, 1963).

${ }^{88}$ See for example: OECD (2013), which discusses inequality as a key topic for international policy debate.

${ }^{89}$ Inequality and the importance of MSEs for inclusive growth are stressed for instance in the strategy 2020 of the Asian Development Bank (ADB) (ADB 2010, 2008). Projects such as the 'Inclusive Micro, Small, and Medium-Sized Enterprise Development Project' (ADB) confirm that support to MSEs is seen as a priority development intervention by development partners and governments in Asia.
} 
growth and employment. Yet the links between the firm size distribution and inequality have received relatively little attention in the literature. The nature of the relationship cannot be understood a priori, but must be analysed using empirical evidence, providing the motivation for this chapter.

Thailand was selected as a case study for a number of reasons. Firstly, although a number of existing studies examine firm size dynamics (Mead and Liedholm, 1998, Wiboonchutikula, 2002, and OECD, 2002), labour market changes (ILO, 2013) and inequality dynamics (Bird et al., 2011; Warr, 2004) in Thailand, there has been little or no analysis of linkages between the firm size distribution and inequality.

Secondly, the pattern experienced by Thailand during the period analysed relatively rapid growth with poverty reduction and stable income inequality makes this an interesting example for both the academic debate and policy makers. Economic growth in Thailand was relatively robust, at 5 percent on average between 1990 and 2011 even though the country was badly affected by internal and external shocks such as the Asian financial crisis in 1997/1998, the recent economic crisis that started in 2008 and floods in 2011. In July 2011 Thailand's income categorization was upgraded to upper middle-income by the World Bank. From a largely agrarian economy Thailand has developed significant industrial and service sectors, particularly manufacturing and tourism. Manufactured products made up 73\% of exports in 2011 (World Bank, 2012) and Thailand is a leading regional hub for the automobile and electronics industries (Wignaraja et al., 2013).

Alongside economic growth, Thailand has made substantial progress in reducing poverty. Poverty incidence (the headcount ratio) at the national poverty line fell from 58.1 percent in 1990 to 13.15 percent in 2011 (World Bank, 2013). Impressive improvements were also made on non-income indicators, including those used in the Human Development Index (United Nations Development Program, 2013). For instance, life expectancy rose from 72.5 years in 1990 to 74.3 years in 2012 and expected years of schooling rose from 8.4 in 1990 to 12.3 in 2012 .

Economic growth has not benefitted everyone equally. Certain regional and population groups, particularly rural communities and ethnic minorities in the Northeast and South of the country, remain among the country's poorest groups (Bird et al., 2011) and continue to lag behind on both income and non-income dimensions of poverty. Nonetheless, overall income inequality, measured by the Gini coefficient, fluctuated only slightly over time, from 0.429 in 1996 to 0.424 in 2006. Since that time the Gini has fallen further, to 0.394 in 2010 (World Bank, 2013). The analysis is therefore likely to be of interest to policymakers from developing countries experiencing or seeking to emulate rapid growth and 
poverty reduction without rising inequality, especially those wishing to understand the roles industrial policy and support to small entrepreneurs can play.

Thirdly, the Government of Thailand is committed to reduction of inequality as a policy objective, alongside economic growth. ${ }^{90}$ Since 2001, a dedicated government office has taken care of development and implementation of specific strategic plans for development of small and medium enterprises. In addition, the government hopes that more microenterprises, many of which are currently informal, can be formalized, adding to the tax base. The analysis of this paper may help policymakers to understand the implications of policies affecting MSEs, for inequality.

Finally, data on firm size and wages, which are required for this analysis, are available for the period in question, specifically, from the Thai LFS of 1995 and 2005.

The findings of this chapter reveal a 'missing middle' pattern in Thailand's firm distribution (4.3.3), and a clear correlation between firm size and wages, even controlling for other factors (4.3.4). A regression based decomposition analysis confirms that firm size plays a significant role in explaining wage inequality, as these two findings imply (4.3.6). The role of the firm size wage differential is significant even when controlling for region, sector and education level of workers.

The empirical findings of this paper show that, contrary to our expectations, the 'missing middle' became more accentuated between 1995 and 2005. The share of the largest firms in employment grew while the proportion in MSEs was stable. Over the same time period wage inequality rose, contrary to the trend for overall income inequality (4.3.5). This finding that wage inequality rose, while overall income inequality fell, could be explained by increased participation of workers in the wage labour market (Rendall, 2013) or by other trends that increase participation in wage labor, such as on-going industrialization and urbanization . In particular, the expansion of female labour market participation over this period is likely to have played a role. Although wages converged at the bottom of the firm size distribution, the gap between wages paid by the smallest and largest firms increased. The overall effect of the change in relative wages was mildly disequalizing.

We find that MSEs are disproportionately located in the poorer regions of the country, and in the agricultural sector. The average education level of workers also rises with firm size. The decomposition results show that education and region play more important roles than the firm size distribution in explaining levels of inequality. Increased education has also played a highly significant role 90 See the Eleventh National Economic and Social Development Plan (2012-2016), available at:
http://www.nesdb.go.th/Portals/0/news/plan/p11/Plan11_eng.pdf. 
in explaining rising wage inequality, as highly educated workers are paid above the average wage. However, the role of firm size is robust to controlling for these correlated factors.

The remainder of the paper is organized as follows: Section 4.2 develops a simple conceptual framework and derives testable hypotheses. These hypotheses are tested in Section 4.3. Section 4.4 concludes.

\subsection{Conceptual framework}

This section reviews the literature on the firm size distribution in developing countries, and examines the links between firm size and wages. Bringing together these two strands of literature allows us to draw hypotheses about the relationship between the firm size distribution and wages inequality, which we apply to the case of Thailand.

\subsubsection{The firm size distribution in developing countries}

Tybout (2000), drawing heavily on evidence from Liedholm and Mead (1987), identified a common pattern, which he calls 'dualism', in the firm size distribution of developing countries: large numbers of microenterprises coexist with a few modern, large-scale firms. By contrast the firm-size distribution in developed economies tends to be closer to log-normal (Cabral and Mata, 2003). This phenomenon has become known as the 'missing middle' and is confirmed by recent cross-country data. Ayyagari et al. (2003) find that, in high-income countries, small and medium enterprises (SMEs) are responsible for over 50 percent of GDP and over 60 percent of employment. But they account for less than half of that share in low-income countries, where microenterprises are more important. This gap in the firm distribution is often referred to as the 'missing middle'. In theory, firms would adopt the most efficient production technology, and select the most efficient mix of labour and capital, so one would not expect heterogeneous firm sizes within industries. The observed heterogeneity of the distribution therefore requires some explanation, and a substantial theoretical and empirical literature has investigated the reasons behind this pattern

A number of authors have generated models where differences in firm size arise because of differences in productivity. In the model by Lucas (1978) firms choose the most efficient size given their underlying production technology, so the firm size distribution depends on the distribution of productivity types. Differences in firm size could also arise, in a model without market imperfections, from differing risk preferences (Kihlstrom and Lafont, 1979). Likewise, if firms face differing productivity shocks then, over time, this could influence the firm size distribution (Jovanovic, 1982 and Hopenhayn, 1992). The distribution of productivity, risk preferences or productivity shocks, or other firm characteristics 
in developing countries would, in this class of models, explain the missing middle.

On the other hand, the nature of markets and institutions in developing countries, rather than firm characteristics, could be the main factor behind the missing middle. Credit market imperfections, for example, tend to be most severe for small firms in developing countries (Dinh et al., 2010). Cabral and Mata (2003) find, using a sample of manufacturing firms in Portugal, that the firm size distribution changed, as the economy expanded, from a right skewed pattern (in line with a missing middle) towards a lognormal distribution. The authors find that credit constraints, which impact particularly severely on small and young firms (Evans and Jovanovic, 1989), explain this pattern, preventing firms growing to a medium-size. In the model of Rauch (1991), larger firms are assumed to face higher unit input costs than smaller firms, if they are formally registered. This may occur in developing countries if the government fails to enforce regulations on small, informal enterprises. The most talented entrepreneurs operate large firms and benefit from returns to scale, which cover the higher input costs, while less talented entrepreneurs choose to remain small and informal in order to escape enforcement. This is consistent with a 'missing middle' pattern. Empirical findings from Tanzania and Sri Lanka by Levy (1993) show that bureaucratic burdens have the largest impacts on small firms, if such firms are formally registered. Alternatively, the largest firms may be able to lobby government for preferential tax breaks or other special treatment. It is also possible that small firms predominate in developing countries because of the different structure of demand - poorer households are more likely than wealthier ones to demand simple goods that can be produced easily by small firms (Tybout, 2000).

Overall, the empirical evidence suggests that the 'missing middle' pattern is widespread in developing countries and explained by a number of factors. In a comprehensive review Tybout (2000) finds that institutional entry barriers and imperfections in financial and labour markets are often present, but that small and geographically dispersed markets and the nature of consumer demand also seem to play a role, as well as factors such as uncertainty about demand and policies, corruption and lack of rule of law.

\subsubsection{The relationship between firm size and wages}

The links between firm size and wages will determine the effects of the firm size distribution on wage inequality, and these are therefore reviewed below.

Many models have taken the Stolper-Samuelson theorem (Stolper and Samuelson, 1941), or similar models as a starting point for analysis of wages and wage inequality. In these models wages are assumed to be related to the 
characteristics of workers, and the main determinant of inequality is the relative wages of skilled and unskilled workers - the return to skills. In these models differences in wages between large and small firms would reflect the differences in skills of their respective employees, usually proxied by their education levels. Differences in skill level between firms of different sizes could arise because of differences in production technologies or for other reasons. For example, the model of Helpman et al. (2010) assumes that it is costly for firms to verify the ability of workers. Combined with the assumption of wage bargaining, the model predicts that the most productive firms invest more in screening, meaning that they are able to hire more able workers and pay higher wages. However, empirical evidence tends to contradict this theorem. In particular, as noted by Felbermayr et al. (2013), a far larger proportion of wage inequality can generally be traced to disparities within relatively narrow skill classes, often attributable to firm characteristics, including firm size, than to observed worker characteristics. Further evidence, using individual fixed-effects (Söderbom et al., 2005), indicates that the wage differences observed between firms of different sizes cannot be traced to differences in unobserved worker characteristics.

A relationship between firm characteristics such as size and wages can occur without differences in worker characteristics. A number of relevant models have been based on the concept of fair wages or efficiency wages, in the context of imperfectly observed effort, inspired by Akerlof (1982), Akerlof and Yellen (1990) and by Shapiro and Stiglitz (1984). In all of these models firms pay their workers a 'premium' to exert effort, because effort is imperfectly observed. If workers' wage expectations are related to the productivity or profits of the firms, more productive firms will pay higher wages - a form of rent sharing (e.g. Egger and Kreickemeier 2010, 2012, and Amiti and Davis, 2012). Evidence suggests that larger firms are more productive on average (van Biesebroeck, 2005a), so it is reasonable to expect a positive relationship between firm size and wages. The model of Davis and Harrigan (2012) introduces heterogeneity in the ability to monitor workers. If larger firms have a lower ability to detect 'shirking', they will pay higher wages. Higher productivity among larger firms can be an assumption of these sorts of models, but also an outcome, as in the case of Egger and Kreieckmeier (2010).

Characteristics of the search and hiring process can also generate a relationship between firm characteristics, including size, and wages. In the model of Felbermayr et al. (2013) a relationship between firm size and wages arises because of convex costs to hiring new workers. Expanding firms fill their vacancies faster by increasing wages to make the jobs more attractive. Therefore, firm growth leads to wage dispersion, with a positive link between wages and firm productivity. The model of Coşar et al. (2011) is another example where the need to search for workers and the costs of adjustment lead to a positive link 
between wages and firm size. A relationship may also arise if larger firms have higher collective wage bargaining coverage.

Overall, it is quite clear that a strong relationship between firm size and wages does exist, including in developing countries (Söderbom et al., 2005). Based on the evidence of Mead and Liedholm (1987) it seems plausible to expect wages to be higher in larger enterprises (with more than one person). Although empirical evidence has so far failed to conclusively identify the reasons for the relationship, the finding of Söderbom et al. (2005) that the relationship is robust to including individual fixed effects shows that it cannot be fully explained by worker characteristics, observed or unobserved.

\subsubsection{Implications for inequality: hypotheses regarding the firm size distribution and wage inequality}

The two streams of literature described above imply that a link between the firm size distribution and inequality will arise, because of two empirical regularities. Firstly, the distribution of firms by size is generally heterogeneous and, in developing countries, skewed towards a 'missing middle' pattern. Secondly, for a variety of reasons, many of which are unrelated to worker characteristics, firm size is positively related to wages.

Conceptually, then, the wage distribution will be affected both by the nature of the firm size distribution - whether or not a 'missing middle' exists - and by the strength of the relationship between firm size and wages. The evolution of wage inequality over time will be impacted by two trends: the evolution of the firm size distribution as the economy develops, and whether the correlation between wages and firm size strengthens or weakens.

Bearing in mind the rapid economic growth and industrial development that took place in Thailand during the period analysed, this conceptual framework allows us to draw the following hypotheses:

1. A 'missing middle' pattern can be observed in Thailand, as in other developing economies - medium-sized firms account for a lower proportion of employment than would be expected in a developed country.

2. There is a strong correlation, unexplained by observed worker characteristics, between firm size and wages in Thailand, as in other economies. 
Taken together, these two hypotheses imply that the firm size distribution in Thailand plays a significant role in explaining wage inequality.

3. The 'missing middle' pattern became less pronounced over the period analysed, moving towards lognormal. In other words, the proportion of workers employed in medium-sized firms rose, while the proportion working in small and micro enterprises fell. A number of the institutional or market imperfections that are hypothesized to explain the 'missing middle' pattern in the literature reviewed above, such as poorly functioning capital markets or excessive burdens of taxation and bureaucracy, might be expected to have improved, either as a cause or as a consequence of economic development. An increased importance of medium-sized firms would be consistent with the pattern observed in Portugal by Cabral and Mata (2003) and with the fact that firm size distributions in developed economies tend towards lognormal.

4. The correlation between wages and firm size has become weaker over the period analysed. In a number of the models reviewed above, the links between firm size and wages are related to market or institutional imperfections. As noted, we expect these problems to have improved as the Thai economy has developed.

The two preceding hypotheses imply a fall in wage inequality, ceteris paribus.

Hypotheses 3 and 4 also imply that the importance of firm size as a factor explaining wage inequality will have decreased over time

Although regional, educational and sectoral disparities are not the main focus of this chapter, they have been consistently found to play important roles in explaining inequality in Thailand. Understanding their impacts will help us to put the findings regarding firm size into context. We also expect these factors to be related with firm size. Therefore, we will also examine how these factors relate to firm size dynamics, what role they play in explaining inequality, and control for them where feasible and appropriate.

\subsection{Empirical analysis}

After a short description of the data used (4.3.1) and of the labour force context (4.3.2), this section proceeds in line with the hypotheses above. Firstly, we examine whether the firm size distribution is characterized by a 'missing middle' 
(4.3.3). Links between wages and firm size are explored in 4.3.4. The wage distribution is described in 4.3.5 and static and dynamic decomposition analyses are used to understand the links between wage inequality and the firm size distribution in 4.3.6.

\subsubsection{Data description}

We use household data from the Thai Labour Force Survey (LFS) 1995 and 2005. The LFS surveys are the most complete source of information about labour force dynamics in Thailand. The samples are representative of the entire population, which included about 31.1 million active labour force participants in 1995 and 34.4 million in 2005.

The LFS surveys did not ask self-employed workers to provide additional information about their firms, meaning that no information is available on firm size or other characteristics for firms without employees. This affects our understanding of the firm size distribution - workers from one person enterprises and from small or family-run businesses that don't pay wages, are omitted from the analysis. ${ }^{91}$ However, the self-employed and employers earn no wages, so these firms could not, in any case, be included in an analysis of wage inequality. Further analysis would be needed to understand the impact of incomes from selfemployment and family businesses on overall income inequality. Government workers are also excluded. Although these workers report wages, the question of firm size is difficult to apply to the public sector. ${ }^{92}$

Another limitation of the LFS is that the firm size variable is discrete, rather than continuous. This choice may well be justified, if respondents find it easier to give an answer within a range, leading to fewer missing values. But, it makes comparison with other sources, which use different cut-offs for firm size groups, difficult. This is particularly true for the 1995 LFS, where the upper group covers all firms with 100 or more employees. However, the analytical techniques used are compatible with discrete data, and we believe that the size categories provide sufficient detail to give a meaningful insight into the questions at hand.

Throughout the analysis we use frequency weights, which reflect the number of workers represented by each observation. This means that our results reflect the importance of firms and firm size from the perspective of workers - this is considered most appropriate for analysis of wage inequality. ${ }^{93}$

\subsubsection{The context: the changing labour force structure}

\footnotetext{
${ }^{91}$ The same problem is acknowledged by other authors, for example Wiboonchutikula (2002).

${ }^{92}$ This question could be applied, in theory to state-owned enterprises. However, as these enterprises may differ in many ways from private sector firms we have excluded them from the analysis. As they account for a very small proportion of employment this makes no substantive difference to our results.

${ }^{93}$ The alternative option would be to weight the observations by the number of firms they represent.
} 
The changing structure of the Thai labour force is important context for our analysis. Table 4-1 shows the distribution of the labour force of Thailand by status, industry, and region in 1995 and 2005. It should firstly be noted that between 1995 and 2005 the size of the active labour force increased in all regions, from 31.1 to 34.4 million in total. Much of this change was likely related to the fact that the working age population increased faster than the overall population, so the country experienced a 'demographic dividend'. Several sources have noted the contribution of demographic change to economic growth in Thailand (for example, Mason and Lee, 2006).

Regional shifts between 1995 and 2005 do not appear large. Bangkok's share in the labour force fell slightly, more than compensated by a rise in the share of the surrounding Central region. The share of the Southern region rose very slightly, while the other regions fell slightly. This relatively muted change over a ten year period seems surprising, given that substantial migration flows have been documented away from rural and remote areas and towards Bangkok and the surrounding region (as reviewed in Punpuing and Richter, 2011). It is likely that the financial crisis of 1997/8, which was felt disproportionately in Bangkok, played a role in slowing, and even reversing, migration during the period studied. Punpuing and Richter (2011) find evidence for a substantial rise in urban-rural migration during the crisis. These 'reverse' migration flows continued after the crisis and even increased in 2002. It is also possible that the LFS underestimates migration, if some unregistered or temporary migrants are excluded from the sample. Other factors, such as an increase in the rate of enrolment in tertiary education, could also have contributed to a fall in the economic activity rate in Bangkok. The finding that the share of the Central region rose is also consistent with the findings of Punpuing and Richter (2011) who found, using a national survey of migration, that workers migrated to the Central region rather than to Bangkok during this period.

We also observe a substantial increase in the share of private employees in the labour force, by around 8 percentage points, and the decrease in the share of unpaid family members, by almost 10 percentage points. As the size of the labour force increased, the findings in Table 4-1 imply that more than 3.6 million additional jobs in private companies were added to the economy - new labour force entrants and, possibly, previously unpaid family employees have been absorbed into the private sector. ${ }^{94}$ About 1.2 million more people were selfemployed. Over the same time period, the number of unpaid family workers fell by 2.4 million. There was a slight increase in the proportion of individuals who reported being an employer or government employee and a slight decrease in the proportion of persons working in state enterprises.

\footnotetext{
${ }^{94}$ It is not possible to tell, using these data, whether these jobs were provided by new firms entering the market, or through expansion of existing firms.
} 
Structural change was also pronounced. The proportion working in agriculture fell in all regions apart from Bangkok - where agricultural activity is insignificant - by seven percentage points overall. Industry and services expanded by 2 and 7 percentage points respectively. Bangkok was the only exception to this pattern. In 1995 the city already had a sizeable industrial base, accounting for 41 percent of the labour force. Between 1995 and 2005 the structure shifted towards services, which by 2005 accounted for 68 percent of employment.

Table 4-1: Overview of labour force structure by status, industry, and region (percent)

\begin{tabular}{|c|c|c|c|c|c|c|c|c|c|c|c|c|}
\hline & \multicolumn{2}{|c|}{ All } & \multicolumn{2}{|c|}{ Bangkok } & \multicolumn{2}{|c|}{ Central } & \multicolumn{2}{|c|}{ Northern } & \multicolumn{2}{|c|}{ Northeastern } & \multicolumn{2}{|c|}{ Southern } \\
\hline & 1995 & 2005 & 1995 & 2005 & 1995 & 2005 & 1995 & 2005 & 1995 & 2005 & 1995 & 2005 \\
\hline \multicolumn{13}{|c|}{ Share of employment (percent) } \\
\hline Agriculture & 50.9 & 41.1 & 0.4 & 0.5 & 34.7 & 23.5 & 59.7 & 51.1 & 72.9 & 61.7 & 52.2 & 44.5 \\
\hline Industry & 20.2 & 22.7 & 40.8 & 31.4 & 32.1 & 37.1 & 15.0 & 18.2 & 10.0 & 13.6 & 15.9 & 15.8 \\
\hline Services & 28.9 & 36.3 & 58.8 & 68.1 & 33.2 & 39.3 & 25.4 & 30.7 & 17.1 & 24.6 & 31.8 & 39.6 \\
\hline \multicolumn{13}{|c|}{ Share of employment (percent) } \\
\hline Employer & 2.8 & 3.0 & 4.2 & 4.8 & 3.3 & 2.9 & 3.4 & 3.7 & 1.8 & 1.7 & 2.6 & 3.7 \\
\hline $\begin{array}{l}\text { Self employed } \\
\text { w/o employees }\end{array}$ & 28.7 & 29.4 & 18.9 & 17.4 & 24.5 & 22.3 & 30.3 & 30.9 & 31.9 & 38.4 & 34.4 & 29.3 \\
\hline $\begin{array}{l}\text { Unpaid family } \\
\text { worker }\end{array}$ & 31.4 & 21.6 & 9.1 & 7.2 & 21.6 & 15.0 & 31.1 & 24.5 & 45.7 & 31.2 & 30.4 & 18.5 \\
\hline $\begin{array}{l}\text { Government } \\
\text { employee }\end{array}$ & 6.6 & 7.9 & 7.0 & 8.1 & 7.2 & 7.3 & 6.7 & 8.1 & 5.6 & 7.6 & 7.9 & 9.3 \\
\hline $\begin{array}{l}\text { Government } \\
\text { enterprise } \\
\text { employee }\end{array}$ & 1.2 & 1.0 & 3.5 & 2.6 & 1.5 & 1.3 & 0.8 & 0.7 & 0.4 & 0.4 & 1.2 & 1.1 \\
\hline $\begin{array}{l}\text { Private } \\
\text { employee }\end{array}$ & 29.2 & 37.1 & 57.3 & 59.9 & 42.0 & 51.3 & 27.7 & 32.0 & 14.6 & 20.6 & 23.5 & 38.1 \\
\hline \multicolumn{13}{|c|}{ Education } \\
\hline None & 3.7 & 3.1 & 1.2 & 1.5 & 2.8 & 8.1 & 7.0 & 8.1 & 2.4 & 1.3 & 5.8 & 3.7 \\
\hline $\begin{array}{l}\text { Less than } \\
\text { elementary }\end{array}$ & 50.5 & 33.3 & 33.1 & 17.1 & 49.7 & 39.8 & 56.2 & 39.8 & 54.7 & 40.0 & 47.3 & 29.7 \\
\hline Elementary & 24.3 & 24.1 & 19.9 & 19.1 & 22.0 & 20.1 & 20.3 & 20.1 & 30.1 & 30.4 & 22.7 & 24.3 \\
\hline $\begin{array}{l}\text { Lower } \\
\text { secondary } \\
\text { Upper }\end{array}$ & 9.5 & 15.0 & 13.2 & 15.1 & 11.7 & 13.3 & 8.4 & 13.3 & 6.9 & 13.2 & 11.2 & 15.9 \\
\hline secondary & 6.5 & 12.4 & 15.5 & 16.0 & 7.8 & 10.5 & 4.5 & 10.5 & 3.6 & 9.5 & 7.4 & 13.7 \\
\hline Post secondary & 5.5 & 12.1 & 17.1 & 31.2 & 6.1 & 8.3 & 3.6 & 8.3 & 2.2 & 5.5 & 5.5 & 12.6 \\
\hline \multicolumn{13}{|c|}{ Share of the active labour force } \\
\hline $\begin{array}{l}\text { Share of the } \\
\text { active labour } \\
\text { force }\end{array}$ & 100.0 & 100.0 & 11.6 & 11.2 & 22.3 & 25.4 & 19.3 & 18.1 & 34.7 & 32.3 & 12.1 & 13.1 \\
\hline
\end{tabular}

Source: Author's computations based on LFS 1995 and 2005.

The period was also characterized by a significant increase in the education level of the workforce. The share of the labour force with at least secondary education has increased in all regions, while the proportion with elementary or less than elementary fell across the board. There was a slight increase in the proportion with no education in Bangkok (from a very low base) and the Northern region, and a more substantial increase in the Central region, possibly because the area has seen an influx of uneducated workers from other regions. Bangkok saw a 
particularly significant rise in the proportion of workers with post-secondary education. By 2005 these made up about 31 percent of the workforce.

\subsubsection{The missing middle in Thailand: the firm size distribution}

Table 4-2 describes the firm size distribution using the LFS 1995 and 2005 and compares the estimates with others available from the literature. This comparison is intended as a plausibility check and in order to see how the distribution compares with those seen in developed countries. It should be noted that understanding the firm size distribution in Thailand is complicated by methodological inconsistencies between sources. Different government agencies use and report different firm size categories and employ different data collection methodologies (OECD, 2011). In particular, as noted above, the categories in the LFS do not overlap perfectly with the categories used in other sources, and we have no data on one-person or other microenterprises without paid workers. We should therefore bear in mind that the importance of microenterprises as sources of employment is understated.

Our results represent the situation for private sector employees. These were 29 and 37 percent of the active labour force in 1995 and 2005, respectively, but 79 and 81 percent of all wage workers.

Table 4-2: The firm size distribution in Thailand, percent of employment by firm size over time, estimates from LFS and from the literature

\begin{tabular}{|c|c|c|c|c|c|c|c|}
\hline Category & $\begin{array}{l}\text { Thailand, } \\
1978^{a}\end{array}$ & $\begin{array}{c}\text { Thailand, } \\
1995^{\mathrm{b}}\end{array}$ & $\begin{array}{l}\text { Thailand, } \\
1996^{c}\end{array}$ & $\begin{array}{l}\text { Thailand, } \\
2005^{\mathrm{d}}\end{array}$ & $\begin{array}{l}\text { Thailand, } \\
2005^{e}\end{array}$ & $\begin{array}{l}\text { Germany } \\
, 2007^{e}\end{array}$ & $\begin{array}{l}\text { Japan, } \\
2007^{e}\end{array}$ \\
\hline 1 to 4 & & 22.2 & & 21.5 & & & \\
\hline 5 to 9 & 58 & 19.3 & 6.35 & 17.3 & & 19.1 & 8.4 \\
\hline 10 to 19 & & 14.5 & & 14.0 & & & \\
\hline 20 to 49 & 11 & 12.9 & 15.54 & 10.4 & 64.8 & 21.6 & 26.5 \\
\hline 50 to 99 & & 8.3 & & 6.7 & & $19.6(50-$ & \\
\hline $100-200$ & & & $\begin{array}{c}30.55 \\
(50-299)\end{array}$ & 7.2 & 12.2 & 249) & $\begin{array}{c}31.1(50- \\
249)\end{array}$ \\
\hline over 200 & 31 & 22.8 & $\begin{array}{c}47.55 \\
(>300)\end{array}$ & 23.0 & 25.1 & $\begin{array}{c}39.6 \\
(>250)\end{array}$ & $\begin{array}{c}34.0 \\
(>250)\end{array}$ \\
\hline
\end{tabular}

Sources: ${ }^{\mathrm{a}}$ Liedholm and Mead (1987), ${ }^{\mathrm{b}}$ Author's computations based on LFS 1995, ${ }^{\mathrm{c}}$ Wiboonchutikula (2002), ${ }^{\mathrm{d}}$ Author's computations based on LFS 2005 and, ${ }^{\mathrm{e}}$ OECD (2011).

The results clearly describe a dualistic distribution. For small and medium-sized firms, the percentage employed declines monotonically with firm size category, despite the fact that the 'width' of the categories increases. In 1995, 31 percent of private sector workers worked in firms with 9 or fewer employees and 28 percent in firms with between 10 and 49 . Only 8 percent of workers were employed in medium-sized enterprises, with between 50 and 99 workers, but a substantial 
proportion - 23 percent - worked in large firms, with over 100 employees. ${ }^{95}$ In the 2005 data we can distinguish firms with over 200 employees, which provides even more convincing evidence of the 'missing middle'. Only 7 percent of workers are employed in the smaller group of large firms, with between 100 and 200 workers, while 23 percent work in the largest firms, of 200 workers or more. ${ }^{96}$ When compared with developed countries (data on Germany and Japan from OECD, 2011, are provided as an example), this suggests a pronounced missing middle.

Contrary to the hypothesis in 4.2.3, the firm size distribution has not moved towards a log-normal distribution between 1995 and 2005. The proportion employed in the smallest firms has stayed roughly static, but there has been an increase of around 7 percent in the proportion working in the largest enterprises.

Our results differ from those of Wiboonchutikula (2002), who found, in 1996, a far lower share of employment in the smallest enterprises - just 6 percent worked in firms with 9 employees or fewer. Alongside this finding, the author found the share of large and medium-sized enterprises to be substantially higher than in most of the developing countries included in Tybout's (2000) review. Firms with 50 or more employees accounted for 78 percent of jobs, and enterprises with between 10 and 50 workers 16 percent.

However, recent estimates by the OECD (2011) are in line with our results, as they also indicate a 'missing middle' pattern. ${ }^{97}$ The categories do not overlap perfectly with those of the LFS, and in particular do not permit detailed analysis at the lower end of the firm size distribution, but the aggregated results are quite close to ours. The OECD (2011) report shows little significant difference between Thailand and OECD countries in terms of the proportion of employment, GDP and exports accounted for by SMEs (here defined as enterprises with fewer than 200 employees). These accounted for 77 percent of employment in 2005. However, SMEs with more than 50 employees are underrepresented compared to OECD countries and to other Asian non-OECD countries, accounting for just 12 percent of employment.

The comparability of our findings to those of Liedlholm and Mead (1987) is limited, as they date to 1978. However, they also appear a plausible fit with our findings, and suggest a missing middle pattern. We therefore conclude that the results of Wiboonchutikula (2002) are likely to have been affected by the methodological issues mentioned above and that the missing middle result is plausible.

\footnotetext{
${ }^{95}$ As noted above, the LFS do not include full information on the smallest household enterprises, as they have no employees. If these enterprises were to be included the pattern of the 'missing middle' would be expected to be even more pronounced.

${ }^{96}$ In the analysis that follows we use the 1995 categories, for the sake of comparability.

${ }^{97}$ Although using a different definition of 'medium size' than Tybout (2000).
} 
Further insights come from examining the relationship between the firm size distribution and region (Table 4-3). The distribution of firm sizes in Bangkok is much more evenly spread than in other regions, closer to distributions observed in developed countries. In other words, it is not characterized by a 'missing middle'. In all of the other regions a large proportion of workers are employed in micro and small enterprises, with very few in either medium-sized firms. The Central region differs from the other regions as it does have a relatively large share, exceeding that of Bangkok, of workers in the largest firms. However, mediumsized firms are absent here too.

Over the period studied the 'missing middle' became more pronounced in all regions, with the share of workers in firms with between 20 and 99 workers falling across the board. The overall rise in the share of the largest enterprises can be traced mainly to the Central region, where it increased by almost 13 percentage points. The increase was somewhat smaller in Bangkok and the North and almost insignificant elsewhere. The share of the smallest microenterprises fell in all regions apart from the South, where it increased by over 10 percent.

Table 4-3: Firm size distribution by region, 1995 and 2005, percent

\begin{tabular}{cccccccccccc}
\multicolumn{4}{c}{ Bangkok } & \multicolumn{2}{c}{ Central } & \multicolumn{2}{c}{ Northern } & \multicolumn{2}{c}{ Northeastern } & \multicolumn{2}{c}{ Southern } \\
\hline $\begin{array}{c}\text { Firm } \\
\text { size }\end{array}$ & 1995 & 2005 & 1995 & 2005 & 1995 & 2005 & 1995 & 2005 & 1995 & 2005 \\
\hline $1-4$ & 14.15 & 13.40 & 23.65 & 16.97 & 31.17 & 26.57 & 29.49 & 25.62 & 34.20 & 44.91 \\
$4-9$ & 11.09 & 9.45 & 17.81 & 14.05 & 25.94 & 24.45 & 25.49 & 27.14 & 21.22 & 15.88 \\
$10-19$ & 12.73 & 12.27 & 11.54 & 10.66 & 18.39 & 19.52 & 15.37 & 18.79 & 14.15 & 11.68 \\
$20-49$ & 18.90 & 17.60 & 8.35 & 7.89 & 10.20 & 10.02 & 9.98 & 9.87 & 11.15 & 9.15 \\
$50-99$ & 13.35 & 12.19 & 7.32 & 6.15 & 4.79 & 4.31 & 6.02 & 4.05 & 6.85 & 5.89 \\
$>100$ & 29.77 & 35.09 & 31.34 & 44.27 & 9.50 & 15.14 & 13.66 & 14.53 & 12.44 & 12.49 \\
\hline
\end{tabular}

Source: Author's computations based on LFS 1995 and 2005.

The firm distribution also varies by sector (results available from author upon request). MSEs are largely concentrated in the relatively poorly paid agricultural sector, and, to a lesser extent, services. Changes in the firm size distribution between 1995 and 2005 have served to accentuate this pattern. The proportion of large firms in industry (over 100 employees) grew significantly. It also increased slightly among service firms. In 2005, 45 percent of industrial workers and 23 percent of service sector employees worked in firms with 100 employees or more. In other words, the character of these sectors changed significantly, from being made up mainly of smaller firms to being dominated by relatively large enterprises. This may be a reflection of changes in fast-growing industries such as automobiles and electronics. The change of firm size composition within the agricultural sector has been small. 
It is also worth noting that firm size is strongly correlated with education, with larger firms particularly likely to hire more educated workers (Table 4-4). In 1995 the share of workers with post-secondary education was 14 percent in the largest firms, compared to just 2 percent in the smallest microenterprises. The share of workers with post-secondary education rose to about 25 percent in 2005 among the largest firms, but to just 3 percent in the smallest.

Table 4-4: Education level by firm size, 1995 and 2005, percent

\begin{tabular}{lccccccc} 
& $\mathbf{1 - 4}$ & $\mathbf{5 - 9}$ & $\mathbf{1 0 - 1 9}$ & $\mathbf{2 0 - 4 9}$ & $\mathbf{5 0 - 1 0 0}$ & $\mathbf{> 1 0 0}$ & Total \\
\hline None & & \multicolumn{7}{c}{$\mathbf{1 9 9 5}$} & & & & \\
Less than elementary & 4.3 & 6.5 & 4.4 & 1.5 & 1.4 & 0.7 & 3.5 \\
Elementary & 31.8 & 27.2 & 26.1 & 26.8 & 30.5 & 27.7 & 28.4 \\
Lower secondary & 9.3 & 10.1 & 11.6 & 9.3 & 15.2 & 18.1 & 12.3 \\
Upper secondary & 3.7 & 4.4 & 6.9 & 13.1 & 15.1 & 16.5 & 9.4 \\
Post-Secondary & 2.0 & 2.9 & 6.0 & 12.8 & 12.6 & 14.0 & 7.7 \\
\hline & & & $\mathbf{2 0 0 5}$ & & & & \\
\hline None & 6.0 & 5.0 & 5.1 & 3.5 & 1.4 & 0.9 & 3.6 \\
Less than elementary & 32.4 & 32.3 & 28.0 & 21.7 & 15.9 & 11.0 & 23.2 \\
Elementary & 32.1 & 31.1 & 29.5 & 23.4 & 21.9 & 18.0 & 25.8 \\
Lower secondary & 17.0 & 16.8 & 15.9 & 16.0 & 18.5 & 22.1 & 18.3 \\
Upper secondary & 9.2 & 9.5 & 10.7 & 15.4 & 17.9 & 22.8 & 14.8 \\
Post-Secondary & 3.4 & 5.3 & 10.7 & 20.0 & 24.4 & 25.1 & 14.3 \\
\hline
\end{tabular}

Source: Author's computations based on LFS 1995 and 2005

Overall, notwithstanding the problems of comparability between sources, we observe a clear 'missing middle' pattern in the firm size distribution in 1995 and 2005. We find this result broadly plausible in comparison with estimates from other sources. The 'missing middle' is visible in all regions except for Bangkok, where the distribution is close to the patterns observed in developed countries. The LFS results indicate that, rather than declining as expected, the 'missing middle' has increased between 1995 and 2005 due to an increase in the proportion employed in the largest firms. This increase occurred mainly in the Central region, but also in Bangkok and the North of the country. Meanwhile, the share of medium-sized firms fell, slightly, across the board and the share of the smallest firms increased in the South.

\subsubsection{The relationship between wages and firm size}

In both 1995 and 2005 we see a correlation between wages and firm size (Table 4-5), with wages rising monotonically with firm size category. The one exception to this relationship is that in 2005 wages in the medium-sized firms were slightly higher than wages in the largest enterprises. 
Table 4-5 Wages per enterprise group for employees in private enterprises (Int. USD)

\begin{tabular}{|c|c|c|c|c|c|c|c|c|}
\hline \multirow[b]{2}{*}{ Category } & \multicolumn{3}{|c|}{1995} & \multicolumn{3}{|c|}{2005} & \multicolumn{2}{|c|}{ Delta } \\
\hline & $\begin{array}{c}\text { mean } \\
\text { monthly } \\
\text { wage in } \\
\text { int. } \\
\text { USD }\end{array}$ & $\begin{array}{c}\text { median } \\
\text { monthly } \\
\text { wage in } \\
\text { int. } \\
\text { USD }\end{array}$ & $\begin{array}{l}\text { Percentage } \\
\text { of } \\
\text { individuals }\end{array}$ & $\begin{array}{c}\text { mean } \\
\text { monthly } \\
\text { wage in } \\
\text { int. } \\
\text { USD }\end{array}$ & $\begin{array}{c}\text { median } \\
\text { monthly } \\
\text { wage in } \\
\text { int. } \\
\text { USD }\end{array}$ & $\begin{array}{l}\text { Percentage } \\
\text { of } \\
\text { individuals }\end{array}$ & $\begin{array}{c}\text { Delta } \\
\text { mean } \\
\text { wage, } \\
\%\end{array}$ & $\begin{array}{c}\text { Delta } \\
\text { mean } \\
\text { wage } \\
\text { absolute, } \\
\text { int. USD }\end{array}$ \\
\hline \multicolumn{9}{|c|}{ Firm size } \\
\hline 1 to 4 & 194 & 161 & 22 & 261 & 213 & 22 & 35 & 67 \\
\hline 5 to 9 & 212 & 161 & 19 & 247 & 210 & 17 & 16 & 35 \\
\hline 10 to 19 & 246 & 188 & 15 & 321 & 240 & 14 & 30 & 75 \\
\hline 20 to 49 & 346 & 250 & 13 & 433 & 292 & 10 & 25 & 87 \\
\hline 50 to 99 & 330 & 237 & 8 & 503 & 312 & 7 & 52 & 173 \\
\hline over 100 & 396 & 242 & 23 & 498 & 292 & 30 & 26 & 102 \\
\hline \multicolumn{9}{|c|}{ Sector } \\
\hline Agriculture & 157 & 129 & 17 & 214 & 175 & 18 & 37 & 57 \\
\hline Industry & 283 & 220 & 52 & 354 & 266 & 49 & 25 & 70 \\
\hline Services & 351 & 242 & 31 & 492 & 301 & 32 & 40 & 140 \\
\hline \multicolumn{9}{|c|}{ Region } \\
\hline Bangkok & 461 & 314 & 23 & 642 & 403 & 18 & 39 & 181 \\
\hline Central & 276 & 220 & 32 & 384 & 274 & 35 & 39 & 107 \\
\hline Northern & 185 & 161 & 18 & 227 & 187 & 16 & 23 & 42 \\
\hline Northeastern & 190 & 161 & 17 & 230 & 195 & 18 & 21 & 40 \\
\hline Southern & 234 & 194 & 10 & 338 & 263 & 13 & 44 & 104 \\
\hline \multicolumn{9}{|c|}{ Education } \\
\hline None & 200 & 129 & 4 & 187 & 164 & 4 & -7 & -13 \\
\hline Less than elementary & 206 & 178 & 39 & 252 & 213 & 23 & 22 & 46 \\
\hline Elementary & 206 & 190 & 29 & 258 & 230 & 26 & 25 & 52 \\
\hline Lower secondary & 280 & 226 & 12 & 292 & 253 & 18 & 4 & 12 \\
\hline Upper secondary & 408 & 315 & 9 & 386 & 292 & 15 & -6 & -22 \\
\hline Post secondary & 807 & 603 & 8 & 897 & 584 & 14 & 11 & 90 \\
\hline Total & 282 & 210 & & 372 & 263 & & 32 & 90 \\
\hline
\end{tabular}

Notes: The estimated proportion of the labour force in each group differs from that of Table 4-1 because this table covers only private sector employees.

Source: Author's computations based on LFS 1995 and 2005; Purchasing Power Parity (PPP) conversion factors from World Development Indicators (World Bank, 2013).

These findings are put into perspective, however, by the importance of the correlation between wages and other variables, particularly education. Wages rise monotonically with education, in both years, with particularly sharp increases at the upper secondary level and post-secondary levels. ${ }^{98}$ The regional differences are also pronounced - in 1995 mean wages in Bangkok were more than twice the level of those in the lowest wage region, the Northeast. Average real wages were lowest in agriculture and highest in services, in both years, although the

${ }^{98}$ Returns to education are not calculated in this chapter, but these results suggest that they are high. 
differences were less pronounced than those between regions or educational levels.

We use regression analysis, with monthly wage in Int. USD as the dependent variable, to examine whether firm size has an effect on wages independent of region, sector and education, all of which are likely correlated. Results are reported in Appendix A-4. Using dummy variables for the six size groups described above, we find that firm size had a significant impact on wages in Thailand in both 1995 and 2005, even controlling for observable characteristics. ${ }^{99}$ However, the coefficients on the firm size dummies are much small than the large coefficients on the upper- and post-secondary dummies, and also smaller than the coefficients on the regional dummies. Firm size has a significant impact on wage, but it does not influence wages as much as a worker's education or of the area they live in.

Wages rose by about 30 percent in real terms between 1995 and 2005 (Table 4-5). This implies that the average worker benefited from economic growth over this period. However, the pattern has varied by firm size. The medium-sized firms, with between 50 and 99 workers, saw an increase of around 52 percent. In the smallest 'micro' enterprises wages rose by 35 percent but in the slightly larger micro firms the increase was only 16 percent. As a consequence, wages in these size groups converged and in 2005 were roughly similar. Wages in the largest firms rose by 26 percent.

Wages grew fastest in services, and in Bangkok, the Central and Southern regions. Workers with elementary or less than elementary education experienced the fastest wage group. Those with secondary education or above saw slower growth. However, as noted above, the proportion with these levels of education rose.

The regression analysis in Appendix A-4 also allows us to quantify how the strength of the relationship between firm size and wages has changed over time. The catch-up of employees of the smallest microenterprises is significant - by 2005 workers in enterprises with 5 to 9 employees were no better off, statistically, than this group. The coefficient on the dummies for the other small firm sizes is relatively stable, but the coefficient for the medium and large enterprises rose. So, while the convergence at the bottom of the distribution confirms our hypothesis that the relationship between firm size and wages would become weaker as Thailand developed, wage levels continued to diverge between the largest and smallest firms.

${ }^{99}$ We used firms with fewer than 5 employees and workers with no education as reference categories. 


\subsubsection{Wage inequality in Thailand}

Figure 4-1 plots the overall wage distributions for private employees for the two years analysed. In 1995 a large proportion of workers were clustered close to the mean value. In 2005 the mean wage had risen, and a larger number of workers were located above the mean, in the right hand tail of the distribution, with wages of 300 Int. USD or above. ${ }^{100}$ This suggests a rise in wage inequality, which is confirmed in the measures of inequality summarized in Table 4-6.

Table 4-6 includes a number of commonly used inequality measures. The Generalized Entropy (GE) class of measures is included: GE(0), or the mean logarithmic deviation (MLD), GE(1), or the Theil Index, and GE(2), which is equivalent to half of the squared coefficient of variation. The Gini coefficient, and measures of the Atkinson class with different levels of inequality aversion are also provided. ${ }^{101} \mathrm{~A}$ higher inequality aversion factor (represented by the number in brackets) makes the Atkinson and GE inequality measures more sensitive to differences at the bottom of the wage distribution. ${ }^{102}$

Figure 4-1: Wage distributions for private employees in Thailand in 1995 and 2005

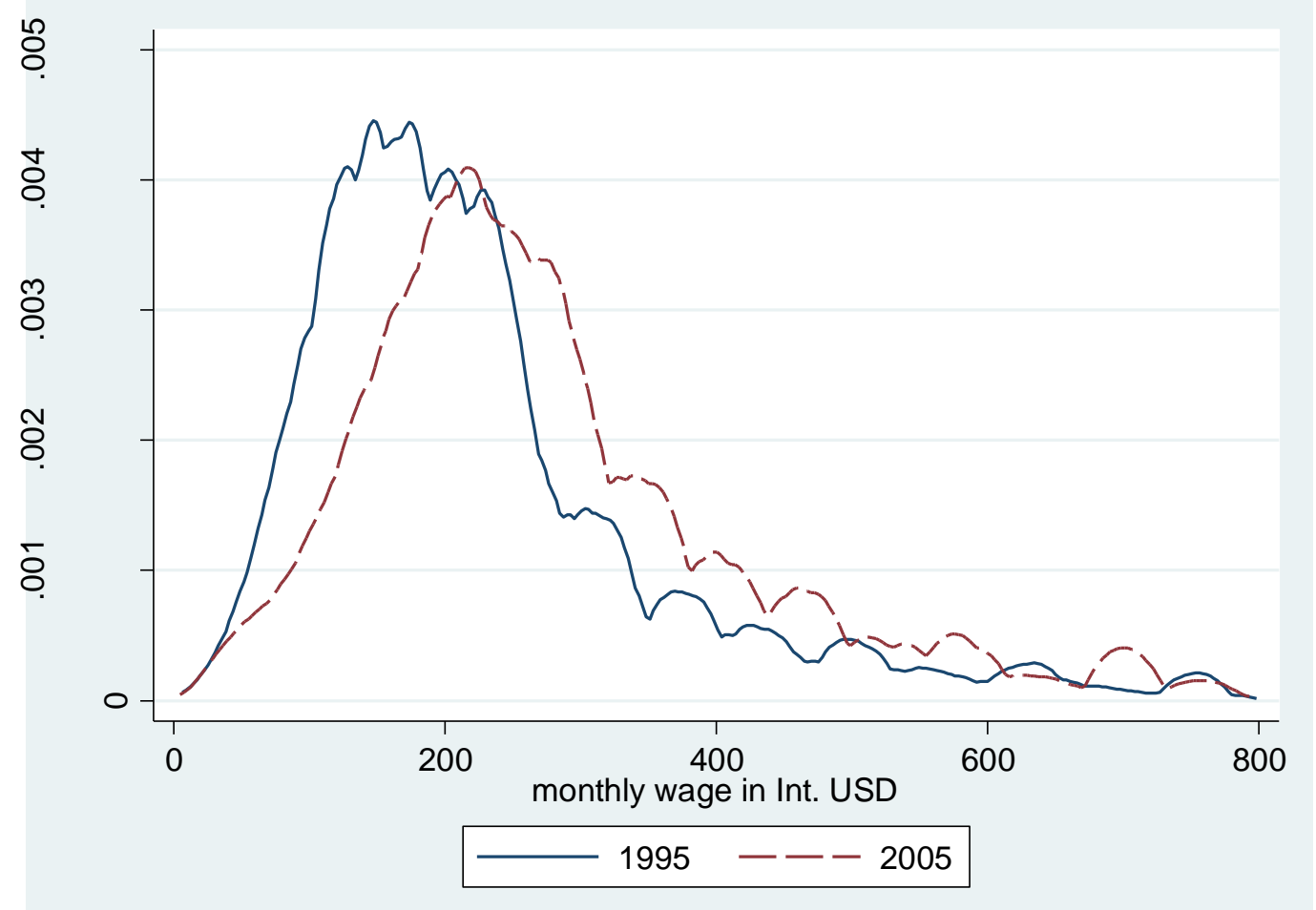

Source: Author's computations based on LFS 1995 and 2005

\footnotetext{
${ }^{100}$ These main results are not altered when we plot the wage distributions by firm size (see Figure 4-2 in the Appendix).

${ }^{101}$ See Cowell (2000) and Atkinson (1970) for details on the different inequality measures.

${ }^{102}$ For our further analysis we focus on the measures of the GE class, because these are decomposable.
} 
The results in Table 4-6 show that the inequality of the wage distribution (for employees in private companies) increased between 1995 and 2005. This is in contrast to overall income inequality, which remained roughly constant, as noted above, and in contrast to our hypothesis in 4.2.3. This implies that other income sources, such as earnings from self-employment, social transfers or agriculture, compensated for the dis-equalizing effect of wages, or that the equalizing effect of the expansion of wage opportunities was enough to mitigate the rise in wage inequality.

The biggest proportional increase occurred using the measures with high inequality aversion factors. These measures are highly sensitive to changes in the lowest part of the distribution. This implies that the increase in the deviation from the mean was most pronounced for the workers at the bottom of the wage distribution. It appears that, as the mean wage rose, a certain group of workers fell further behind the average.

Table 4-6: Inequality measures for overall wage distributions

\begin{tabular}{|c|c|c|c|c|c|c|c|}
\hline & $\begin{array}{c}\mathrm{GE}(0) \\
(\mathrm{MLD})\end{array}$ & $\begin{array}{l}\text { GE (1) (Theil } \\
\text { Index) }\end{array}$ & $\begin{array}{c}\mathrm{GE}(2) \\
\text { (Half the } \\
\text { squared } \\
\text { coefficien } \\
\mathrm{t} \text { of } \\
\text { variation) }\end{array}$ & $\begin{array}{c}\text { Gini } \\
\text { coefficient }\end{array}$ & $\mathrm{A}(0.5)$ & $\mathrm{A}(1)$ & $\mathrm{A}(2)$ \\
\hline 1995 & 0.2649 & 0.3342 & 0.6581 & 0.3959 & 0.1371 & 0.2328 & 0.3728 \\
\hline 2005 & 0.3115 & 0.3808 & 0.7345 & 0.4245 & 0.1570 & 0.2676 & 0.4359 \\
\hline $\begin{array}{l}\text { Inequality } \\
\text { change }\end{array}$ & 0.1756 & 0.1395 & 0.1162 & -0.0723 & $\begin{array}{c}- \\
0.1453\end{array}$ & $\begin{array}{c}- \\
0.1499\end{array}$ & $\begin{array}{c}- \\
0.1693 \\
\end{array}$ \\
\hline
\end{tabular}

Source: Author's computations based on LFS 1995 and 2005.

\subsubsection{Linking the firm size distribution and wage inequality}

Table 4-7 decomposes the MLD and Theil index, two commonly used measures of inequality, into within and between group inequalities, examining firm size, sector, regional differences, and educational differences.

In line with our expectations (4.2.3), differences in wages between firm size groups help explain inequality in both years. Their importance fell very slightly over time. In 1995 differences in average wages between different firm size groups explained 15 percent of inequality, as measured by MLD, and in 2005 they explained 14 percent.

The decompositions in Table 4-7 mirror the findings from the descriptive statistics, showing that education and regional differences are more important in explaining overall inequality than firm size. Sector, on the other hand, explains 
only around 12 percent of the MLD, less than firm size. It is also important to note that only a small proportion of total inequality is explained by differences between groups. Even differences in pay by education level can explain only 38 percent of wage inequality. The rest can be attributed to wage inequality within the respective groups. ${ }^{103}$

Table 4-7: Inequality decomposition by sector, firm size, and region

\begin{tabular}{|c|c|c|c|c|c|c|c|c|c|}
\hline & & \multicolumn{3}{|c|}{$\operatorname{MLD}(\mathrm{GE}(0))$} & \multicolumn{5}{|c|}{ Theil } \\
\hline & & Within & Between & Total & $\begin{array}{c}\text { Between } \\
\text { /Total }\end{array}$ & Within & between & Total & $\begin{array}{c}\text { Between } \\
\text { /Total } \\
\end{array}$ \\
\hline 1995 & Firm size & 0.224 & 0.041 & 0.265 & 0.154 & 0.294 & 0.041 & 0.334 & 0.121 \\
\hline 2005 & & 0.267 & 0.045 & 0.311 & 0.144 & 0.337 & 0.044 & 0.381 & 0.115 \\
\hline 1995 & Sector & 0.232 & 0.033 & 0.265 & 0.123 & 0.305 & 0.029 & 0.334 & 0.086 \\
\hline 2005 & & 0.273 & 0.038 & 0.311 & 0.122 & 0.345 & 0.035 & 0.381 & 0.093 \\
\hline 1995 & Region & 0.205 & 0.060 & 0.265 & 0.226 & 0.272 & 0.062 & 0.334 & 0.186 \\
\hline 2005 & & 0.244 & 0.067 & 0.311 & 0.216 & 0.312 & 0.069 & 0.381 & 0.180 \\
\hline 1995 & Education & 0.161 & 0.100 & 0.261 & 0.382 & 0.206 & 0.124 & 0.330 & 0.376 \\
\hline 2005 & & 0.193 & 0.118 & 0.310 & 0.380 & 0.242 & 0.139 & 0.381 & 0.365 \\
\hline
\end{tabular}

Source: Author's computation based on LFS 1995 and 2005

Notes: Firm size: 1 to 4, 5 to 9, 10 to 19, 20 to 49, 50 to 99, 100 and above; Region: Bangkok, Central, Northern, Northeastern, Southern; Sector: Agriculture, Industry, Services; Education: None, Less than Elementary, Primary, Lower Secondary, Upper Secondary, Post-Secondary.

As noted, firm size is strongly correlated with both region and sector. Larger firms are concentrated in the better-off regions and in the highest paying sector, industry. Size is also be correlated with education. In order to better understand these interrelationships we use a regression-based decomposition method, based on Fields (2002). We employ the STATA command 'ineqrbd' written by Fiorio and Jenkins (2008) and include region, sector, and education dummy variables as controls. The results are based on the regressions in Appendix A-4, and are displayed in Table 4-8. The estimated contribution of a particular variable to wage inequality is related to the strength of the correlation between the variable in question and wages, and to the variability of the variable itself among the population in question. Positive coefficients indicate that a variable has a disequalizing effect on wages. For instance, a rise in wages in Bangkok would have a strong disequalizing effect by further widening the wage gap. A rise in wages for workers in MSEs would lead to a decrease in overall wage inequality.

\footnotetext{
103 The finding that within group inequalities account for most of the total wage inequality is unsurprising given the broad character of the groups. However, even when using 21 industry groups based on a 3 digit International Standard Industry Classification (ISIC) by the UN the main findings of Table 4-7 are unaltered. Our findings are also in line with Jenkins (1995) who also finds that within group inequality accounts for most of the inequality. In the same study, this finding holds for all decomposition groups.
} 
The results indicate that the nature of the firm size distribution, together with the correlation between firm size and wages, accounts for about 2 percent of wage inequality in 1995 and 2005, controlling for other factors. The wages received by workers in small firms have an equalizing impact, but the high wages received by workers of medium and larger enterprises are disequalizing. The overall effect is disequalizing, although its importance decreased slightly between 1995 and 2005 .

Region and education in particular play a more important roles in explaining overall inequality. The unequal distribution of upper and post-secondary education, together with the apparently high returns already identified, explains around 22 percent of total wage inequality. This runs contrary to the argument of Felbermayr et al. (2013), that a larger proportion of wage inequality can generally be traced to firm characteristics than to education. Further, even when education is included, only around 30 percent of inequality can be explained by observed variables, according to the regression based technique. Differences in wages between workers with the same level of education, in the same region and firm size group explain around 70 percent of overall wage inequality.

Table 4-8: Contribution of each variable to wage inequality, percent, estimated using regression based decomposition

\begin{tabular}{lcc} 
& 1995 & 2005 \\
\hline Firm size & & \\
\hline 5 to 9 & -0.2886 & -0.0037 \\
0 to 19 & -0.0852 & -0.0988 \\
20 to 49 & 0.3265 & 0.1178 \\
50 to 99 & 0.1653 & 0.3065 \\
Over 100 & 1.8417 & 1.697 \\
\hline Sector & & \\
\hline Industry & 0.0157 & 0.0789 \\
Services & 0.4032 & 0.5211 \\
\hline Education & & \\
\hline Less than & 0.5323 & -0.759 \\
Elementary & 0.8076 & -0.5936 \\
Lower secondary & 0.0024 & -0.3756 \\
Upper secondary & 1.3913 & 0.1498 \\
Post-secondary & 19.613 & 21.494 \\
\hline Region & & \\
\hline Bangkok & 6.3591 & 6.1881 \\
Central & -0.0767 & 0.1813 \\
Northeastern & -0.0955 & -0.0722 \\
Southern & -0.1206 & -0.2193 \\
\hline Residual & 69.2082 & 71.3875 \\
\hline
\end{tabular}

Source: Author's computations based on LFS 1995 and 2005. 


\subsection{Conclusions}

This paper examined the role of firm dynamics for the development of wage inequality in Thailand between 1995 and 2005. The main findings are:

1. A 'missing middle' pattern is observed in Thailand, as in other developing economies - medium-sized firms account for a lower proportion of employment than would be expected in a developed country. This pattern was present in both 1995 and 2005. Bangkok is the only region with a relatively even firm size distribution.

2. There is a strong correlation between firm size and wages. Regression analysis showed that this correlation is unexplained by observed worker characteristics.

As expected given these findings, the firm size distribution in Thailand plays a significant role in explaining wage inequality, in both 1995 and 2005, even when we control for the correlation of firm size with region, education and sector.

3. Rather than moving towards a lognormal distribution over the period analysed the firm size distribution became more 'dualistic', with the proportion of workers employed in the largest firms rising slightly, while the proportion in the smallest firms remained roughly stable. The increase in the proportion of large firms was most pronounced in the Central region, which surrounds Bangkok city, while the Southern region saw a notable increase in the proportion of microenterprises.

4. At the bottom of the firm size distribution wages in the smallest microenterprises have caught up with wages in slightly larger small firms. But the wages of these two groups have diverged from the wages received by workers at top of the firm size distribution.

Contrary to our expectations, and to the trend in overall inequality, we observed a rise in wage inequality between 1995 and 2005. This is partly explained by the accentuation of the 'missing middle'. Workers who gained opportunities in the largest enterprises gained access to higher wages than the workers in micro and small enterprises. As the 'middle' of the distribution remained absent, this increased wage inequality. The increase in wages at the top of the firm size distribution, which outweighed the convergence at the bottom, also explains part of the increase. 
Although regional, sectoral and educational disparities are not the main focus of this chapter, they have been considered in order to put the findings into context, and in order to understand the effect of firm size controlling for these correlated variables. Results from a regression based decomposition show that education and region play a far larger role in explaining wage inequality than the firm size distribution.

Because of the difficulties of causal interpretation and certain other data limitations the implications of these findings for policy should be considered avenues for future investigation. They would need to be verified with further evidence and investigation of causal links. Fruitful avenues for future research are therefore as follows:

As the accentuation of the 'missing middle' pattern between 1995 and 2005 contributed to rising wage inequality, it would be worthwhile investigating the reasons why medium-sized enterprises make up a small and shrinking proportion of employment and what has constrained the numerous MSEs from making a transition to medium-size status. The factors identified by Tybout (2000), including institutional entry barriers, imperfections in financial and labour markets, small and geographically dispersed markets, the nature of consumer demand, uncertainty about demand and policies, corruption and lack of rule of law should all be considered. A comparison of the business climate in Bangkok, which is not characterized by a 'missing middle', with the rest of the country, might be a particularly fruitful avenue for investigation.

The reasons for the link between firm size and wages deserve further investigation. The results of the chapter indicate that the higher wages in the largest firms are not explained purely by observed characteristics of their workers, such as education. In this context, an investigation of the factors determining access to well-paid jobs in larger enterprises could contribute to our understanding of wage inequality.

The strong relationship between wages and education level, and the importance of education in determining inequality, are striking, even though they are not the main topic of this chapter. Although increasing education over this period actually increased inequality in wages, further increases, reaching a larger proportion of the workforce, may have the potential to reduce wage inequality. Part of the 'return' to education appears to come from improved access to jobs in larger enterprises. The reasons why better educated workers are able to access large firms, and what sort of skills and educational backgrounds these firms demand, could also be analysed.

Overall income inequality, measured using household data, remained roughly constant over time. One possible explanation is that other sources of income 
became more equal. But it is also highly likely that the expansion of opportunities in wage employment, which is better paid than other income-earning activities, mitigated the increasing inequality within the group of wage workers. If this is the case, then the expansion of MSEs, by providing new employment opportunities, may well have prevented a rise in overall inequality over the time period in question. This hypothesis would need to be investigated with suitable household survey data.

Finally it should be noted, as explored in the model of Gall (2005), that the causal relationship between the firm size distribution and wage inequality may run both ways, with inequality being caused by but also explaining or reinforcing the 'missing middle'. Further research could examine whether Thailand is prone to a self-reinforcing pattern where existing inequality prevents the firm distribution moving away from the dualistic pattern, towards the more even pattern that characterizes developed countries. 


\section{Appendix A-4}

Table 4-9: OLS regression, dependent variable monthly wage in int. USD, used for regression based inequality decomposition

\begin{tabular}{|c|c|c|}
\hline & (1) & (2) \\
\hline & 1995 & 2005 \\
\hline \multirow[t]{2}{*}{ Size: 5 to 9} & $22.111 * * *$ & 0.347 \\
\hline & $(5.307)$ & $(6.676)$ \\
\hline \multirow[t]{2}{*}{ Size 10 to 19} & $17.269 * *$ & $28.746^{* * *}$ \\
\hline & $(5.811)$ & $(7.152)$ \\
\hline \multirow[t]{2}{*}{ Size: 20 to 49} & $38.807 * * *$ & $39.904 * * *$ \\
\hline & $(6.222)$ & $(8.065)$ \\
\hline \multirow[t]{2}{*}{ Size: 50 to 99} & $43.821 * * *$ & $73.343 * * *$ \\
\hline & $(7.306)$ & $(9.463)$ \\
\hline \multirow[t]{2}{*}{ Size: Over 100} & $74.778 * * *$ & $90.482 * * *$ \\
\hline & $(5.614)$ & $(6.763)$ \\
\hline \multirow[t]{2}{*}{ Industry } & $18.541 * * *$ & $-19.687 * *$ \\
\hline & $(5.279)$ & $(6.362)$ \\
\hline \multirow[t]{2}{*}{ Services } & $19.967 * * *$ & $28.221 * * *$ \\
\hline & $(-5.715)$ & $(6.663)$ \\
\hline \multirow[t]{2}{*}{ Less than elementary } & $-19.138 *$ & $55.952 * * *$ \\
\hline & $(9.533)$ & (11.524) \\
\hline \multirow{2}{*}{ Elementary } & $-38.998 * * *$ & $41.488 * * *$ \\
\hline & $(9.796)$ & $(11.591)$ \\
\hline \multirow[t]{2}{*}{ Lower sceondary } & 17.165 & $53.569 * * *$ \\
\hline & $(10.551)$ & (11.969) \\
\hline \multirow[t]{2}{*}{ Upper secondary } & $116.496 * * *$ & $122.685 * * *$ \\
\hline & (11.066) & $(12.334)$ \\
\hline \multirow[t]{2}{*}{ Post secondary } & $500.632 * * *$ & $581.444 * * *$ \\
\hline & $(11.471)$ & $(12.579)$ \\
\hline \multirow[t]{2}{*}{ Bangkok } & $163.800 * * *$ & $257.16^{* * *}$ \\
\hline & $(5.768)$ & $(7.418)$ \\
\hline \multirow[t]{2}{*}{ Central } & $55.011 * * *$ & $87.845^{* * *}$ \\
\hline & $(5.135)$ & $(6.453)$ \\
\hline \multirow[t]{2}{*}{ Northeastern } & 6.168 & 5.670 \\
\hline & $(5.720)$ & $(7.093)$ \\
\hline \multirow[t]{2}{*}{ Southern } & $26.485^{* * *}$ & $103.619 * * *$ \\
\hline & $(6.834)$ & $(7.773)$ \\
\hline \multirow[t]{2}{*}{ Constant } & $140.692 * * *$ & $104.2489 * * *$ \\
\hline & $(10.089)$ & (11.918) \\
\hline Adjusted R-squared & 0.3079 & 0.2858 \\
\hline $\mathrm{N}$ & 24392 & 34915 \\
\hline
\end{tabular}

Notes: Robust standard errors in parentheses $\mathrm{p}<0.10, * * \mathrm{p}<0.05, * * * \mathrm{p}<0.01$.

Reference categories: Size: 1-4 employees; Education: no formal education; Region: Northern.

Source: Author's computations based on LFS 1995 and 2005 
Figure 4-2: Wage kernel density estimates by enterprise size

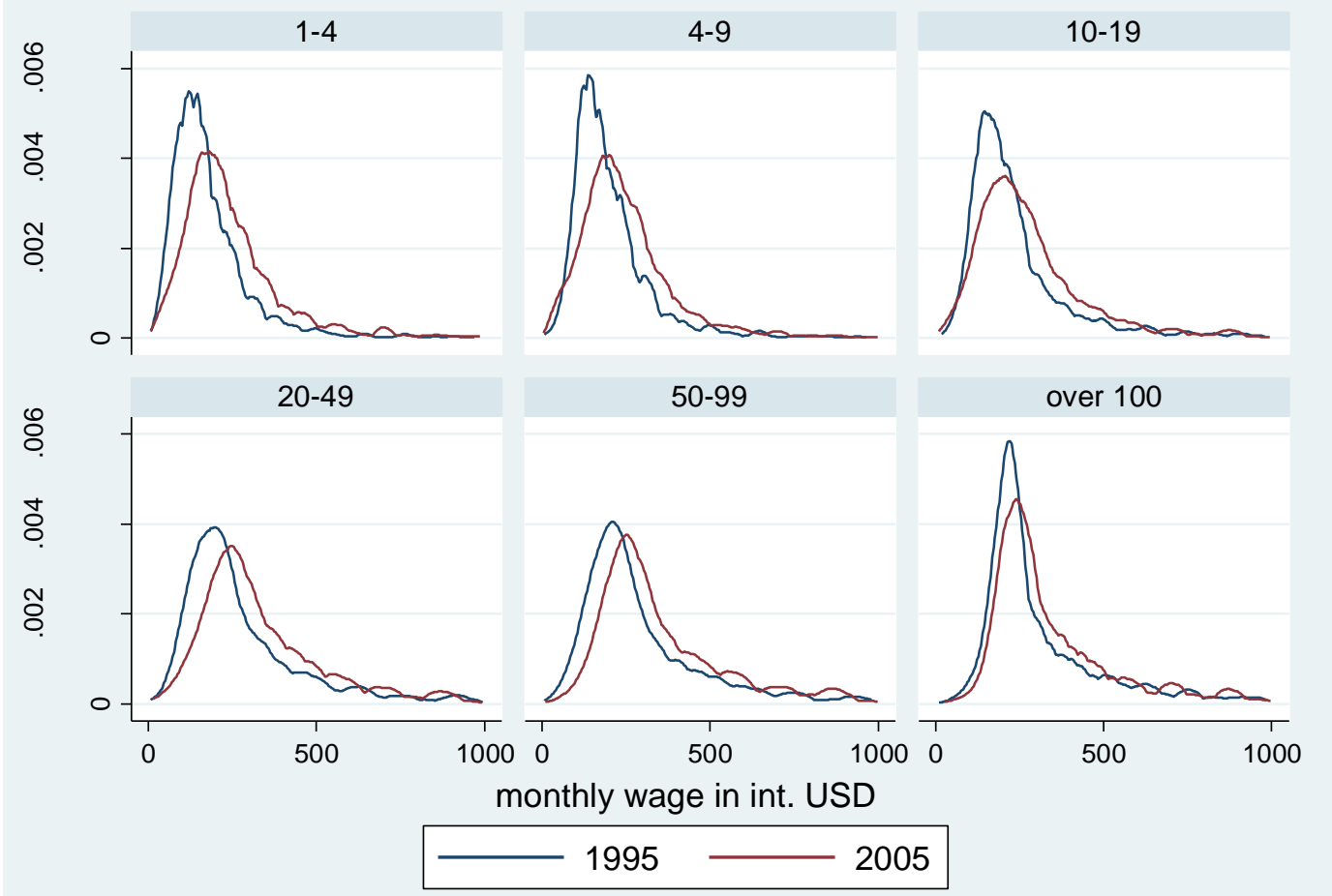

Source: Author's computations based on LFS 1995 and 2005 


\section{References}

Aghion, P. and Bolton P. (1997). A Theory of Trickle-Down Growth and Development. Review of Economic Studies. 64(2). 151-172.

Aitken, B., and Harrison, A. (1999). Do Domestic Firms Benefit from Direct Foreign Investment? Evidence from Venezuela. The American Economic Review. 89(3). 605-618.

Akerlof, G. (1982). Labour Contracts as Partial Gift Exchange. Quarterly Journal of Economics. 97(4). 543-569.

Akerlof, G., and Yellen, J. (1990). The Fair Wage-Effort Hypothesis and Unemployment. Quarterly Journal of Economics. 105(2). 255-83.

Akresh, R. (2005). Understanding Pareto Inefficient Intra household Allocations. IZA working paper No. 1858. Institute for the Study of Labour, Bonn.

Amine, L. And Straub, K. (2010). Women Entrepreneurs in Sub-Saharan Africa: An Institutional Theory Analysis from a Social Marketing Point of View. Entrepreneurship and Regional Development. 21(2). 183-211.

Amiti, M. and Davis, D. (2012). Trade, Firms, and Wages: Theory and Evidence. Review of Economic Studies. 79(1). 1-36.

Andrews, M. Golan, J. and Lay, J. (2010). Efficiency of Male and Female onFarm Labour Supply: Evidence from Uganda. Paper presented at 2010 Bolivian Conference on Development Economics (BCDE2010), La Paz, November 18 and 19, 2010.

Angelini, P., and Generale, A. (2008). On the Evolution of Firm Size Distributions. The American Economic Review. 98(1). 426-438.

Apps, P. and R. Rees (2009). Public Economics and the Household. Cambridge University Press, Cambridge.

Athukorala, P. (2011). Production Networks and Trade Patterns in East Asia: Regionalization or Globalization? Asian Economic Papers. 10(1). 65-95.

Atkinson, A. (1970). On The Measurement of Inequality. Journal of Economic Theory. 2(3). 244-263.

Asian Development Bank (ADB) (2008). Strategy 2020: Working for an Asia and Pacific Free of Poverty. Asian Development Bank, Manila.

Asian Development Bank (ADB) (2010). An Agenda for High and Inclusive Growth in the Philippines. Asian Development Bank, Manila. 
Ayyagari, M., Beck, T. and Demirgüç-Kunt, A. (2003). Small- and MediumEnterprises Across the Globe: a New Database. World Bank Policy Research Working Paper 3127. World Bank, Washington, D.C..

Banerjee, A. and Duflo, E. (2004). Do Firms Want to Borrow More? Testing Credit Constraints Using a Directed Lending Program. CEPR Discussion Papers No. 4681. Center for Economic and Policy Research, London.

Banerjee, A. and Duflo, E. (2005). Growth Theory through the Lens of Development Economics. In: Aghion, P. and Durlauf, S. (eds.), Handbook of Economic Growth. First edition. 473-552. Elsevier, Philadelphia.

Banerjee, A. and Newman, A. (1993). Occupational choice and the Process of Development. Journal of Political Economy. 101(2). 274-298.

Baum, C., Schaffer, E., and Stillman, S. (2003). Instrumental Variables and GMM: Estimation and Testing. Stata Journal. 3(1). 1-31.

Barr, A. (1998). Enterprise performance and the functional diversity of social capital. CSAE Working Paper Series 1998-01, Centre for the Study of African Economies, University of Oxford.

Beck, T., Demirgüc-Kunt, A., and Maksimovic, V. (2005). Financial and Legal Constraints to Growth: Does Firm Size Matter? The Journal of Finance. 60(1). 137-177.

Belsley, D. A., Kuh, E. and Welsch, R. E. (1980) Regression Diagnostics. Wiley, New York.

Bigsten, A., Collier, P., Dercon, S., Fafchamps, M., Gauthier, B., Gunning, J., Oduro, A., Oostendorp, R., Patillo, C., Söderbom, M., Teal, F., and Zeufack, A. (2003). Credit Constraints in Manufacturing Enterprises in Africa. Journal of African Economies. 12(1). 104-125.

Bigsten, A., Collier, P., Dercon, S., Fafchamps, M., Gauthier, B., Gunning, J. W., Oduro, A., Oostendorp, R. Pattillo, C., Söderbom, M., Teal, F., and Zeufak, A. (2004). Do African Manufacturing Firms Learn from Exporting? Journal of Development Studies. 40(3). 115-141.

Binswanger, H. P., and Rosenzweig, M. R. (1986). Behavioral and Material Determinants of Production Relations in Agriculture. Journal of Development Studies. 22(3). 503-539.

Bird, K., Eiichi, S., and Luxmon, A. (2011). Poverty, Income Inequality, and Microfinance in Thailand. Southeast Asia Working Papers No. 6. Asian Development Bank, Manila.

Blinder, A. (1973). Wage Discrimination: Reduced Form and Structural Estimates. Journal of Human Resources. 8(4). 436-455. 
Böhme, M., and Thiele, R. (2012). Is the Informal Sector Constrained from the Demand Side? Evidence for Six West African Capitals. World Development. 40(7). 1369-1381.

Bourguignon, F., Browning, M., Chiappori, P., and Lechene, V. (1993). Intra Household Allocation of Consumption: A Model and Some Evidence from French Data. Annals of Economics and Statistics. 29. 137-156.

Bourguignon, F., Ferreira, H. and Leite, P. (2008). Beyond Oaxaca-Blinder: Accounting for Differences in Household Income Distributions. Journal of Economic Inequality. 6(2). 117-148.

Brilleau A., Roubaud, F., and Torelli, C. (2005). L'emploi, le Chômage et les Conditions d'activité, Enquêtes 1-2-3, Phase 2. Stateco. 99. 54-84.

Brilleau A., Ouedraogo, E., and Roubaud, F. (2005a). L'Enquête 1-2-3 dans les Principales Agglomérations de l'UEMOA: la Consolidation d'une Méthode. Stateco. 99. 15-19.

Browning, M. and Chiappori, P. (1998). Efficient Intra-Household Allocations: A General Characterization and Empirical Tests. Econometrica. 66 (6). 12411278.

Browning, M and J. Gørtz (2006). Spending Time and Money within the Household. Economics Series Working Papers 288. University of Oxford, Oxford.

Cabral, L., and Mata, J. (2003). On the Evolution of the Firm Size Distribution: Facts and Theory. American Economic Review. 93(4). 1075-1090.

Chen, M., Vanek, J. and Heintz, J. (2006). Informality, Gender and Poverty. Economic and Political Weekly. 41(21). 2131-2139.

Clerides, S., Lach, S., and Tybout, J. (1998). Is Learning by Exporting Important? Micro-Dynamic Evidence from Colombia, Mexico, and Morocco. The Quarterly Journal of Economics. 113(3). 903-947.

Cooley, T., and Quadrini, V. (2001). Financial Markets and Firm Dynamics. The American Economic Review. 91(5). 1286-1310.

Coşar, K., Guner, N., and Tybout, J. (2011). Firm Dynamics, Job Turnover, and Wage Distributions in an Open Economy. NBER Working Paper. 16326, National Bureau of Economic Research, Cambridge, MA.

Cowell, F. A. (2000). Measurement of Inequality. In A. Atkinson and F. Bourguignon (Eds.), Handbook of Income Distribution (pp. 87-166). Elsevier, Philadelphia.

Cunningham, W., and Maloney, W. (2001). Heterogeneity in the Mexican MicroEnterprise Sector: An Application of Factor and Cluster Analysis. Economic Development and Cultural Change. 50(1). 131-156. 
Davis, D., Harrigan, J. (2011). Good jobs, bad jobs, and trade liberalization. Journal of International Economics. 84(1). 26-36.

Daymont, T. and Andrisani, P. (1984). Job Preferences, College Major, and the Gender Gap in Earnings. Journal of Human Resources. 19 (3). 408-428.

De Loecker, J. (2007). Do Exports Generate Higher Productivity? Evidence from Slovenia. Journal of International Economics. 73(1). 69-98.

De Mel, S., McKenzie, D., and Woodruff, C. (2008). Returns to Capital in Microenterprises: Evidence from a Field Experiment. The Quarterly Journal of Economics. 123(4). 1329-1372.

De Mel, S., McKenzie, D., and Woodruff, C. (2009). Are Women More Credit Constrained? Experimental Evidence on Gender and Microenterprise Returns. American Economic Journal: Applied Economics. 1(3). 1-32.

De Mel, S., McKenzie, D., and Woodruff, C. (2012). Business Training and Female Enterprise Start-up, Growth, and Dynamics: Experimental Evidence from Sri Lanka. Policy Research Working Paper Series No. 6145. The World Bank, Washington, D.C..

Deininger, K., and Squire, L. (1998). New Ways of Looking at Old Issues: Inequality and Growth. Journal of Development Economics. 57(2). 259287.

De Soto, H. (1989). The other path. Harper and Row Publishers, New York.

Diao, X., Ratts $\varnothing$, J., and Stokke, H. E. (2006). Learning by Exporting and Structural Change: A Ramsey Growth Model of Thailand. Journal of Policy Modeling. 28(3). 293-306.

Di Falco, S. and Bulte, E. (2009). Social Capital and Weather Shocks in Ethiopia: Climate Change and Culturally-induced Poverty Traps. Working Paper. London School of Economics, London.

Di Falco, S. and Bulte, E. (2011). A Dark Side of Social Capital? Kinship, Consumption and Savings. Journal of Development Studies. 47(8). 11281151.

Dinh, H., Mavridis, D. and Nguyen, H. (2010) The Binding Constraint on Firms' Growth in Developing Countries. Policy Research Working Paper No. 5485. The World Bank, Washington D.C..

Dollar, D. Hallward-Driemeier, M. and Mengistae, T. (2005). Investment Climate and Firm Performance in Developing Economies. Economic Development and Cultural Change. 54(1). 1-31.

Egger, H. and Kreickemeier, U. (2010). Worker-specific Effects of Globalisation. The World Economy. 33(8), 987-1005. 
Egger, H. and Kreickemeier, U. (2012). Fairness, trade, and inequality. Journal of International Economics. 86(2). 184-196.

Evans, D. (1987). The Relationship Between Firm Growth, Size, and Age: Estimates for 100 Manufacturing Industries. The Journal of Industrial Economics. 35(4). 567-581.

Evans, D., and Jovanovic, B. (1989). An Estimated Model of Entrepreneurial Choice under Liquidity Constraints. Journal of Political Economy. 97(4). 808-827.

Fafchamps, M. (1999). Rural Poverty, Risk, and Development. Oxford University, Center for the Study of African Economies, Oxford. Report submitted to the Food and Agriculture Organization of the United Nations.

Fafchamps, M. (2000). Ethnicity and Credit in African Manufacturing. Journal of Development Economics. 61(1). 205-235.

Fafchamps, M., and Pender, J. (1997). Precautionary Saving, Credit Constraints, and Irreversible Investment: Theory and Evidence from Semiarid India. Journal of Business and Economic Statistics. 15(2). 180-194.

Fafchamps, M., McKenzie, D. Quinn, S and Woodruff, C. (2011). When is Capital Enough to get Female Microenterprises Growing? Evidence from a Randomized Experiment in Ghana, CSAE Working Paper WPS/2011-11. Center for the Study of African Economies, Oxford.

Fajnzylber, P., Maloney, W., and Rojas, G. (2006). Releasing Constraints to Growth or Pushing on a String? The Impact of Credit, Training, Business Associations, and Taxes on the Performance of Mexican Micro-firms. Policy Research Working Paper No. 3807. The World Bank, Washington, D.C..

Felbermayr, G., Impulliti, G., and Prat, J. (2013). Wage Inequality, Firm Dynamics, and International Trade, mimeo.

Fernandes, A., and Isgut, A. (2005). Learning-by-doing, Learning-by-exporting, and Productivity: Evidence from Colombia. Policy Research Working Paper No. 3544. The World Bank, Washington D.C..

Fields, G. (1989). Changes in Poverty and Inequality in Developing Countries. World Bank Research Observer. 4(2). 167-85.

Fields, G. (1990). Labour Market Modelling and the Urban Informal Sector: Theory and Evidence. In: Turnham, D., Salomé, B., and Schwartz, A. (eds.). The Informal Sector Revisited. OECD Development Centre Seminar Series. OECD, Paris.

Fields, G. (2002). Accounting for Income Inequality and its Change: A New Method, With Application to the Distribution of Earnings in the United States. Cornell University, mimeo. 
Fiorio, C. and Jenkins, S. (2008). INEQRBD: Stata Module to Calculate Regression-based Inequality Decomposition.

Fisman, R., and Svensson, J. (2007). Are Corruption and Taxation really Harmful to Growth? Firm level Evidence. Journal of Development Economics. 83(1). 63-75.

Fox, L., and Sohnesen, T. (2012). Household Enterprises in Sub-Saharan Africa: why they Matter for Growth, Jobs, and Livelihoods. World Bank Policy Research Working Paper No. 6184. The World Bank, Washington, D.C..

Gall, T. 2005. Inequality, Incomplete Contracts, and the Size Distribution of Business Firms. Junior Economists Peer Reviewed Series Working Paper, mimeo.

Galor, O. and Zeira, J. (1993). Income Distribution and Macroeconomics. Review of Economic Studies. 60(1). 35-52.

Girma, S., Greenaway, D., and Kneller, R. (2004). Does Exporting Increase Productivity? A Microeconometric Analysis of Matched Firms. Review of International Economics. 12(5). 855-866.

Greene, W. (1999). Econometric Analysis, Prentice Hall, Upper Saddle River, New Jersey, USA.

Griffiths, W., Carter Hill, R., and Judge, G. (1993). Learning and Practicing Econometrics. John Wiley and Sons, New York.

Grimm, M., Gubert, F., Koriko, O. Lay, J. and Nordman, C. (2010). Kinship Ties and Entrepreneurship in Western Africa, mimeo.

Grimm, M., Krueger, J. and Lay, J. (2011). Barriers to Entry and Returns to Capital in Informal Activities: Evidence from sub-Saharan Africa. Review of Income and Wealth. 57(s1). 1475-4991.

Grimm, M., Knorringa, P, and Lay, J. (2012). Constrained Gazelles: High Potentials in West Africa's Informal Economy. World Development. 40(7). 1352-1368.

Goldstein, M. and C. Udry (2008). The Profits of Power: Land Rights and Agricultural Investment in Ghana. Journal of Political Economy. 116(6). 981-1022.

Görg, H., and Greenaway, D. (2004). Much Ado about Nothing? Do Domestic Firms Really Benefit from Foreign Direct Investment? The World Bank Research Observer. 19(2). 171-197.

Hart, K. (1973). Informal Income Opportunities and Urban Employment in Ghana. The Journal of Modern African Studies. 11(1). 61-89. 
Hausman, R., Rodrik, D., and Velasco, A. (2005). Growth diagnostics. John F. Kennedy School of Government, Harvard University, mimeo. Cambridge, MA.

Helpman, E., Itskhoki, O. and Redding, S. (2010). Inequality and Unemployment in a Global Economy. Econometrica. 78(4). 1239-1283.

Henley, A., Arabsheibani, R., and Carneiro, F. (2006). On Defining and Measuring the Informal Sector, World Bank Policy Research Working Paper No. 3866. The World Bank, Washington D.C..

Hopenhayn, H. A. 1992. Entry, Exit, and Firm Dynamics in Long Run Equilibrium. Econometrica 60(5). 1127-1150.

Ihrig, J., and Moe, K. (2004). Lurking in the Shadows: the Informal sector and Government Policy. Journal of Development Economics. 73(2). 541-557.

International Labour Organization (ILO) (1993). Resolutions Concerning Statistics of Employment in the Informal Sector Adopted by the 15th International Conference of Labour Statisticians. ILO, Geneva

International Labour Organization (ILO) (2002). Women and Men in the Informal Economy: a Statistical Picture. ILO, Geneva.

International Labour Organization (ILO) (2013). Thailand - A Labour Market Profile. ILO, Geneva.

Jacoby, H. (1991). Productivity of Men and Women and the Sexual Division of Labour in Peasant Agriculture of the Peruvian Sierra. Journal of Development Economics. 37(1-2). 265-287.

Jenkins, S. (1995). Accounting for Inequality Trends: Decomposition Analyses for the UK, 1971- 86. Economica. 62(245), 29-63.

Jones, F., and Kelley, J. (1984). Decomposing Differences between Groups : A Cautionary Note on Measuring Discrimination. Sociological Methods and Research. 12(3). 323-343.

Jovanovic, B. (1982). Selection and the Evolution of Industry. Econometrica. 50(3). 649-670.

Karlan, D and Zinman, J. (2010). Expanding Credit Access: Using Randomized Supply Decisions to Estimate the Impacts, Society for Financial Studies, vol. 23(1), pages 433-464.

Kihlstrom, R., and Laffont, J. (1979). A General Equilibrium Entrepreneurial Theory of Firm Formation Based on Risk Aversion. Journal of Political Economy. 87(4). 719-748.

Kremer, M., Lee, J., and Robinson, J. (2010). The Return to Capital for Small Retailers in Kenya: Evidence from Inventories. mimeo, Harvard University. 
Krugman, P., Cooper, R. , and Srinivasan, T. (1995). Growing World Trade: Causes and Consequences. Brookings Papers on Economic Activity No. 1. Brookings, Washington D.C..

Kmenta, J. (1967), On Estimation of the CES Production Function. International Economic Review. 8(2). 180-192.

Kuznets, S. (1963). Quantitaive Aspects of the Economic Growth of Nations VII:. Distribution of Income by Size. Economic Development and Cultural Change. 11(2). 1-80.

Lachaud, J. (1990). The Urban Informal Sector and the Labour Market in SubSaharan Africa. The informal sector revisited. OECD, Paris.

Lay, J., M'Mukaria, G., and Mahmoud, T. (2008). Few Opportunities, Much Desperation: The Dichotomy of Non-agricultural Activities and Inequality in Western Kenya. World Development. 36(12). 2713-2732.

Levy, B. (1993). Obstacles to Developing Indigenous Small and Medium Enterprises: An Empirical Assessment. The World Bank Economic Review. 7(1). 65-83.

Liedholm, C. (2002). Small Firm Dynamics: Evidence from Africa and Latin America. Small Business Economics. 18(1). 225-240.

Liedholm, C., and Mead, D. (1987). Small Scale Industries in Developing Countries: Empirical Evidence and Policy Implications. Food Security International Development Papers 54062, Michigan State University, Department of Agricultural, Food, and Resource Economics.

Lloyd-Ellis, H. and Bernhardt, D. (2000). Enterprise, Inequality and Economic Development. Review of Economic Studies. 67(1). 147-168.

Lucas, R. (1978). On the Size Distribution of Business Firms. Bell Journal of Economics. 9(2). 508-523.

Luke, N., and Munshi, K. (2006). New Roles for Marriage in Urban Africa: Kinship Networks and the Labour Market in Keny. Review of Economics \& Statistics. 88(2). 264-282.

Lundberg, S., Pollak, R. and T. Wales (1997). Do Husbands and Wives Pool their Resources?. Journal of Human Resources. 33(3). 463-480.

Maloney, W. (2004). Informality Revisited. World Development. 32(7). 11591176.

Markusen, J., and Venables, A. (1999). Foreign Direct Investment as a Catalyst for Industrial Development. European Economic Review. 43(2). 335-356.

Mason, A. and Lee, R. (2006). Reform and Support Systems for the Elderly in Developing Countries: Capturing the Second Demographic Dividend. GENUS LXI I(2). 11-35. 
McKenzie, D., and Woodruff, C. (2006). Do Entry Costs Provide an Empirical Basis for Poverty Traps? Evidence from Mexican Microenterprises. Economic Development and Cultural Change. 55(1). 3-42.

McMillan, J., and Woodruff, C. (2002). The Central Role of Entrepreneurs in Transition Economies. The Journal of Economic Perspectives. 16(3). 153170.

Mead, D. C., and Liedholm, C. (1998). The Dynamics of Micro and Small Enterprises in Developing Countries. World Development. 26(1). 61 - 74.

Moser, C. (1978). Informal Sector or Petty Commodity Production: Dualism or Dependence in Urban Development?. World Development. 6(9-10). 10411064.

Nichter, S., and Goldmark, L. (2009). Small Firm Growth in Developing Countries. World Development. 37(9). 1453-1464.

Oaxaca, R. (1973). Male-female Wage Differentials in Urban Labour Markets. International Economic Review. 14(3). 693-709.

Organisation for Economic Co-operation and Development (OECD). (2002). Measuring the Non-Observed Economy - A Handbook. OECD, Paris.

Organisation for Economic Co-operation and Development (OECD) (2011). Thailand: Key Issues and Policies, in: OECD studies on SMEs and Entrepreneurship. OECD, Paris.

Organisation for Economic Co-operation and Development (OECD) (2013). Poverty and Inequality Disparities in Cambodia, Lao PDR, Myanmar and Viet Nam. In: Southeast Asian Economic Outlook 2013: With Perspectives on China and India. OECD, Paris.

Park, A., Yang, D., Shi, X., and Jiang, Y. (2010). Exporting and Firm Performance: Chinese Exporters and the Asian Financial Crisis. The Review of Economics and Statistics. 92(4). 822-842.

Peattie, L. (1987). An Idea in Good Currency and How It Grew: The Informal Sector. World Development. 15(7). 851-860.

Punpuing. S. and Richter, K. (2011). Urbanization and Migration Impact. In National Economic and Social Development Board (NESDB) and the United Nations Population Fund (UNFPA). Impact of Demographic Change in Thailand. UNFPA, Bangkok.

Quisumbing, A. and Maluccio, J. (2003). Resources at Marriage and Intrahousehold allocation: Evidence from Bangladesh, Ethiopia, Indonesia, and South Africa. Oxford Bulletin of Economics and Statistics. 65(3). 283328. 
Rakowsky, C. (1994). Covnvergence and Divergence in the Informal Sector Debate: A Focus on Latin America 1984-92. World Development. 22(4). 501-516.

Rauch, J. (1991). Modelling the informal sector formally. Journal of development Economics. 35(1). 33-47.

Reinhart, C., and Rogoff, K. (2009). The Aftermath of Financial Crises. American Economic Review. 99(2). 466-472.

Rendall, M. (2013). Structural Change in Developing Countries: Has it Decreased Gender Inequality?. World Development. 45(1). 1-16.

Roubaud, F. (2008). Mixed Surveys Using the Modular Approach. In: ILO Manual on Surveys of Informal Employment and Informal Sector. Chapter 7. ILO, Geneva.

Saracoğlu, D. (2008). The Informal Sector and Tax on Employment: A Dynamic General Equilibrium Investigation. Journal of Economic Dynamics and Control. 32(2). 529-549.

Schneider, F., Buehn, A., and Montenegro, C. (2010). Shadow Economies all over the World: New Estimates for 162 Countries from 1999 to 2007. Policy Research Working Paper Series No. 5356. The World Bank, Washington, D.C..

Schündeln, M. (2004), Returns to Capital and Financial Constraints. mimeo, Harvard University.

Schündeln, M. (2006), Modeling Firm Dynamics to Identify the Cost of Financing Constraints in Ghanaian Manufacturing. mimeo, Harvard University.

Schultz, P.T., (1990). Testing the Neoclassical Model of Family Labour supply and fertility, Journal of Human Resources. 25(4), 599-634.

Sen, A. (1999). Development as Freedom. Oxford University Press, Oxford.

Shapiro, C., and Stiglitz, J. (1984). Equilibrium Unemployment as a Worker Discipline Device. American Economic Review. 74 (3). 433-444.

Sleuwaegen, L., and Goedhuys, M. (2002). Growth of Firms in Developing Countries, Evidence from Côte d'Ivoire. Journal of Development Economics. 68(1). 117-135.

Söderbom, M., Teal, F., and Wambugu, A. (2005). Unobserved heterogeneity and the relation between earnings and firm size: evidence from two developing countries. Economics Letters. 87(2). 153-159.

Stenkula, M. (2006). The European Size Distribution of Firms and Employment. Working Paper Series No. 683. Research Institute of Industrial Economics, Stockholm. 
Stock, J., Wright, J., and Yogo, M. (2002). A Survey of Weak Instruments and Weak Identification in Generalized Method of Moments. Journal of Business and Economic Statistics. 20(4). 518-529.

Stolper, W., and Samuelson, P. (1941). Protection and Real Wages. Review of Economic Studies. 9 (1). 58-73.

Teal, F., and Söderbom, M. (2001). Firm Size and Human Capital as Determinants of Productivity and Earnings. Economics Series Working Papers No. WPS/2001-09. University of Oxford, Oxford.

Thomas, D., and Chen, C. (1994). Income Shares and Shares of Income: Empirical Tests of Models of Household Resource Allocation. RAND Working Paper Series (94-08). Research and Development, Washington, D.C..

Tokman, V. (1989). Policies for a Heterogeneous Informal Sector in Latin America. World Development. 17(7). 1067-1076.

Tybout, J. (1983). Credit Rationing and Investment Behavior in a Developing Country. Review of Economics and Statistics. 65 (4). 598-607.

Tybout, J. R. (2000). Manufacturing Firms in Developing Countries: How Well Do They Do, and Why? Journal of Economic Literature, 38(1), pp. 11-44.

Udry, C. (1996). Gender, Agricultural Production, and the Theory of the Household. Journal of Political Economy. 104 (5). 1010-1046.

Udry, C. and Anagol, S. (2006). The Return to Capital in Ghana. American Economic Review. 96(2). 388-393.

United Nations Conference on Trade and Development (UNCTAD) (2013). Online database 'UNCTADStat'. Available at: http://unctadstat.unctad.org/ReportFolders/reportFolders.aspx?sCS_referer= andsCS_ChosenLang=en, accessed March $19^{\text {th }}, 2013$

United Nations Development Program (UNDP) (2013). Human Development Indicators. Available at: http://hdr.undp.org/en/statistics/. UNDP, New York, accessed March 20 2013.

Van Biesebroeck, J. (2005). Exporting Raises Productivity in sub-Saharan African Manufacturing Firms. Journal of International Economics. 67(2). 373-391.

Van Biesebroeck, J. (2005a). Firm Size Matters: Growth and Productivity Growth in African Manufacturing. Economic Development and Cultural Change. 53(3). $545-583$.

Wagner, J. (2012). International Trade and Firm Performance: a Survey of Empirical Studies since 2006. Review of World Economics. 148(2). 235267. 
Warr, P. (2004). Globalization, Growth, and Poverty Reduction in Thailand. ASEAN Economic Bulletin. 21(1). 1 - 18.

Wiboonchutikula, P. (2002). Small and Medium Enterprises in Thailand: Recent Trends. Small Business Economics. 18 (1). 211-224.

Wignaraja, G. (2012). Engaging Small and Medium Enterprises in Production Networks: Firm-level Analysis of Five ASEAN Economies. Asian Development Bank Institute (ADBI) Working Paper No. 361. ADBI, Tokyo.

Wignaraja, G. Krueger, J. and A. Tuazon (2013): Production Networks, Profits, and Innovative Activity: Evidence from Malaysia and Thailand. Asian Development Bank Institute (ADBI) Working Paper No. 406. ADBI, Tokyo.

World Bank (2013). World Development Indicators Online Database. Available at:

http://databank. worldbank.org/ddp/home.do?Step=12andid=4andCNO=2, accessed August $4^{\text {th }}, 2013$.

World Bank (2012). , Thailand Economic Monitor. The World Bank, Washington D.C.. 


\section{Eidesstattliche Versicherung}

Ich versichere an Eides Statt, dass ich die eingereichte Dissertation

„Constraints to informal entrepreneurs in developing countries: An empirical analysis“"

selbstständig verfasst habe.

Anderer als der von mir angegebenen Hilfsmittel und Schriften habe ich mich nicht

bedient. Alle wörtlich oder sinngemäß den Schriften anderer Autorinnen und/oder Autoren entnommenen Stellen habe ich kenntlich gemacht. 